\title{
Rhabdovirus Genetics
}

\author{
Craig R. Pringle
}

\section{INTRODUCTION}

\section{A. Negative-Strand RNA Viruses}

There are five families of RNA viruses in which the negative strand is sequestered in the extracellular virion. Viruses of two of these families, the Rhabdoviridae and the Paramyxoviridae, have unitary linear genomes, whereas viruses of the other three families, Arenaviridae, Bunyaviridae, and Orthomyxoviridae, have segmented genomes comprising, respectively, two, three, and seven or eight subunits. The informational macromolecules that comprise the genomes of rhabdoviruses and paramyxoviruses are among the largest functional RNA molecules and are exceeded in size only by those of the plus-strand coronaviruses. Reanney (1982, 1984) has calculated that the upper size limit for any RNA virus genome cannot be much in excess of 17,600 nucleotides (mol. wt. $\approx 5.7 \times 10^{6}$ ) as a consequence of the low copying fidelity of RNA polymerases. The segmentation of the genomes of the other negative-strand viruses may be a consequence of such constraints on molecular size or a device for decoupling the transcription of individual genes. Whatever the reason, the genetic properties of the segmented-genome viruses differ substantially from those of the unsegmented-genome viruses, because variation in the former is generated by reassortment of genome subunits as well as by mutation. Mutation is the sole mechanism of variation in unsegmented-genome viruses, since the intramolecular recombination observed with positive-

CRAIG R. PRINGLE • Department of Biological Sciences, University of Warwick, Coventry CV4 7AL, England. 
strand RNA viruses does not seem to be permissible for any negativestrand RNA virus.

\section{B. Rhabdoviruses}

The family Rhabdoviridae comprises a diverse collection of viruses linked by a common bullet-shaped or bacilliform morphology. The host organisms include vertebrates (birds, fishes, amphibians, marsupials, and mammals), invertebrates (insects and arachnids), plants (monocotyledons and dicotyledons), and protists (amoeba). Several plant rhabdoviruses, such as lettuce necrotic yellows, bridge major taxonomic gaps, being capable of multiplying in both their plant host and their insect vector. Only a few of more than 75 named rhabdoviruses are included so far in the two recognized genera (Brown et al., 1979).

The genus Vesiculovirus comprises nine viruses [the two serotypes of vesicular stomatitis virus (VSV), Chandipura virus, Isfahan virus, Piry virus, Jurona virus, Keuraliba virus, La Joya virus, and Yug Bugdanovac virus]. The Indiana serotype of VSV comprises the subtypes Indiana, Cocal, Argentina, and Brazil, and the New Jersey serotype the Concan and Hazelhurst subtypes. The vesiculoviruses mature and accumulate in the cytoplasm and bud from the plasma membrane. All five viral gene products-the large $(L)$, glycosylated $(G)$, matrix $(M)$, nonstructural (NS), and nucleocapsid $(\mathrm{N})$ proteins-are present in the virion. Four plant viruses (lettuce necrotic yellows virus, broccoli necrotic yellows virus, sonchus virus, and wheat striate mosaic virus) closely resemble the vesiculoviruses and have been designated the subgroup A plant rhabdoviruses.

The genus Lyssavirus comprises rabies virus and the five rabiesrelated viruses: Duvenhage virus, Kotonkan virus, Lagos bat virus, Mokola virus, and Obodhiang virus. Kotonkan virus is exceptional in being isolated from culicoides insects. Again, all five viral gene products [the L, G, $M_{2}, M_{1}(=N S)$, and $N$ proteins] are present in the virion. These viruses mature and accumulate in the cytoplasm and bud predominantly from internal or de novo synthesized membranes. Four plant viruses (potato yellow dwarf virus, eggplant mottled dwarf virus, sonchus yellow net virus, and sowthistle yellow vein virus) closely resemble the lyssaviruses and have been designated the subgroup B plant rhabdoviruses. These viruses bud at the inner membrane of the nuclear membrane and accumulate perinuclearly. The plant rhabdoviruses, together with tomato spotted wilt virus (a possible bunyavirus) and carrot mottle virus (a possible togavirus|, are unique among plant viruses in possessing outer envelopes, although specific receptors for attachment of any plant virus have not been identified. The ubiquitous presence of RNA-dependent RNA polymerase activity in normal plant tissue further highlights the evolutionary enigma of plant rhabdoviruses.

The remaining 37 named animal and 67 plant rhabdoviruses listed 
by Matthews (1982) are virtually uncharacterized, with the exception of Sigma virus, which had a long history of study as a hereditary factor of the insect Drosophila prior to its recognition as a rhabdovirus. It is possible that the genetic organization of some of these viruses may differ substantially from the vesiculovirus and lyssavirus patterns, since particle length (and presumably nucleic acid content) of the animal rhabdoviruses varies considerably, and some of the presumptive plant rhabdoviruses are known only as nucleus-associated unenveloped nucleocapsids. Indeed, Kurath and Leong (1985) have recently characterized the gene products of the fish rhabdovirus infectious hematopoietic necrosis virus (IHNV), which resembles rabies virus more than VSV in terms of its structural proteins. Six messenger RNAs (mRNAs) were detected by denaturing gel electrophoresis and their coding assignments determined by hybrid selection and in vitro translation experiments. Five mRNAs encoded the L, G, $M_{1}, M_{2}$, and $N$ structural proteins, whereas the sixth encoded a nonstructural nonviral (NV) protein with a molecular weight of approximately 12,000. Kurath et al. (1985) determined the gene order by R-loop mapping using plasmids carrying complementary DNA (cDNA) copies of the six mRNAs of IHNV. The gene order was deduced to be $\left(3^{\prime}\right) \mathrm{N}-\mathrm{M}_{1^{-}}$ $\mathrm{M}_{2}$-G-NV-L $\left(5^{\prime}\right)$, which is identical to that of rabies virus (Flamand and Delagneau, 1978) apart from the insertion of NV between G and L. The complete nucleotide sequence of the Pasteur strains of rabies virus has now been obtained confirming this gene order (Tordo et al., 1986). In the rabies virus genome, however, there is a long intercistronic sequence between the $G$ and $L$ genes sufficient to accommodate an additional gene in place of the dinucleotide junction of the VSV genome. The additional sequence may represent either an evolving gene or a relict gene since all three reading frames are blocked. Thus, the vesiculovirus genome pattern may not be typical of the Rhabdoviridae as a whole.

The genetic properties of rhabdoviruses discussed in this chapter refer exclusively to the vesiculoviruses, the lyssaviruses, and Sigma virus of Drosophila. This survey of the genetics of rhabdoviruses covers developments up to the end of 1985. Earlier phases are described in reviews by Flamand (1980), Pringle (1975, 1977, 1982), and Pringle and Szilagyi (1980).

\section{Comparison of the Rhabdovirus and Paramyxovirus Genomes}

Comparison of the order of the genes in the genomes of three paramyxoviruses with the order of genes in VSV suggests that the rhabdovirus genome is the least complex of the unsegmented-genome negative-strand RNA viruses. Figure 1 indicates the order and possible functional homologies of the genes of VSV, Sendai virus, and respiratory syncytial virus. VSV lacks one of the two envelope $G$ proteins of the parainfluenza viruses (Sendai virus), whereas the genome of the pneumovirus respiratory syn- 
Paramyxoviridae

RS Virus

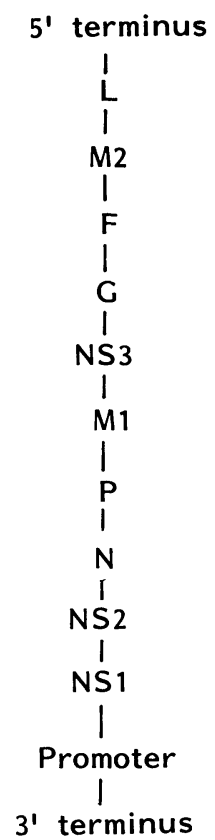

Sendai Virus

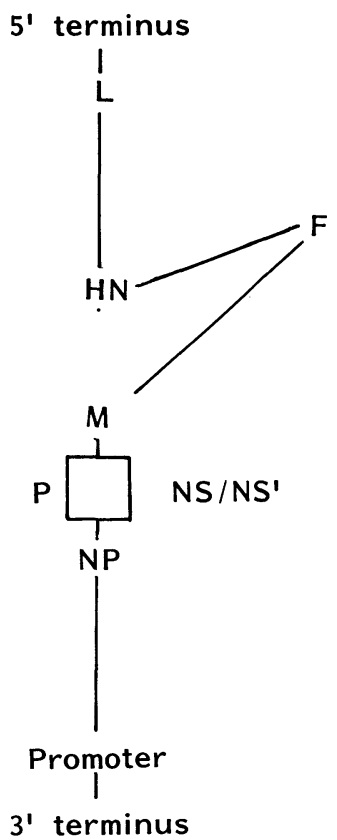

Rhabdoviridae

VS V

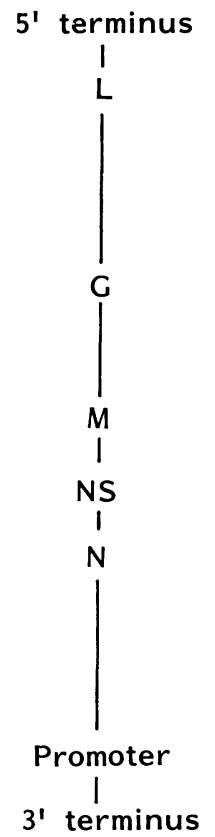

FIGURE 1. Genome structure of the unsegmented negative-strand RNA viruses. The diagram shows the order and presumed functional homologies of the genes of VSV, Sendai virus, and respiratory syncytial (RS) virus. (L) Large (polymerase) protein; (M) matrix protein; (F) fusion protein; (G) spike glycoprotein; (HN) hemagglutinin; $(\mathrm{P})$ phosphoprotein; $(\mathrm{N})$ nucleocapsid protein; (NP) nucleoprotein; (NS) nonstructural protein (in Sendai virus and RS virus) or polymerase-associated core protein (in VSV).

cytial virus is substantially more complex, encoding an additional unglycosylated membrane protein and two additional presumptive nonstructural proteins.

\section{ORGANIZATION OF THE VESICULOVIRUS GENOME}

\section{A. General Features}

The determination of the complete sequence of the $\mathrm{L}$ gene of the Mudd-Summers strain of the Indiana serotype of VSV (Schubert et al., 1984) has closed the remaining gap in the sequence and established the basic features of the vesiculovirus genome. The nucleotide sequence of the $\mathrm{L}$ gene of the Mudd-Summers strain and the sequences of the leader region and the N, NS, M, and G genes of the San Juan strain of VSV 
Indiana taken together establish the primary structure of the VSV genome. The genome, including the untranslated leader region, the five genes, the four intercistronic junctions, and the terminal tail region, is $11,162 \mathrm{nu}$ cleotides in length. The VSV genome is revealed as a remarkably simple entity; $99.37 \%$ of the nucleotides of the genome are transcribed, and 93.88\% encode polypeptide-specifying information. The leader RNA and the five genes are arranged in a linear sequence without overlaps and with the minimum of untranscribed intervening and terminal sequences. The short 47-nucleotide untranslated leader sequence and the five monocistronic mRNAs are transcribed from the $3^{\prime}$ terminus of the genome by a virion-associated RNA-dependent RNA polymerase, and the five mRNAs are present in infected cells in decreasing order of abundance in inverse relation to their proximity to the $3^{\prime}$ terminus (Villareal et al., 1976). This divergence from equimolar synthesis has been termed "attenuation" to indicate partial termination of transcription occurring at or near the intercistronic boundaries (Iverson and Rose, 1981). The rate of transcription (elongation) in vitro appeared to be 3.7 nucleotides per second within all five genes and markedly slower at intergenic junctions. The order of the genes that determine the five structural proteins in the $5^{\prime}$ to $3^{\prime}$ direction is $L, G, M, N S$, and N; L denotes the gene that codes for the large viral polymerase; $G$, the gene that codes for the membrane glycoprotein that forms the virion spikes; $M$, the gene that codes for the unglycosylated matrix protein; NS, the gene that codes for the polymerase-associated phosphoprotein - the original designation NS, for nonstructural, being a misnomer [see Chapter 2 (Section II.B)]-and N, the gene that codes for the nucleocapsid protein, confirming earlier deductions from the kinetics of UV inactivation of gene function in vivo and in vitro with a coupled transcription-translation system. There is no apparent expansion of coding capacity by use of multiple reading frames and no splicing signals that might indicate processing of mRNA. The NS gene of the MuddSummers strain of VSV Indiana, however, contains a second open reading frame (Hudson et al., 1986) and a $7000 \mathrm{~mol}$. wt. gene product has been identified by in vitro translation of a mixture of VSV polyadenylated mRNAs (Herman, 1986). Hybrid arrest translation showed that the VSV phosphoprotein $(\mathrm{P})$ and the $7 \mathrm{k}$ protein were translated from the NS mRNA. The $P$ and $7 \mathrm{k}$ proteins were both immunoprecipitated by an anti-P monoclonal antibody, indicating that the two products of the NS gene are encoded in the same reading frame. The results of hybrid arrest translation using mRNA fragments indicated that the $7 \mathrm{k}$ protein was produced by binding of ribosomes and initiation of translation internally at a site several hundred nucleotides downstream from the capped 5 '-terminus. Herman (1986) has pointed out that small proteins encoded in the same open reading frame as the $P$ protein are common in paramyxoviruses, and it would be logical to redesignate the NS gene as the P gene since the phosphoprotein is a virion component. The function of the $7 \mathrm{k}$ protein has not yet been established. 
All the gene products apart from the leader RNA appear in the virion, the number of protein molecules per virion being in the following ranges: L, 20-30; G, 500-1500; M, 1600-4000; NS, 100-300; N, 1000-2000. The basic features of the organization of the VSV genome are summarized in Table I, together with the molecular weights of the viral proteins inferred from the sequence data.

\section{B. Leader RNA}

The leader RNA of 47 nucleotides is neither capped, polyadenylated, nor translated. Its function is undefined, but it is implicated in the inhibition of host RNA synthesis (McGowan et al., 1982; Grinnell and Wagner, 1984). The nascent plus and minus leader RNA contains an encapsidation nucleation site perhaps represented by a five-times-repeated A residue at every third position from the $5^{\prime}$ end (Blumberg et al., 1983). The leader region is separated from the first polypeptide-specifying gene by the sequence AAA (or AAAA in the New Jersey serotype) (Keene et al., 1980; McGeoch et al., 1980).

\section{Intercistronic Junctions}

The five genes are separated by junction regions of almost identical structure. The intergenic junctions consist of a unadecamer $\left(3^{\prime}\right)$-AUACUUUUUUU- $\left(5^{\prime}\right)$ corresponding to the sequence (5')-UAUGAAAAAAA- $\left(3^{\prime}\right)$ at the mRNA-polyadenylic acid [poly(A)] junction to each message, which is presumed to be the signal for synthesis of the poly(A) tails of the mRNAs by reiterative copying ("slippage polymerization"). This unadecamer is followed by the dinucleotide GA (or CA in the case of the NS : M junction), which is untranscribed and marks the intercistronic junction. These dinucleotide spacers are followed immediately by sequences with the general form ( $\left.5^{\prime}\right)$-AACAGNNAUC- $\left(3^{\prime}\right)$ complementary to the $5^{\prime}$ end of the mRNA, where $\mathrm{N}$ represents a variable site (McGeoch, 1979, 1981). At the $5^{\prime}$ end of the genome, there is an untranscribed region of 59 nucleotides beyond the $3^{\prime}$ terminus of the $\mathrm{L}$ gene. The function of this region is not known, but there is a polarity in the distribution of adenine and uridine residues at the $5^{\prime}$ end of the genome, such that $32(53 \%)$ of the first 60 bases are adenines and $29(48 \%)$ of the next 60 are uridines. The last 125 nucleotides of the genome can be arranged in a configuration with $62 \%$ of the bases paired. Schubert $e t$ al. (1980) have pointed out that this degree of secondary structure is greater than the self-complementarity of transfer RNA (tRNA), in which $55 \%$ of the bases are paired; consequently, it is likely that this potential secondary structure has some functional significance, even though $\mathrm{N}$ protein is normally associated with the $5^{\prime}$ terminus. There is, however, 


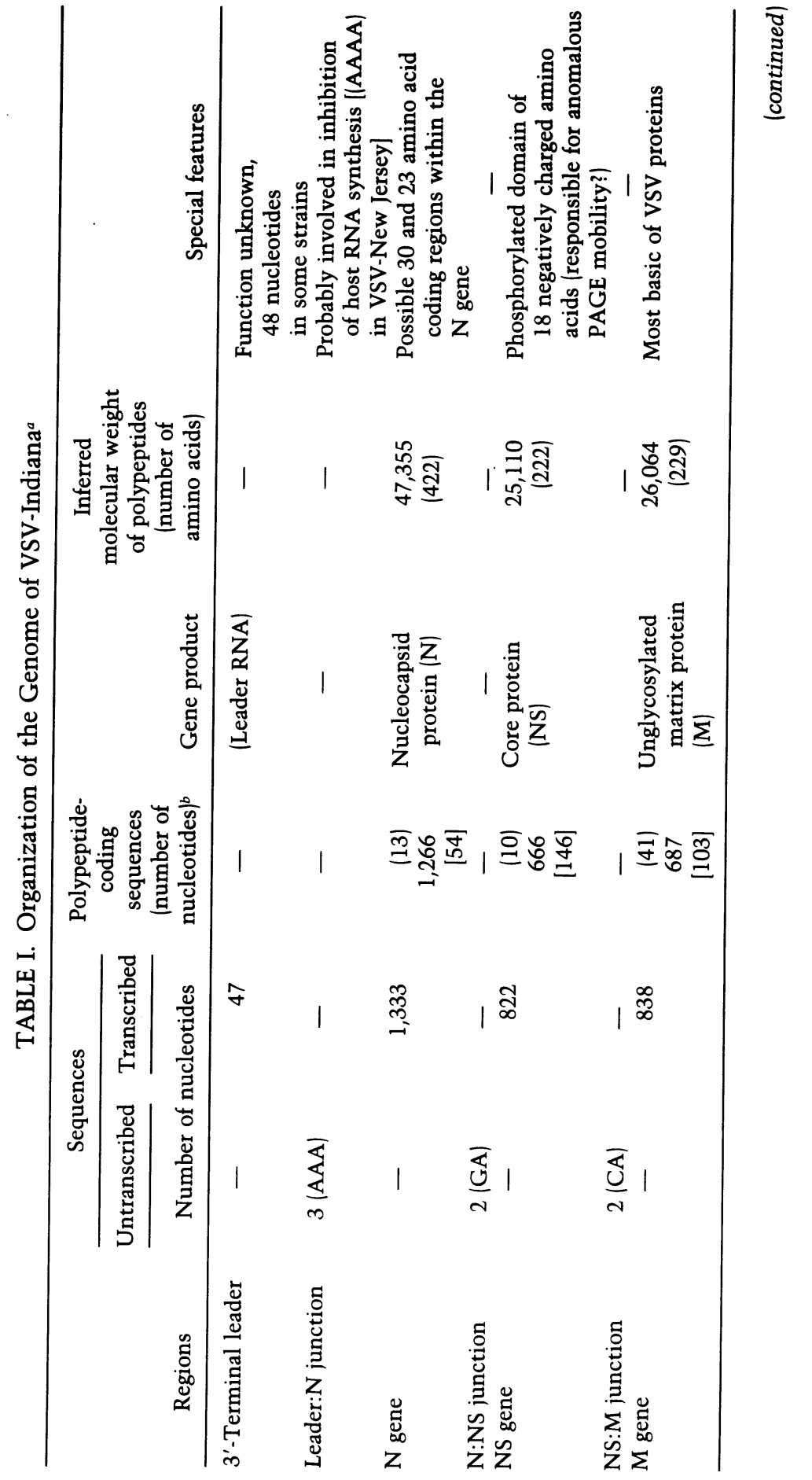




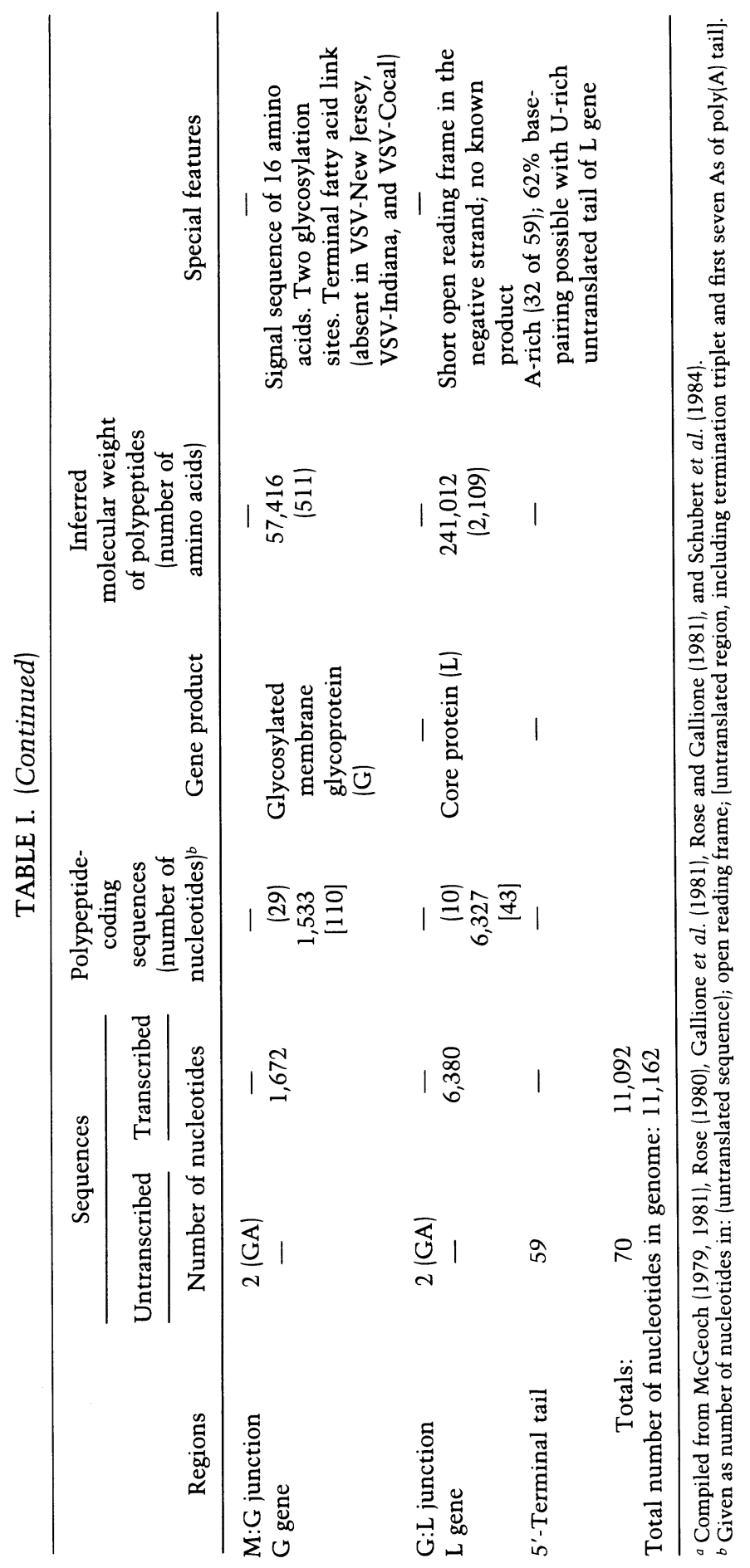


no indication of potential secondary structure at the intercistronic boundaries that could account for the phenomenon of attenuation.

\section{L Gene}

At 6380 nucleotides, the $\mathrm{L}$ gene accounts for $57.16 \%$ of the genome, approximating the size of the complete genome of tobacco mosaic virus (6395 nucleotides) and exceeding that of the entire genome of the ribophage MS2 (4569 nucleotides). The L protein has a molecular weight of 241,012 , comprising $60.38 \%$ of the total coding capacity of the VSV genome. There are some short open reading frames in the genome-sense strand of the L gene, the largest of which is sufficient to encode a polypeptide with a molecular weight of about 10,000 , but there is no evidence for the existence of a functional transcript. Consequently, there is no evidence in this rhabdovirus of the ambisense disposition of functional genetic information on both positive and negative strands that has been observed in the case of the S RNA of the bunyavirus Punta Tora (Akashi et al., 1984) and the S RNA of the arenavirus Pichinde (Auperin et al., 1984).

\section{E. G Gene}

The G gene, at 1672 nucleotides, is the next largest gene, encoding a polypeptide of 511 amino acids with a molecular weight of 57,416 . The 511-amino-acid sequence includes an amino-terminal signal peptide of 16 amino acids that does not appear in the mature protein. There are two hydrophobic domains, one in the signal peptide and the other in the 20amino-acid transmembrane segment close to the $\mathrm{COOH}$ terminus. There are two glycosylation sites, Asn-Ser-Thr at position 178-180 and AsnGly-Thr at position 335-337. One or two molecules of fatty acid are esterified to the G protein, probably as serine residues on the aminoterminal side of the hydrophobic transmembrane region, presumably stabilizing the association of this domain with the membrane (Rose and Gallione, 1981). Two of five serine residues are missing in this region of the G protein of VSV-New Jersey, which does not contain esterified fatty acid, and are probably the esterification sites (Gallione and Rose, 1983). Schlesinger et al. (1984) have reported that the San Juan strain but not the Orsay strain of VSV-Indiana became temperature-sensitive by inhibition of the removal of glucose in the initial stages of processing of the asparagine-linked oligosaccharides. The amino termini of the VSV and rabies virus $G$ proteins are conserved and a peptide corresponding to the amino-terminal 25 amino acids of the VSV glycoprotein has been shown to be a pH-dependent hemolysin (Schlegel and Wade, 1985). It may be that the membrane-destabilizing properties of this domain are important for glycoprotein function. 


\section{F. M Gene}

The M gene, with a size of 838 nucleotides, encodes a basic polypeptide of 229 amino acids with a molecular weight of 26,064 . The amino terminus is highly basic, with 8 lysines in the first 19 amino acids. A triple proline sequence separates this basic domain from the rest of the molecule. This basic domain may interact with genomic RNA, since Mprotein mutants and in vitro experiments have implicated $M$ protein in the regulation of transcription (Rose and Gallione, 1981). Unlike the M protein of influenza virus, there are no long hydrophobic or nonpolar regions that might suggest a direct association of this protein with membranes.

\section{G. NS Gene}

The NS gene, with a size of 822 nucleotides, encodes a polypeptide of 222 amino acids with a molecular weight of 25,110 . This protein runs anomalously in sodium dodecyl sulfate-polyacrylamide gel electrophoresis (SDS-PAGE) with an apparent molecular weight in the range $40,000-50,000$. There is a domain with 18 negatively charged and no positively charged amino acids within a stretch of 44 in the amino-terminal half of the polypeptide. A deficiency of SDS binding in this region could explain the aberrant electrophoretic mobility; alternatively, the polypeptide could migrate as a dimer. The protein is phosphorylated, but dephosphorylation decreases the electrophoretic mobility and is not responsible for the aberrant mobility (Gallione et al., 1981). The NS protein is phosphorylated at multiple sites $(6-10)$ and the phosphorylated sites on the NS protein of VSV-Indiana obtained either from infected cell cytoplasm (Bell and Prevec, 1985) or virions (Hsu and Kingsbury, 1985) have been mapped by chemical cleavage to the amino-terminal third of the molecule. Sites in a domain located to a peptide lying between amino acids 35 and 78 appear to be constitutively phosphorylated and five potential phosphorylation sites in this region are conserved in four different strains of VSV (Hudson et al., 1968; Rae and Elliott, 1986a). The results of Bell and Prevec (1985) were consistent with the existence of the NS polypeptide as a monomer, consequently the aberrant mobility of NS in polyacrylamide gel electrophoresis is unlikely to be a consequence of dimerization.

\section{H. N Gene}

Finally, the $\mathrm{N}$ gene, with a size of 1333 nucleotides, encodes a polypeptide of 422 amino acids with a molecular weight of 47,355 . There are two additional AUG codons located in secondary ribosome-binding sites 
near the $5^{\prime}$ end that could initiate synthesis of short polypeptides in a second reading frame (Gallione et al., 1981). However, transcripts have not been identified, and although corresponding open reading frames are present in the Ogden strain of VSV-New Jersey (Banerjee et al., 1984), they are shorter and the second is not present in the Missouri strain of VSV-New Jersey (McGeoch et al., 1980). There is also an additional AUG codon in the Ogden sequence before the binding site, which is not present in the Missouri strain, and another before the third binding site. It is unlikely that these sites play any significant role in translation.

\section{Gene Products}

The five mRNAs are capped, methylated, and polyadenylated, whereas the leader RNA is not. The $3^{\prime}$-terminal adjacent region is conserved in at least five vesiculoviruses (McGeoch, 1981), although the polymerasebinding site located at position 16-30 in the middle of the leader region (Keene et al., 1981b) does not appear to be. The precise function of the leader RNA is unclear, but plus-strand leader appears to be involved in the inhibition of cellular RNA synthesis, because in vitro VSV leader RNA or its cDNA inhibited transcription of adenovirus by polII and polIII (McGowan et al., 1982; Grinnell and Wagner, 1984). It has been shown, however, using mutant $t s \mathrm{G} 22$ (II), which is competent for primary transcription, that viral protein synthesis is required for inhibition of host macromolecular synthesis (Unger and Reichmann, 1973). Leader RNA has been shown to have an encapsidation nucleation site for $\mathrm{N}$ protein and to react specifically with La protein, an antigen that reacts with antibodies from patients with systemic lupus erythematosus (Kurilla and Keene, 1983). However, the plus-strand leader RNA of mutant virus isolated from persistently infected L cells, in which there is no inhibition of macromolecular synthesis, binds La protein as efficiently as wild-type virus. The La protein-leader interaction appears to be involved more in the control of replication rather than in direct inhibition of host macromolecular synthesis (Wilusz et al., 1985). No base changes have been found in the leader sequence of several tdCE and hrCE host-range mutants of VSV-New Jersey; consequently, the putative host factor associated with these mutants (see Section VII) is unlikely to be the La protein (Keene, personal communication).

\section{J. Codon Usage}

There is nonrandom utilization of codons in all five mRNAs, with an overall deficiency of the dinucleotide CG affecting the codon usage for serine, proline, threonine, alanine, and arginine. The CG deficit is observed both within and between codons; consequently, it is unlikely 
to be an adaptation to a shortage of tRNA species that recognize the CG dinucleotide. The reason for the CG deficiency in viral RNA and vertebrate DNA in general remains unexplained.

\section{COMPARATIVE SEQUENCE ANALYSIS}

\section{A. N-Gene Termini}

McGeoch et al. (1980) compared the terminal sequences of the nucleocapsid (N)-protein gene mRNA of vesicular stomatitis virus (VSV)Indiana (Glasgow strain) and VSV-New Jersey (Missouri strain, Hazelhurst subtype) to identify the positions of the initiation and termination of translation in each. About 200 residues adjacent to the 3 '-terminal poly(A) tract of the $\mathrm{N}$ mRNA were determined. Taking the two regions together, there was $70.8 \%$ sequence homology between the two strains, compared with the $4-20 \%$ homology estimated from annealing experiments. Figure 2 is a graphic representation of the sequence homologies of the $3^{\prime}$ terminus of the N genes of VSV-Indiana, VSV-New Jersey, VSV-Cocal, and Chandipura virus, showing the extent of sequence divergence and the regions of overall homology.

Figure 3 shows another example of this approach in which the $5^{\prime}$ and 3 ' amino acid sequences derived from the nucleotide sequences of the $\mathrm{N}$ gene (McGeoch et al., 1980; Banerjee et al., 1984) of the Missouri and Ogden strains of VSV-New Jersey are compared. The Ogden and the Missouri strains represent the Concan and the Hazelhurst subtypes of VSVNew Jersey, respectively (Reichmann et al., 1978). There is a considerable

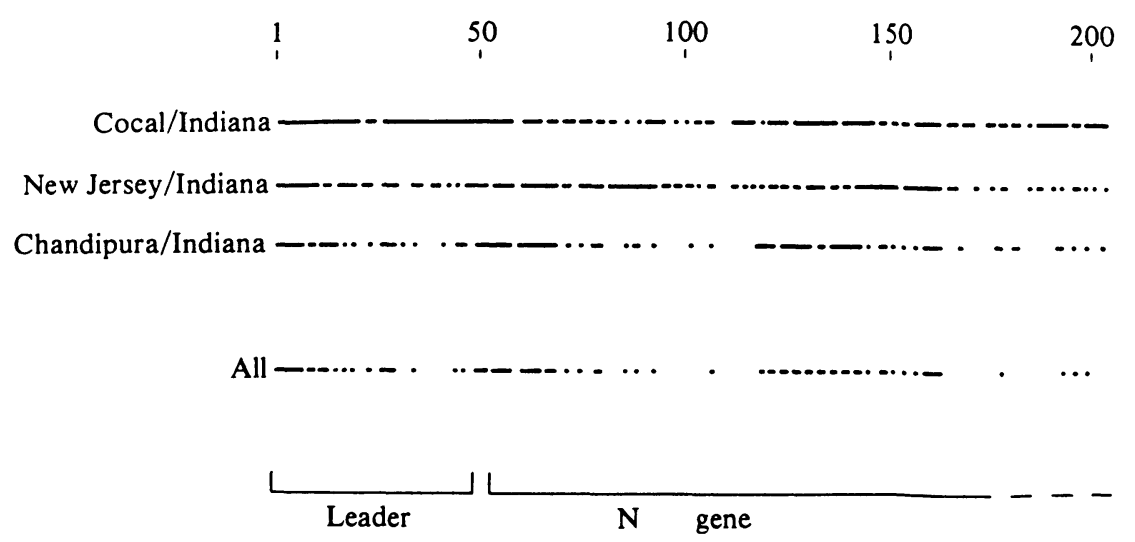

FIGURE 2. Comparison of the sequences at the 3 ' termini of four vesiculoviruses. For pairs of sequences, and for all four, regions of homology are represented by a heavy line. Where necessary, realignment has been made to allow for different leader and leader- $\mathrm{N}$ gene space lengths. Reproduced from McGeoch (1981). 
A

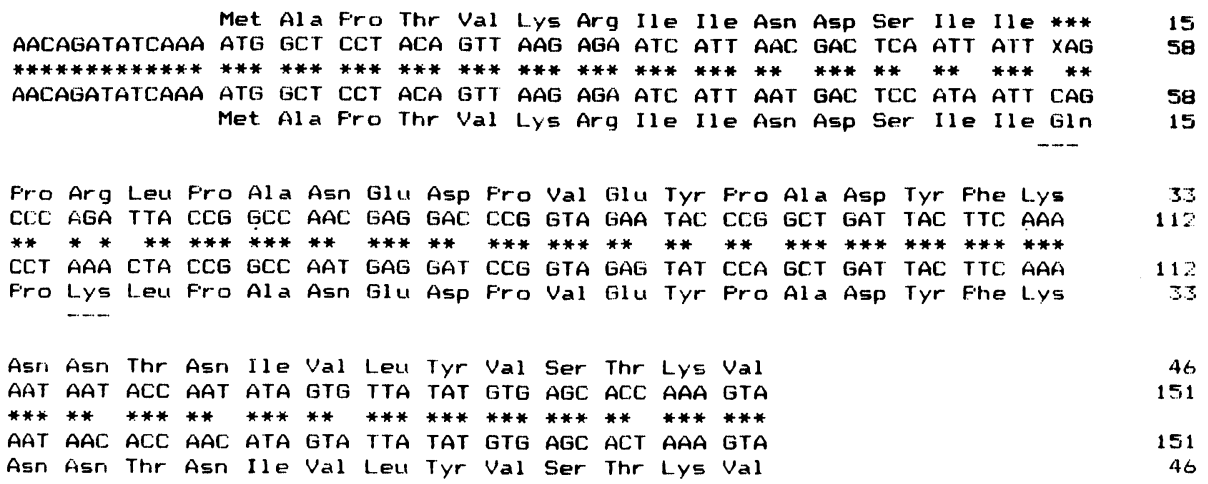

B

Lys Gly Arg Asn Val Val Asp Trp Leu Gly Trp Tyr Asp Asp Asn Gly Gly Lys 18

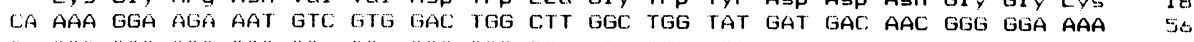

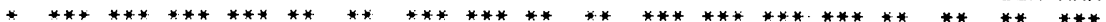
Cb aAa gga aga aAT GTt GTa gaC tgG CTC GGT TGg tat Gat gac aAt gGa gGg aAa Lys Gly Arg Asn Ual Val Asp Trp Leu Gly Trp Tyr Asp Asp Asn Gly Gly lys 18

Fro Thr Fro Asp Met Leu Asn Fhe Ala Arg Arg Ala Val Asn Ser Leu Gin Ser 36 CCC ACA CCA GAT ATG CTC AGC TTC GCA AGA AGA GCA GTT AAC TCT CTG CAG TCA

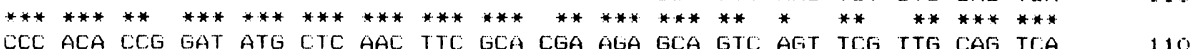
Fro Thr fro Asp Met Leu Asn fhe Ala Arg Arg fila Val Ser Ser leu Gin Ser 36

Leu Arg Glu Lys Thr Ile Gly Lys Tyr Ala Lys Ala Glu Fhe Asn Lys ..... CTT CGT GaG AAG ACA ATT GGC AAA TAT GCC AAG GCA GAG TTT AAC aAG TGA CAAGC: 16 ?

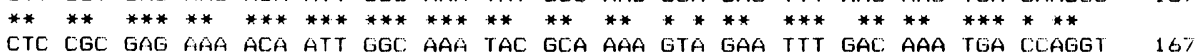
Leu Arg Glu Lys Thr Ile Gly Lys Tyr Ala Lys Val Glu Fhe Asp Lys .......

tTaagataccactatcactattatattctatgttatatatg 208

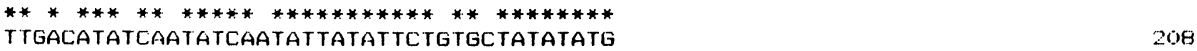

FIGURE 3. A comparison of the $5^{\prime}$-end $(A)$ and $3^{\prime}$-end (B) sequences of the $N$ genes of the Missouri strain (McGeoch et al., 1980) and the Ogden strain (Banerjee et al., 1984) of VSVNew Jersey. The Missouri sequence is given above and the Ogden sequence below. Identical residues are indicated by asterisks, and coding changes are underlined.

degree of sequence divergence, perhaps not surprising since the Hazelhurst subtype strain was isolated from a pig in Missouri in 1943 and the Concan subtype strain from a cow in Utah in 1949. Of the nucleotides at the $5^{\prime}$ end, $10 \%$ are changed, and at the $3^{\prime}$ end, $2.2 \%$ (or $14.2 \%$ overall). Of the 43 nucleotide changes, 33 are in the third codon position; therefore, the number of coding changes is low, one at the $5^{\prime}$ and three at the $3^{\prime}$ end (i.e., four overall). Thus, comparative nucleotide sequencing of a small region of the genome can be an accurate method of determining relationships within the family Rhabdoviridae, a method that is more sensitive and definitive than peptide mapping, annealing experiments, or oligonucleotide fingerprinting. 


\section{B. G Genes}

Gallione and Rose (1983) have compared the nucleotide sequences of the glycoprotein $(G)$ gene of VSV-Indiana and VSV-New Jersey (Ogden strain). The positions and sizes of the transmembrane domains, signal sequences, and glycosylation sites are identical in VSV-Indiana and VSVNew Jersey, but the lengths of the coding sequences differ, encoding 511 and 517 amino acids, respectively. The untranscribed regions of VSVNew Jersey are smaller, totaling 25 nucleotides compared with the 126 of VSV-Indiana.

The complete nucleotide sequence of the G gene of the ERA strain of rabies virus has been determined by Anilionis et al. (1981) and that of the CVS strain by Yelverton et al. (1983). The deduced amino acid sequences of the two G proteins show about $90 \%$ homology. The VSVIndiana (San Juan strain) and rabies virus (ERA strain) $G$ proteins are approximately the same size, with 511 and 524 amino acids, respectively. There are three putative glycosylation sites in the rabies virus $\mathrm{G}$ protein (Asn-X-Ser and Asn-X-Thr) and two in the G protein of VSV (Asn-X-Thr), the $\mathrm{COOH}$-terminus-proximal glycosylation sites being aligned exactly. Comparison of the predicted amino acid sequences of the two glycoproteins has revealed significant homologies. Although the lengths of the two proteins differ, the signal and transmembrane sequences are aligned exactly. Nevertheless, the corresponding sequences are not highly conserved, which indicates that the only dominant requirement in these regions is hydrophobicity. In the optimum alignment, there is $20 \%$ identity of sequence (with higher values in limited regions, e.g., the 24 amino acids preceding and including the putative glycosylation sites nearest the $\mathrm{COOH}$ terminus). This value is less than that between Semliki Forest virus and Sindbis virus $(47 \%)$ and about equal to that between the $\beta$ chain of human hemoglobin and human myoglobin or between the matrix (M) protein of VSV-Indiana and the M protein of influenza A virus. At the nucleotide level, there was much less apparent homology.

A remarkable amino acid homology has been reported between a segment of the rabies virus $G$ protein and the entire sequence of the long (71 to 74-residue) curaremimetic neurotoxins of snake venom (Lentz et al., 1984). The greatest identity occurs in the region of the 20-amino-acid highly conserved "toxic" loop in the middle of the neurotoxin molecule, which is known to interact with the acetylcholine (ACh)-binding site of the ACh receptor. These observations and the fact that rabies virus binds to regions with abundant $\mathrm{ACh}$ receptors suggests that direct binding of rabies virus $\mathrm{G}$ protein to the $\mathrm{ACh}$ receptor may contribute to the neurotropism of this virus.

Kotwal et al. (1983) have compared the amino-terminal amino acid sequences of VSV-Indiana (Toronto HR strain), VSV-New Jersey (Concan subtype), and VSV-Cocal. There was little sequence homology in the 16amino-acid (17-amino-acid in Cocal virus) signal-peptide region of the 
unglycosylated precursors, apart from a high content of hydrophobic amino acids. By contrast, the amino-terminal sequence of the mature envelope glycoproteins was highly conserved for at least 24 amino acids. The biological function of this highly conserved region remains to be elucidated.

\section{NS Genes}

The complete sequences of the NS genes of strains of both the Concan and Hazelhurst subtypes of the New Jersey serotype of VSV have been obtained by Gill and Banerjee (1985) and Rae and Elliott (1986a), respectively, and of the San Juan (Indiana subtype) and Mudd-Summers (Cocal subtype) of the Indiana serotype by Gallione et al. (1981) and Hudson et al. (1986), respectively. The mRNAs of the New Jersey strains are identical in length (856 nucleotides excluding poly A), as are those of the Indiana strains (814 nucleotides). There is about $50 \%$ homology between the NS genes of the two subtypes compared with $85 \%$ for the two New Jersey strains and $97 \%$ for the two Indiana strains. The greater divergence of the two New Jersey subtypes may reflect the marked difference in host range of the two subtypes (Schnitzlein and Reichmann, 1985).

Comparison of the predicted amino acid sequences of the NS proteins shows only $33 \%$ homology between the two subtypes, which is considerably less than the homology between the $\mathrm{G}(51 \%)$ and $\mathrm{N}(69 \%)$ proteins of these serotypes. Hudson et al. (1986) identified two domains: an acidic region (domain I) and a basic region (domain II). The conserved phosphorylation sites lie within domain I, and domain II is represented by the conserved carboxy-terminal region. Despite the lack of amino acid homology elsewhere in the molecule, the relative charge distribution and hydropathy are preserved. Hudson et al. (1986) suggested that domain II, by binding to a specific site on genome or antigenome RNA, is involved in the initiation of replication or transcription, whereas domain I, by mimicking the RNA template, binds $\mathrm{N}$ protein thereby facilitating polymerase entry. Eleven additional conserved potential phosphorylation sites are regularly spaced between domains I and II and phosphorylation at these sites would enhance the mimicry of RNA structure.

\section{M Genes}

The M genes of the San Juan strain (Rose and Gallione, 1981) and the Glasgow and Orsay strains (Gopalakrishna and Lenard, 1985) of VSVIndiana have been sequenced. The coding region of the former strain differs from the latter pair in 13 nucleotides, causing 6 amino acid substitutions. The Glasgow and Orsay strains are more similar, differing by 8 nucleotides causing 4 amino acid changes. 


\section{DELETION MUTANTS}

\section{A. Genome Structure}

\section{General Features}

The defective interfering (DI) particles of vesicular stomatitis virus (VSV) and other rhabdoviruses that accumulate during multiplication at high multiplicities of infection (undiluted passage) contain only a portion of the viral genome and are formally equivalent to deletion mutants.

Characteristically, these incomplete genomes (in DI particles) interfere with the replication of the complete genome (standard virus). Nevertheless, they are themselves dependent on the polymerase of standard virus for their own multiplication, because DI particles invariably have lost a portion of the $\mathrm{L}$ gene and none can encode a functional polymerase. Since the complete sequence of the L gene (Schubert et al., 1984) and partial sequences of several DI particles have been determined, it is now possible to map precisely the extent of the deletions in DI-particle genomes and to characterize the sites of recombination of the deleted molecules (Meier et al., 1984).

Four types of DI-particle genomes can be distinguished, these being designated: (1) fusion, (2) panhandle, (3) snapback, and (4) compound (Lazzarini et al., 1981; Perrault, 1981). All four types of genomes have structural features in common; namely, variable portions of the $\mathrm{L}$ gene are deleted, the $5^{\prime}$-terminal regions of the deleted genomes are identical in sense and sequence to the $5^{\prime}$ terminus of the minus strand of the complete genome, and the $3^{\prime}$-terminal regions are identical to the $5^{\prime}$ terminus of either the minus or the plus strand of the complete genome. These features are diagrammed in Fig. 4.

\section{Panhandle DI Particles}

The snapback and panhandle (the most common type) DI particles have lost the entire N, NS, M, and G coding regions in addition to the $3^{\prime}$ end of the L gene. These DI particles can neither transcribe functional mRNA nor complement any of the six groups of temperature-sensitive (ts) mutants. The extent of the deletions ranges from $90 \%$ for the smallest DI particles, which are all derived from $t s$ mutants belonging to complementation group III VSV-Indiana, to $50 \%$ for the largest DI particles (Reichmann and Schnitzlein, 1979). These DI particles interfere specifically with the replication of homotypic standard virus, and less well or not at all with heterotypic viruses according to their degree of antigenic relatedness. The 3 ' termini of panhandle DI particles are identical in sense and sequence to the $3^{\prime}$ terminus of the plus strand of standard virus and are hence complementary to the $5^{\prime}$ terminus of the DI genome because of the inverted complementarity of the terminal regions of the standard 


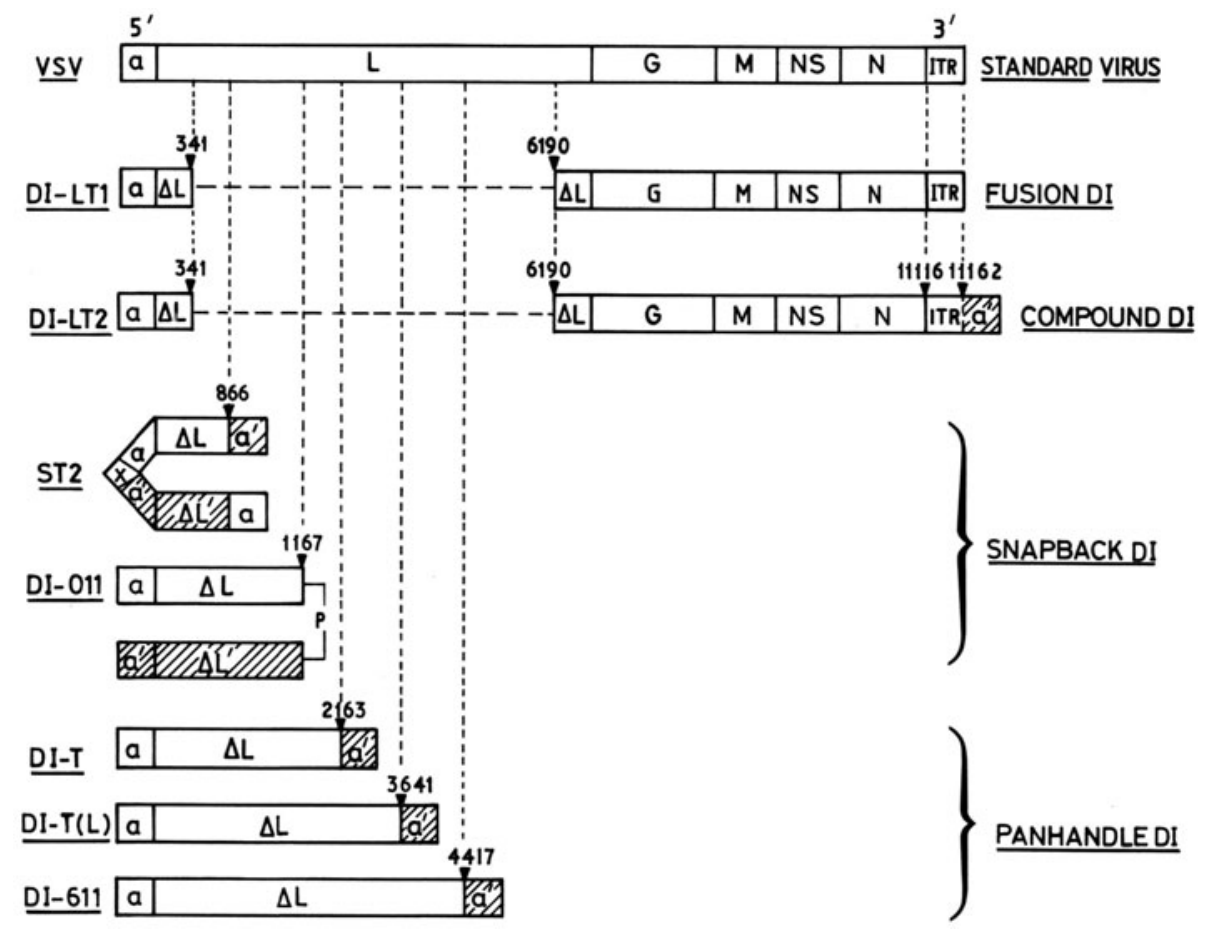

FIGURE 4. Structure of the genome of four types of deletion mutants of VSV. (a, $\left.a^{\prime}\right)$ Complementary terminal sequences; (ITR) inverted terminal repeat; ( $(Z)$ complementary plussense sequences. Compiled from Meier et al. (1984), Lazzarini et al. (1981), and Nichol et al. (1984).

genome. The generation of this type of DI particle can be explained by disengagement of the polymerase during transcription of the $5^{\prime}$ end of the plus-strand replicative template and reattachment at a site adjacent to the $5^{\prime}$ terminus followed by copy-back synthesis to the $5^{\prime}$ terminus. As a consequence, the $3^{\prime}$ end of the DI-particle genome is identical to the $3^{\prime}$ end of the plus strand.

Analysis of the sequences at the points of recombination in three panhandle DI particles of the Mudd-Summers strain by Meier et al. (1984) indicated that the boundary between the panhandle regions and the $\mathrm{L}$ gene was precisely defined. The added 3 '-end sequences were 46 (or exceptionally 45) nucleotides long, suggesting that synthesis of the negativestrand leader RNA may have been the first step in the generation of these panhandle DI genomes. Presumably, the polymerase and the negative leader RNA detach from the plus-strand template and resume synthesis on a negative-strand template. The abundance of leader RNA transcripts and the excess of negative-strand templates over plus-strand templates in the infected cell favor a copy-choice model of generation of DI particles, rather than a copy-back model. O'Hara et al. (1984) have described DI 
genomes with more complex configurations that appeared in the course of prolonged undiluted lytic passages or from persistently infected cells, but all can be interpreted by detachment of the polymerase and template switching.

\section{Snapback DI Particles}

Snapback DI particles, which are less common, contain RNA with extensive self-complementarity. Snapback DIO11 has complementary sequences of 860 nucleotides, covalently linked by a single phosphate group. The 5 '-terminal linked sequence represents $7-8 \%$ of the standard genome. A unique feature of this DI particle is that the parental and progeny strands generated during replication have the same nucleotide sequence. Unlike other DI particles, the covalently linked "turnaround" region shows no homology to either the $5^{\prime}$ or the $3^{\prime}$ termini. The generation of DI particles of this type is best explained by polymerase-template switching during replicative synthesis on a plus-strand template, perhaps as a result of "tailgating" behind a slower-preceding polymerase. If the switch to the progeny strand occurs symmetrically across the replication fork, two completely complementary strands will result. Perrault and Leavitt (1977) concluded on the basis of electron-microscope studies that snapback DI particles derived from mutant $t s \mathrm{G} 31$ (III) of the Indiana strain of VSV had inverted complementary sequences at the plus-negative strand junction. Sequence analysis of the termini has confirmed this structure (Nichol et al., 1984). It is apparent that other types of snapback particles exist in addition to the DI011 type and are generated by a different mechanism. The snapback DI particle designated ST2, which Nichol and colleagues characterized, differs from DI011 in the possession of inverted complementary termini and reverse orientation of the hairpin. This is illustrated in Fig. 4. It is likely that ST2 is derived directly from the panhandle ST1 DI particle present in the same material. Gillies and Stollar (1980) observed that snapback DI particles with $90-95 \%$ self-complementarity were the predominant type of DI particles present after two passages of standard VSV in Aedes albopictus cells, whereas snapback particles were not detected among the DI particles generated by three passages in baby hamster kidney (BHK) cells. The snapback particles generated in $A$. albopictus cells induced interference in the mosquito cells only, unlike the BHK-derived DI particles, which interfered in both cell types with similar efficiency. A single passage in the heterologous culture reversed the specificity of interference.

\section{Fusion DI Particles}

The large DI particles may have panhandle-, fusion-, or compoundtype genomes. Large DI particles of the latter two types are derived predominantly from the Toronto HR strain of VSV-Indiana. Fusion-type DI particles represent internal deletions of the $\mathrm{L}$ gene, leaving the terminal 
regions intact. The HR LT1 DI has 5848 nucleotides deleted within the L gene. Compound-type DI particles resemble fusion DI particles in structure, except that the $3^{\prime}$ terminus is a compound structure, as illustrated for DI LT2 in Fig. 4. The HR LT2 DI particle also has an L-gene deletion of similar extent and two initiation sites in tandem at the $3^{\prime}$ end of the RNA. Unlike the HR LT1 DI particle, these particles were transcriptionally inactive, and unlike the panhandle DI particles, which transcribed a 46-mer product, the internally located leader RNA region appeared to be muted (Keene et al., 1981a). DI-particle genomes with parental ends predominated in early passages and were gradually replaced by genomes with compound complementary ends. It is unlikely that interfering ability is an attribute of a particular end structure, since Keene et al. (1979) have described a DI particle of VSV-New Jersey with a genome having parental ends that was able to induce interference. The LT DI particles can be transcribed in vivo and in vitro and complement $t$ sutants, because the G, M, NS, and N genes are undeleted. The G mRNA, however, yields a product larger than the viral $G$ protein, presumably because of readthrough into the $\mathrm{L}$ gene. A distinguishing functional characteristic of the LT DI particles of VSV-Indiana is their ability to interfere heterotypically with VSV-New Jersey.

Analysis of the sequences around the recombination sites of fusion DI particles has ruled out the existence of a conserved signal sequence specifying termination or resumption of RNA synthesis. In addition, no stable secondary structures can be discerned in the regions adjacent to the site of recombination; therefore, secondary structure does not appear to be involved in the generation of DI particles. Nevertheless, certain sequence homologies adjacent to the points of termination and resumption of synthesis have been recognized. Two hexanucleotides, ATCTGA and GATTGG, separated by approximately the same number of intervening nucleotides occur in the genome four nucleotides before the beginning of the deletion and seven nucleotides before the end of the deletion. This suggests that weak base-pairing between the template and the nascent progeny strand occurs close to the site of resumption of synthesis, or perhaps there is a preferential association of the polymerase with these sequences. Synthesis of the compound HR LT2 DI particle can be explained best in terms of the copy-choice model described for panhandle DI particles (Section IV.A.2).

\section{Induction}

Perrault et al. (1981) have obtained a variant (Pol R1) of the Mudd-Summers strain of VSV-Indiana after several cycles of heat inactivation that appears to be an N-protein mutant (see Section VII.F.2). Subsequently, the Pol R1 variant generated DI particles that synthesized almost full-length copies of their RNA, unlike the wild-type panhandle DI particles, which produced a 46-mer transcript of the leader region only.

The mechanisms of induction of DI particles are obscure, but host 
factors are clearly involved. Suppression of host-cell macromolecular synthesis by treatment with actinomycin D prior to virus infection with VSV cloned and propagated in actinomycin-pretreated cells prevented the induction of DI particles. Actinomycin treatment had no effect on the replication of preexisting DI particles (Kang and Allen, 1978). These results are consistent with the view that DI particles play a role in the modulation of infection; i.e., induction of DI particles is a host-cell-dependent function that moderates the spread of virus in the host prior to the full development of the immune response.

\section{B. Role of Host Factors}

Holland et al. (1976) observed that a subline of Hela cells was incapable of generating DI particles of VSV. Kang et al. (1981) observed that DI particles of different sizes were generated by high-multiplicity passage in human and mouse cells and that none were induced in primary diploid fibroblasts (strain 544). Analysis of seven human-mouse L cell somaticcell hybrids revealed that inability to generate DI particles was a dominant characteristic. Chromosome 16 was the only human chromosome common to all seven hybrids, and it was concluded that a factor on this chromosome is responsible for suppression of induction of DI particles. Both parents and all the hybrids, however, supported the replication of preexisting DI particles. Ability to generate DI particles was regained on loss of chromosome 16 from the hybrid clones. The mechanism of action of the suppressor function of chromosome 16 has not been determined.

\section{MUTATION AND MUTABILITY}

\section{A. General Features}

Mutation can be studied at two levels-the phenotypic level and the level of changes in the nucleotide sequence. Conditional lethal mutants, predominantly temperature-sensitive $(t s)$ mutants, are suitable for the analysis of viral gene function, because this phenotype can be associated with mutation in any essential function of the viral genome.

The $t s$ mutants of VSV-Indiana are designated conventionally as follows: phenotype (ts); origin B (for Bratislava), G (Glasgow), O (Orsay), L (Lodish), M (Massachusetts), T (Toronto), or W (Winnipeg); clone number; complementation group (in parentheses). For example: $t s \mathrm{G} 11(\mathrm{I})$ is $t s \mathrm{mu}-$ tant 11 of the Glasgow strain classified in complementation group I.

Table II lists the phenotypes of the mutants and variants of rhabdoviruses that have been used in genetic analysis. The majority of these phenotypes represent single-step genetic mutations, but a few, such as the spontaneous variants of Sigma virus, probably represent multiple 


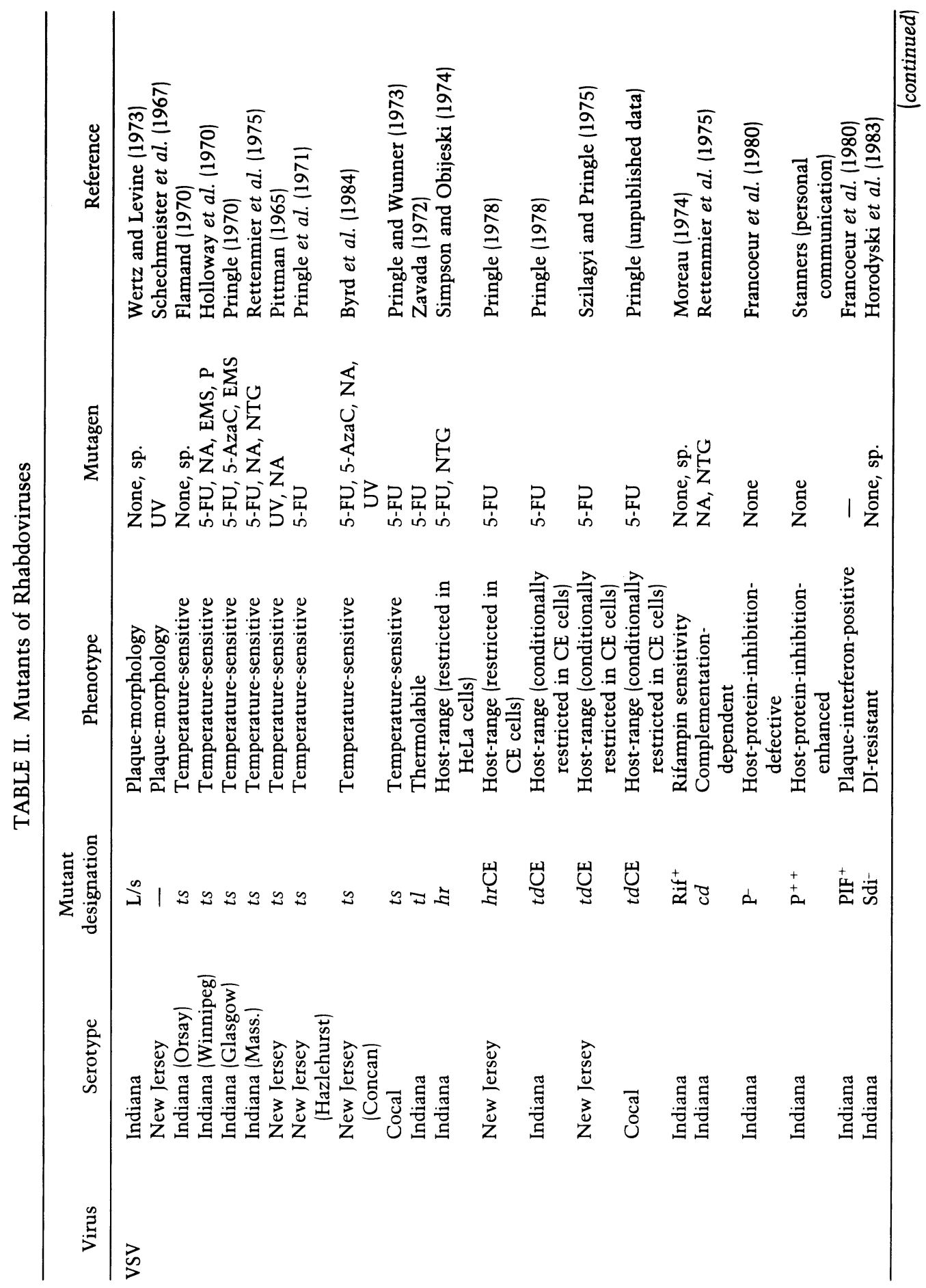




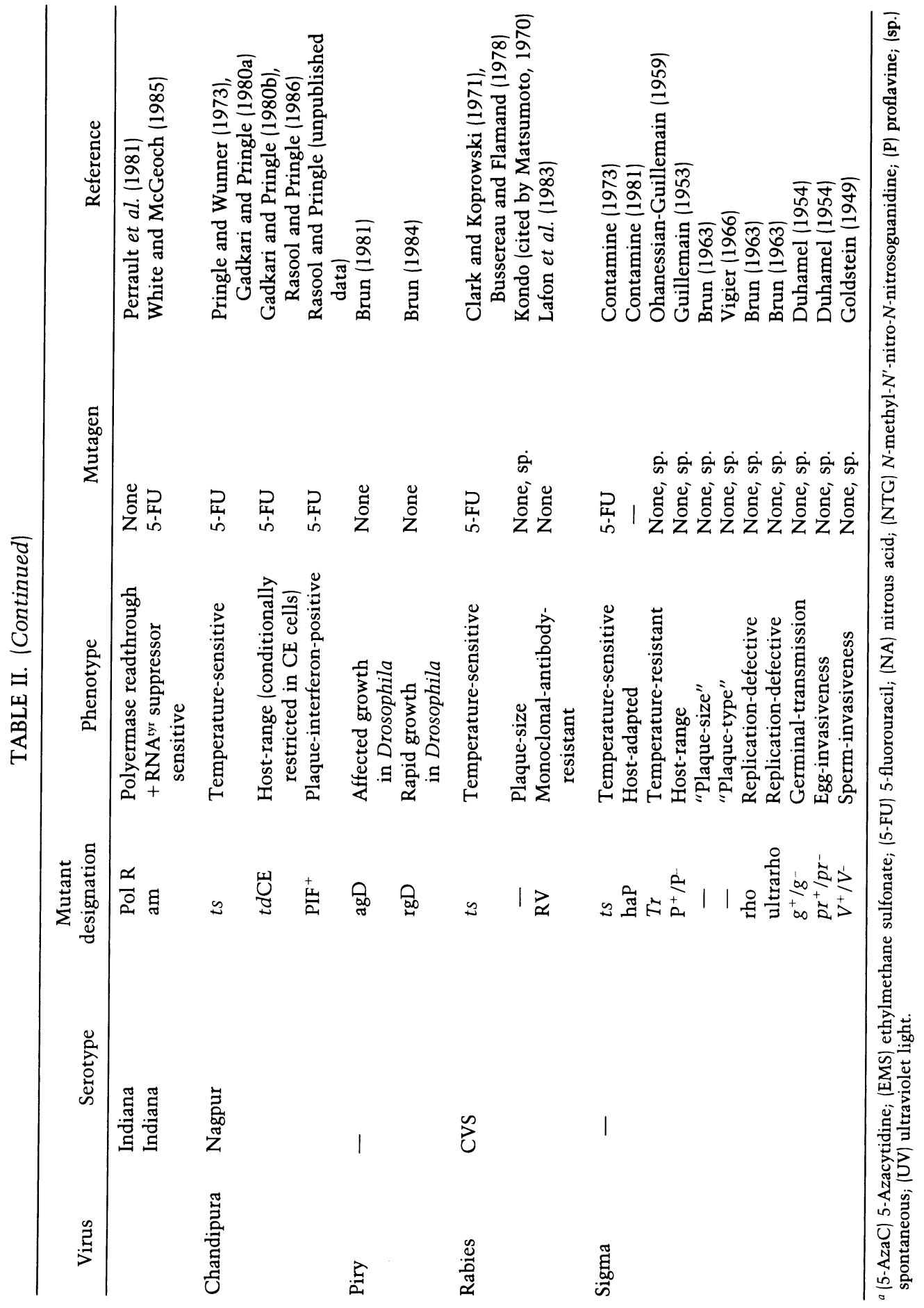


genetic changes. In the case of the three ts mutants comprising complementation group E of vesicular stomatitis virus (VSV)-New Jersey and $t s 045(\mathrm{~V})$ of VSV-Indiana, the inferred single-step nature of the change has been confirmed by oligonucleotide sequencing (see Section VII).

\section{B. Mutation Frequency and Mutation Rate}

In VSV, spontaneous mutation frequency for specific characteristics can be high even in the face of contrary selection (Flamand, 1980). Flamand (1980) calculated the rate of production of $t s$ mutants in stocks of VSV-Indiana propagated in chick-embryo fibroblasts (CEF) as $1.1 \times 10^{3}$ using the formula: $m=0.43 f / \log N-\log N_{\mathrm{o}}$, where $m$ is the mutation rate, $f$ is the frequency of mutants, $N$ is the total population size, and $N_{\mathrm{o}}$ is the initial size of the population (=1 in the case of a virus clone). In other words, the probability that a single base change resulting in a $t s$ mutation will occur in a given replication event is approximately one in a thousand. Since about $90 \%$ of $t s$ mutations in VSV are located in the polymerase gene, this figure of $10^{3}$ approximates the mutation rate per gene. This value is similar to the intrinsic error rate for enzymatic nucleicacid synthesis (Reanney, 1984). In the case of DNA synthesis, proofreading reduces the final error rate to $10^{-9}$ to $10^{-10}$. Since there is no corrective mechanism in RNA synthesis, the error rate remains $10^{5}$ to $10^{6}$-fold greater than in DNA copying.

Because of the high mutation rate per nucleotide, any RNA genome can be described only in a probabilistic sense. For example, in the course of determining the sequence of the L gene of VSV-Indiana, each region of the genome was sequenced five times on average (Schubert et al., 1984). At least 20 nucleotide differences were observed between different overlapping cDNA clones. Of these nucleotide differences, 15 represented base substitutions, 11 of which would produce an amino acid change in the gene product. The remaining 5 differences comprised 1 single-nucleotide addition and 4 single-nucleotide deletions. These changes would cause frameshifts with premature termination, producing truncated L-protein molecules. It is possible that some or all of these nucleotide changes were introduced during reverse transcription, but two of the deleted nucleotides were identical, and these changes at least were unlikely to have been generated during reverse transcription, since the enzyme would have to make the same error at the same site in independent transcripts. The final sequence established for the $\mathrm{L}$ gene, therefore, is a consensus sequence. A full length L-gene clone omitting the 20 nucleotides diverging from the consensus sequence was constructed and inserted into a simian virus 40 (SV40) expression vector. The vector was then transfected into COS cells, and the functional activity of the product of this L-gene construct was established by the complementation and rescue of a superinfecting nonrevertible polymerase-defective mutant $t s$ G11(I) (Schubert 
and co-workers, personal communication), confirming the correctness of the sequence.

Flamand (1980) reported that the frequency of mutation of the Orsay stock of VSV was similar in different cell systems and that propagation of CEF-adapted virus in different cells did not result in genetic instability. Pringle and Wunner (1975) reported that the frequencies of $t s$ mutants in stocks of VSV-Indiana, VSV-New Jersey, and VSV Cocal propagated under comparable conditions were similar and around 1\%. Youngner et al. (1976) reported a frequency of $4.4 \%$ for their stock of VSV-Indiana. However, it is clear that the figure obtained will depend to some extent on the temperature arbitrarily chosen as the restrictive temperature and that comparison of data obtained in different laboratories is therefore not necessarily meaningful.

Flamand (1980) has shown that change in the temperature of incubation, on the other hand, resulted in a transient genetic instability. In one experiment, the frequency of ts mutants reached $8.3 \%$ at the second passage at $39.3^{\circ} \mathrm{C}$ compared with $2.6 \%$ at $30^{\circ} \mathrm{C}$. It was concluded that passage at low multiplicity of infection under uniform temperature conditions did not result in change of the overall temperature sensitivity of the wild-type virus, unlike the situation commonly observed with picornaviruses, in which, for instance, in the case of poliovirus, nine passages at low temperature resulted in loss of ability to grow at high temperature.

Oligonucleotide mapping is the most sensitive method for detecting genetic change, short of complete sequencing, provided there is at least $90 \%$ sequence homology between viruses under comparison (Young et al., 1981). In the case of VSV-Indiana, it has been shown by oligonucleotide fingerprinting that there are appreciable differences between strains isolated from different localities or at different times (Clewley et al., 1977), whereas prolonged passage of any particular isolate in cultured cells produced little significant change (Clewley et al., 1977; Holland et al., 1980, 1982). Brand and Palese (1980) concluded from oligonucleotide mapping of influenza virus and VSV after 12 plaque-to-plaque passages in chickembryo cells that VSV exhibited greater genetic stability than influenza virus. Nucleotide changes were detected in eight of eight subclones of influenza virus, but in only one of four VSV subclones at this passage level. On the other hand, Portner et al. (1980), using monoclonal antibodies, concluded that the mutation rates to antibody resistance for influenza virus, VSV, and Sendai virus were indistinguishable and approximately $10^{-4.5}$ per replication event.

The frequency of $t s$ mutants reported in stocks of other rhabdoviruses varies over a wide range, from $0.3 \%$ to $12.5 \%$, respectively, in the case of the lyssaviruses rabies virus and Lagos bat virus (Bussereau and Flamand, 1975; Clark and Wiktor, 1974). However, these comparisons are not meaningful in view of differences in restrictive temperature.

On the other hand, departures from this apparent genetic stability are common. An extreme example is the observation of Clark (1978) that 
several high-passage strains of rabies virus, previously regarded as genetically stable with no adult-mouse-killing potential, became neurovirulent after two to five passages in cultured human or mouse neuroblastoma cells, with a change in pathogenicity becoming evident even after a single passage. This newly acquired neurovirulence remained a stable genetic property during subsequent propagation in nonneuroblastoma cells.

It has also been observed that $t s$ mutants accumulate during passage in the insect Drosophila melanogaster (Printz, 1970) and in Drosophila cells in culture (Mudd et al., 1973). However, this phenomenon may be to a certain extent a function of the lower temperature of propagation.

\section{Genome Evolution during Persistent or High-Multiplicity Infection}

\section{Persistent Infection}

Extensive genetic changes occur in VSV maintained in persistently infected cells or passaged for a period at high multiplicities of infection. This phenomenon has been comprehensively studied at the molecular level by Holland and colleagues.

Holland and Villareal (1974) established a persistent infection in BHK21 cells using $t s \mathrm{G} 31$ (III), a ts mutant of complementation group III of VSV-Indiana, in the presence of its own homologous defective interfering (DI) particles at semipermissive temperature to restrict cytopathogenicity. A stable persistent infection was achieved after a few passages, and its subsequent maintenance was associated with the appearance of a new DI particle, rather than with temperature sensitivity of the initiating mutant or the small spherical DI particle so far uniquely associated with group III mutants (Reichmann et al., 1971). The progress of this infection, designated Car4, has been monitored by T1-ribonuclease oligonucleotide mapping over the course of nine years. Continuous and progressive evolution was observed, with changes in the oligonucleotide maps accumulating sequentially. By 7.5 years, 24 changes had accumulated, which represents about 240 base changes, or $2 \%$ of the entire genome, since the large unique oligonucleotides represent only about $10 \%$ of the total sequence.

Comparison of the pattern of development of the T1-ribonuclease oligonucleotide-map changes in independently initiated persistent infections during sequential lytic cycles at high multiplicity with the pattern during persistent infection of Aedes albopictus cells indicates that the rapid genome evolution of VSV under these conditions is essentially random and unprogrammed (Spindler et al., 1982). Factors involved in this process may include intergenomic complementation between lethal and semilethal mutants, cis and trans activity of a "mutator" gene, and selection mediated by DI particles.

Complementation-dependent mutations of VSV were identified by 
Rettenmier et al. (1975) using a special screening procedure. It is clear, therefore, that such cryptic mutants exist and could contribute to the genetic variation that accumulates during persistent infection or in stocks maintained at high multiplicity.

A trans-acting "mutator" gene in VSV has been characterized by Pringle et al. (1981). The "mutator" phenotype is associated with mutant $t s \mathrm{D} 1$ of VSV-New Jersey, enhancing the mutability of homologous and heterologous VSV multiplying in the same cells. It was estimated that mutant $t s \mathrm{D} 1$ had accumulated base changes amounting to $0.5 \%$ of the genome, although it was only a few passages removed from the parental wild-type. It is clear that mutator-type genes occur in rhabdoviruses and could be responsible for rapid genome evolution.

\section{Sdi- Mutants}

The selective effect of DI particles was first recognized by Kawai and Matsumoto (1977) when during persistent infection of BHK-21 cells by rabies virus there appeared small plaque mutants that were resistant to interference by the DI particles initially present in the culture. Subsequently, Horodyski and Holland (1980, 1981) observed the same phenomenon in their BHK persistently VSV-infected Car4 culture, and in addition they showed that there was a progressive replacement of these mutants. The appearance of resistant virus, the Sdi- ${ }^{-}$phenotype, was soon followed by the generation of new DI particles to which the virus was now fully susceptible, culminating in another cycle of mutation, escape, and susceptibility (Horodyski et al., 1983). There is thus a simultaneous evolution of both virus and DI particles.

Complementation tests with these Sdi- mutants indicated that at least two different viral functions were involved in the origin of $\mathrm{Sdi}^{-}$ mutants. Horodyski et al. (1983) also demonstrated, using chimeric DI particles, that the template RNA, rather than the envelope proteins of the DI particles, was responsible for the specific interference with the $\mathrm{Sdi}^{-}$and $\mathrm{Sdi}^{+}$mutants of the helper virus. Sequence analysis of the $5^{\prime}$ and $3^{\prime}$ termini of various Sdi- mutants isolated sequentially during persistent infection or lytic infection at high multiplicity revealed a stepwise accumulation of stable base changes within the area of the replicationinitiation site at their $5^{\prime}$ end. Fewer mutations accumulated in the region of transcription initiation at their $3^{\prime}$ terminus.

The most striking feature of the $5^{\prime}$-end sequence was the clustering of mutations in the sequence of 54 nucleotides adjacent to the terminus of the genome. There were 11 single site changes in the genomes of 9 different DI particles from the Car4 and Car6 independently derived persistent infections and from Car51 derived from Car4 after 5 years, whereas only 2 mutations were observed in the tail end of the L-gene mRNA. The 10 single site changes that were observed in Car4 and Car51 accumulated in a stepwise manner; i.e., once a base change appeared, it remained 
present in subsequent isolates, suggesting that selection operated in its favor. This stepwise accumulation of mutants was also observed in 11 Sdi- mutants obtained by undiluted passage of mutant tsG31(III) itself; 5 changes accumulated sequentially and 4 coincided with 4 of the changes observed in the series of Sdi- mutants obtained from the Car4 persistent infection. Interestingly, the Glasgow strain (from which the persistent infections were initiated) differed from the Mudd-Summers strain of VSVIndiana at two sites within this 169-nucleotide region, but neither coincided with sites affected in Sdi- mutants. The Sdi- phenotype does not depend entirely on mutations in this region, however, since base substitutions were not observed in this region in $3 \mathrm{Sdi}^{-}$mutants of this series or in 2 derived from another persistent infection, Car21.

The $3^{\prime}$-terminal region of the same Sdi- mutants was also determined from position 14 to positions $220-330$ from the $3^{\prime}$ terminus. This region does not differ between the two strains of VSV, and fewer changes were observed in the Sdi- mutants at the $3^{\prime}$ end; four mutations accumulated sequentially within the leader-RNA region, and another seven in the Ngene region (three of which were silent). However, several Sdi- mutants exhibited no changes in this region. It is possible that the $3^{\prime}$-terminal region is more conserved than the $5^{\prime}$ end because of its involvement in both replication and transcription control.

An invariable characteristic of all Sdi- mutants is impaired virion polymerase activity. Presumably, since DI-particle-mediated selection affects replication, mutations involving the polymerase complex are also likely to affect its transcriptase function as well. It was concluded that they represented compensatory changes to accommodate $\mathrm{Sdi}^{-}$mutations that affect replication- or encapsidation-gene products or both $\left(\mathrm{O}^{\prime} \mathrm{Hara}\right.$ et al., 1984).

Reconstruction experiments in BHK-21 cells confirmed that DI-particle-resistant virus was at a selective advantage over wild-type virus in the presence of DI particles and that this effect was observed even when the resistant mutant was added at low levels relative to wild-type virus in the inoculum (Horodyski and Holland, 1984). Consequently, recurrent DI-particle-mediated selection could be the driving force in the continual evolution of virus during persistent infection or passage at high multiplicity.

\section{Temperature-Sensitive Mutants}

Youngner and Quagliana (1976) reported that ts mutants mimicked DI particles and interfered with the multiplication of wild-type virus at both permissive and restrictive temperatures, when the $t s$ mutants were present at 10-fold excess in the inoculum. Flamand (1980) and Spindler et al. (1982), however, did not observe interference using various ts mutants at equal multiplicity in the inoculum with wild-type virus. Nonetheless, two uncharacterized ts mutants isolated from the Car4 persistent 
infection at 60 and 76 months were able to interfere with wild-type VSVIndiana and $t s \mathrm{G} 31(\mathrm{III})$, the mutant used to initiate the Car4 persistent infection. Variants of this sort may augment the selective role of DI particles.

Persistent infections also initiated by mutant $t s \mathrm{G} 31$ (III) have been established and maintained over a four-year period in neural (glioma and oligodendroglioma) cells and mouse L-929 cells (Huprikar et al., 1986). The virus derived from the nonneural L-929 cells and from oligodendroglioma cells remained highly neurovirulent in three-week-old Swiss mice, whereas virus from glioma cell cultures had lost virulence by the 20th passage and remained nonvirulent for a further 180 passages.

Neurovirulence rapidly returned, however, during intracerebral passage in mice, or more slowly during the course of passage in L-929 cells. The mechanism underlying the loss of neurovirulence in glioma cells but not in oligodendroglioma cells was not established, but passage in glioma cells was accompanied by selection of RNA -ve mutants. It is clear that alterations in pathogencis can occur by selection of mutants mediated by specific virus-host interactions.

\section{DI Particles}

The precise mechanism of interference remains to be elucidated, but it is clear that it operates at the level of RNA replication /reviewed by Reichmann and Schnitzlein, 1979; Lazzarini et al., 1981; Perrault, 1981), and DI-particle replication is required for interference to be expressed (Bay and Reichmann, 1979). The inverted terminal complementary structures common to the most frequent DI particles contain recognition sites for initiation of replication and encapsidation, giving the DI particles a competitive advantage.

$\mathrm{O}^{\prime} \mathrm{Hara}$ et al. (1984) also sequenced the $5^{\prime}$ and $3^{\prime}$ termini of $16 \mathrm{DI}$ particles isolated from the same persistent infections or series of undiluted lytic passages of $t s \mathrm{G} 31$ (III). All the $16 \mathrm{DI}$ particles investigated were panhandle-type and derived from the $5^{\prime}$ end of standard virus, displaying terminal complementarity for sequences extending from 54 to several hundred nucleotides. Of the 16 DI particles, 12 exhibited complex structural patterns with the sequences internal to the termini extensively rearranged. Some of these DI particles were derived from multiple intraand interstrand recombinational events; nevertheless, the derivation of each can be explained by a polymerase-template switching model. Terminal complementarity with a minimum of 46 nucleotide pairs appears to be essential for the competitive survival of DI particles, but there appeared to be no defined sites for termination or restriction of replication. The degree of freedom accorded the internal rearrangements of the DI genome suggests that these sites are irrelevant in determining survival and interfering capacity. However, since some DI-particle genomes have the same replication-initiation sequence as resistant Sdi- mutants, the 
internal sequences of the DI-particle genomes, despite their scrambled nature, must contain information that enables the Sdi- polymerase to discriminate between the nondefective viral template and the defective DI genome. Neither overall size of the DI-particle genome nor size of the complementary region beyond the 46-nucleotide minimum appears to play any role in determining the competitive ability of DI particles, because large DI particles could supersede small DI particles during the evolution of a culture.

Base substitutions were also observed in the terminal regions of the DI genomes (some in the complementary region), and comparison of these base substitutions with the substitution present in the $5^{\prime}$-terminal region of the various $\mathrm{Sdi}^{-}$mutants suggested that DI particles with specific terminal base substitutions were selected during virus evolution of persistent or acutely infected cultures. In fact, less than $1 \%$ of the bases in the region of DI genomes homologous or complementary to the first 170 bases of the $5^{\prime}$ terminus of standard virus differed from those found at the same stage of persistent or acute infection in the homologous nondefective viral $5^{\prime}$ terminus. In all cases, the $3^{\prime}$ end of the DI-particle genomes had base substitutions complementary to those at the $5^{\prime}$ end in the region of complementarity. It appears, therefore, that DI particles with specific arrays of terminal complementary base substitutions have selective advantage. The selected array of terminal base changes is generally similar to that in the nondefective virus that predominates at that stage in the evolution of the culture. One DI particle was exceptional in exhibiting a clustering of specific $A \rightarrow G$ (and complementary $U \rightarrow C$ ) substitutions, possibly indicative of repetitive misincorporation by an error-prone polymerase. Indeed, the genetic properties of rhabdoviruses are dependent predominantly on the characteristics of the virion-associated polymerase.

Wilusz et al. (1985) have determined the nucleotide sequences of the terminal noncoding regions of VSV isolated after long-term persistent infection of mouse L cells. Several mutations were observed in the 3'terminal region, but no $5^{\prime}$-end mutations were detected, in contrast to the hypermutability observed in the region of the genome of VSV propagated as a persistent infection of BHK cells (O'Hara et al., 1984). This difference may be a consequence of the apparent absence of DI particles from the L-cell carrier cultures. The role of DI particles in the generation of variation in unsegmented-genome viruses deserves further study.

\section{GENETIC INTERACTIONS}

\section{A. Absence of Genetic Recombination}

Although the reality of intermolecular recombination has been fully established for three positive-strand RNA viruses, the picornaviruses, poliovirus (Agol et al., 1984), foot-and-mouth disease virus (King et al., 
1982), and the coronavirus mouse hepatitis virus (Lai et al., 1985), there have been no reports of recombination in negative-strand RNA viruses apart from subunit reassortment in those viruses that have segmented genomes. Experiments with temperature-sensitive $(t s)$ mutants indicate that the frequency of recombination, if it occurs, cannot be greater than $10^{-5}$. Attempts to isolate recombinants of vesicular stomatitis virus (VSV)New Jersey by selection of wild-type virus from mixed infections with $t s$ mutants distinguishable by the differential electrophoretic mobility of four of the five virion polypeptides were no more successful (Pringle et al., 1981).

\section{B. Complementation Groups}

Spontaneous and mutagen-induced ts mutants of the Glasgow, Massachusetts, Orsay, and Winnipeg strains of VSV-Indiana (Flamand, 1970; Holloway et al., 1970; Pringle, 1970; Rettenmier et al., 1975), VSV-Cocal (Pringle and Wunner, 1973), VSV-New Jersey (Hazelhurst subtype) (Pringle et al., 1971), VSV-New Jersey (Concan subtype) (Byrd et al., 1984), and Chandipura virus (Gadkari and Pringle, 1980a) have been classified into complementation groups (Tables IIIa-d). Temperature-sensitive mutants of rabies virus have also been isolated, but complementation has not been convincingly demonstrated even between mutants with distinct phenotypic properties, and these mutants remain ungrouped (Bussereau and Flamand, 1978). The homologies of the complementation groups of the three different strains of VSV-Indiana were established precisely (Flamand and Pringle, 1971; Cormack et al., 1973).

Brun (1984) has described mutants of Piry virus that are temperaturesensitive (at $28^{\circ} \mathrm{C}$ ) in Drosophila and has provisionally classified them into complementation groups. The assay system is complicated, making use of the $\mathrm{CO}_{2}$ sensitivity of adult insects, and is beyond the scope of this chapter. Piry virus was chosen for this work because it most resembles Sigma virus in the extent of the $\mathrm{CO}_{2}$ sensitivity it induces in Drosophila. Piry virus appears to be under the control of the same host regulatory genes as Sigma virus. Although Sigma virus is unable to multiply in mammalian cells, Brun has suggested that Sigma is a vesiculovirus that became trapped in a nonbiting dipteran and came to behave as a hereditary factor to ensure its survival.

Complementation between $t s$ mutants derived from different viruses is not observed, except for limited complementation between RNA-positive mutants of the serologically related VSV-Indiana and VSV-Cocal (Pringle and Wunner, 1973). Recently, Byrd et al. (1984) demonstrated efficient complementation between the Concan and Hazelhurst subtypes of VSV-New Jersey, but not between the Concan subtype and VSV-Indiana. A closer relationship between the Concan subtype and VSV-Indiana was suspected because the HR LT1 defective interfering particle of the 
TABLE IIIa. Complementation Groups of VSV-Indiana

\begin{tabular}{llrrrrrrrrr}
\hline & \multicolumn{8}{c}{ Complementation group } & & \\
\cline { 3 - 7 } \multicolumn{1}{c}{ Strain } & \multicolumn{1}{c}{ Origin $^{a}$} & I & II & III & IV & V & VI & Unclassified & Total \\
\hline Orsay & Spontaneous & 58 & 2 & 2 & 5 & 3 & 1 & 0 & 71 \\
Orsay & 5-FU, NTG, NA & 18 & 0 & 2 & 1 & 1 & 0 & 0 & 22 \\
Glasgow & 5-FU, 5-AzaC, EMS & 177 & 2 & 3 & 22 & 0 & 0 & 6 & 210 \\
Winnipeg & 5-FU, NA, EMS, P & 7 & 0 & 2 & 2 & 0 & 0 & 14 & 25 \\
Massachusetts & 5-FU, NA, NTG & - & 0 & 3 & 0 & 2 & 2 & 1 & 8 \\
Totals: & 260 & 4 & 12 & 30 & 6 & 3 & 21 & 336 \\
Gene assignments: & L & NS & M & N & G & (NS) & & \\
\hline
\end{tabular}

${ }^{a}$ (5-AzaC) 5-Azacytidine; (EMS) ethylmethane sulfonate; (5-FU) 5-fluorouracil; (NA) nitrous acid; (NTG) $N$-methyl- $N^{\prime}$-nitro- $N$-nitrosoguanidine; (P) proflavine; (UV) ultraviolet light.

TABLE IIIb. Complementation Groups of VSV-Cocal

\begin{tabular}{lcccccccc}
\hline & & \multicolumn{5}{c}{ Complementation } \\
Strain & Origin & $\alpha$ & $\beta$ & $\gamma$ & $\delta$ & Unclassified & Total \\
\cline { 2 - 7 } & 5-FU & 29 & 2 & 3 & 6 & 0 & 40 \\
Glasgow & Gene assignments: & - & - & G & - & & \\
\hline
\end{tabular}

TABLE IIIc. Complementation Groups of VSV-New Jersey

\begin{tabular}{|c|c|c|c|c|c|c|c|c|c|}
\hline \multirow[b]{2}{*}{ Subtype } & \multirow[b]{2}{*}{ Strain } & \multirow[b]{2}{*}{ Origin } & \multicolumn{5}{|c|}{$\begin{array}{l}\text { Complementation } \\
\text { group }\end{array}$} & & \multirow[b]{2}{*}{ Total } \\
\hline & & & A B & $\mathrm{C}$ & $\mathrm{D}$ & $\mathrm{E}$ & & & \\
\hline Hazelhurst & Missouri & 5-FU & 1721 & 4 & 1 & 3 & 2 & 1 & 49 \\
\hline Concan & Concan & 5-FU, 5-AzaC, NA, UV & 314 & 0 & 0 & 0 & 0 & 0 & 17 \\
\hline Totals: & & & 2035 & 4 & 1 & 3 & 2 & 1 & 66 \\
\hline \multicolumn{3}{|c|}{ Gene assignments: } & $N \quad L$ & $\mathbf{M}$ & (G?) & NS & $\mathrm{L}$ & & \\
\hline
\end{tabular}

TABLE IIId. Complementation Groups of Chandipura Virus

\begin{tabular}{lcccccccccc}
\hline & & \multicolumn{8}{c}{$\begin{array}{c}\text { Complementation } \\
\text { group }\end{array}$} \\
\cline { 2 - 10 } Strain & Origin & ChI & ChII & ChIII & ChIV & ChV & ChVI & Unclassified & Total \\
\hline Nagpur & $5-\mathrm{FU}$ & 44 & 2 & 1 & 1 & 1 & 1 & 0 & 50 \\
Gene assignments: & - & (G?) & - & - & $(\mathrm{M} ?)$ & - & & \\
\hline
\end{tabular}


latter virus cross-interferes with the Concan subtype but not with the Hazelhurst subtype, but the relationship was not reflected in an ability to cross-complement. It remains an anomaly that phenotypic mixing (see Section XI), which is a form of complementation, occurs between vesiculoviruses and a wide range of heterologous enveloped viruses, while complementation between $t s$ mutants is restricted to serologically related viruses.

The occurrence of extensive intragenic complementation is responsible for the anomaly of six complementation groups and only five open reading frames in the genome. Analysis of a collection of 50 ts mutants of Chandipura virus resulted in identification of six groups (Gadkari and Pringle, 1980a) containing 44, 2, 1, 1, 1, and 1 mutant, respectively. Weak complementation was observed between individual members of the majority group (ChI) such that it could be subdivided into groups ChIa and $\mathrm{ChIb}$. Intragroup complementation was most extensive in subgroup ChIb, and one mutant in this group complemented all but one (ts Ch598) of the remaining mutants in group ChI. It is evident, therefore, that if mutant ts Ch598 had not been isolated and included in the analysis, the number of complementation groups would have been increased to seven. Sporadic and limited intragenic complementation had been reported previously in analysis of the Orsay collection of spontaneous ts mutants (Flamand, 1970) and the induced Winnipeg mutants (Wong et al., 1972), but it was not observed in analysis of the larger collection of 5-fluorouracil-induced mutants of the Glasgow strain of VSV-Indiana. In circumstances in which intragenic complementation occurs, which depends mainly on the properties of the individual mutants, the number of complementation groups can be overestimated because intragenic and intergenic complementation cannot always be distinguished. The hypothesis of Gadkari and Pringle (1980a) that the sixth complementation group in three different rhabdoviruses (VSV-Indiana, VSV-New Jersey, and Chandipura virus) did not imply the existence of a sixth genome product has been confirmed by analysis of the functional properties of $t s$ mutants of all three viruses and the complete sequencing of the genome of VSV-Indiana. The extent of intragenic complementation in group $\mathrm{ChI}$ of Chandipura virus suggests that the virion polymerase is a multimeric protein in its functional form.

Analysis of the functions of representative mutants of VSV-New Jersey suggested that mutants classified in complementation groups $B$ and F were L-protein mutants, leaving the remaining four viral proteins to be assigned to groups $\mathrm{A}, \mathrm{C}, \mathrm{D}$, and $\mathrm{E}$. Conclusive gene assignments have been made in the case of three of the four (see Section VII). In VSV-Indiana, Deutsch et al. (1979) have argued from UV-rescue experiments that the solitary mutant (ts082) representing group VI in the Orsay collection of spontaneous ts mutants is an NS-protein mutant, thus reducing the number of intergenic complementation groups to five. The RNA-negative mutants comprising the sixth group of Rettenmier et al. (1975) have not been assigned, and it is not known whether they are the result of mutation in the L, NS, or another viral protein specifying a multifunctional or 
multimeric protein. In both these cases, the second product encoded in the NS gene of VSV-Indiana (Herman, 1986) may account for the enigmatic sixth complementation group tentatively identified by both Rettenmier et al. (1975) and Flamand (1980).

\section{GENE ASSIGNMENT}

\section{A. Homologies of the Complementation Groups}

The gene assignments of the temperature-sensitive $(t s)$ mutants of the complementation groups of vesicular stomatitis virus (VSV)-Indiana, VSV-Cocal, VSV-New Jersey, and Chandipura virus based on functional analyses have been reviewed comprehensively (Pringle and Szilagyi, 1980; Pringle, 1982). These data are summarized in Table IV, supplemented with more recent information that mainly concerns VSV-New Jersey. The increasing ease and speed of nucleotide-sequencing techniques promise to revolutionize this area.

The only assignment among the VSV-Indiana and VSV-New Jersey complementation groups that has defied functional analysis and limited sequencing is the single mutant that defines complementation group D of VSV-New Jersey. By exclusion, its temperature sensitivity should be the consequence of a lesion in the glycoprotein (G) gene, but there is no direct evidence of this. Mutant $t s \mathrm{Dl}$ uniquely exhibited atypical electrophoretic mobility of the $\mathrm{G}$ and nucleocapsid $(\mathrm{N})$ virion polypeptides, and each of these characteristics could apparently revert to wild-type independently of the ts phenotype. Additional phenotypes, some involving the nonstructural (NS) polypeptide, appeared during sequential cloning of this mutant, indicating that mutations affecting polypeptide mobility were generated at high frequency during propagation of $t s \mathrm{D} 1$. Furthermore, mutations affecting the electrophoretic mobility of the G, N, NS, and matrix $(M)$ polypeptides were induced in heterologous rhabdoviruses multiplying in the same cells. Recombintion and posttranslational modification of proteins were not involved in these phenotypes. Virions of $t s \mathrm{Dl}$ with complete or incomplete genomes appeared to be equally competent in this respect. It was concluded that $t s \mathrm{Dl}$ fortuitously carried a "mutator"-type mutation that could act both in cis and in trans.

Aberrant glycosylation could have accounted for the atypical mobility of some of the G-protein mutants, whereas initially the N-protein mutants exhibited faster mobilities in polyacrylamide gel, suggesting a smaller polypeptide. However, determination of the nucleotide sequence from each terminus of the $\mathrm{N}$ gene to about 200 nucleotides of one of these N-protein mutants, of a revertant, and of the wild-type parent did not reveal any changes compatible with synthesis of a shorter polypeptide, as a result of either premature termination or late initiation of translation. The mutant (and its revertant), however, differed from wild-type at two positions: a $\mathrm{C} \rightarrow \mathrm{U}$ change in the noncoding leader RNA and an $\mathrm{A} \rightarrow \mathrm{G}$ 
TABLE IV. Gene Assignments

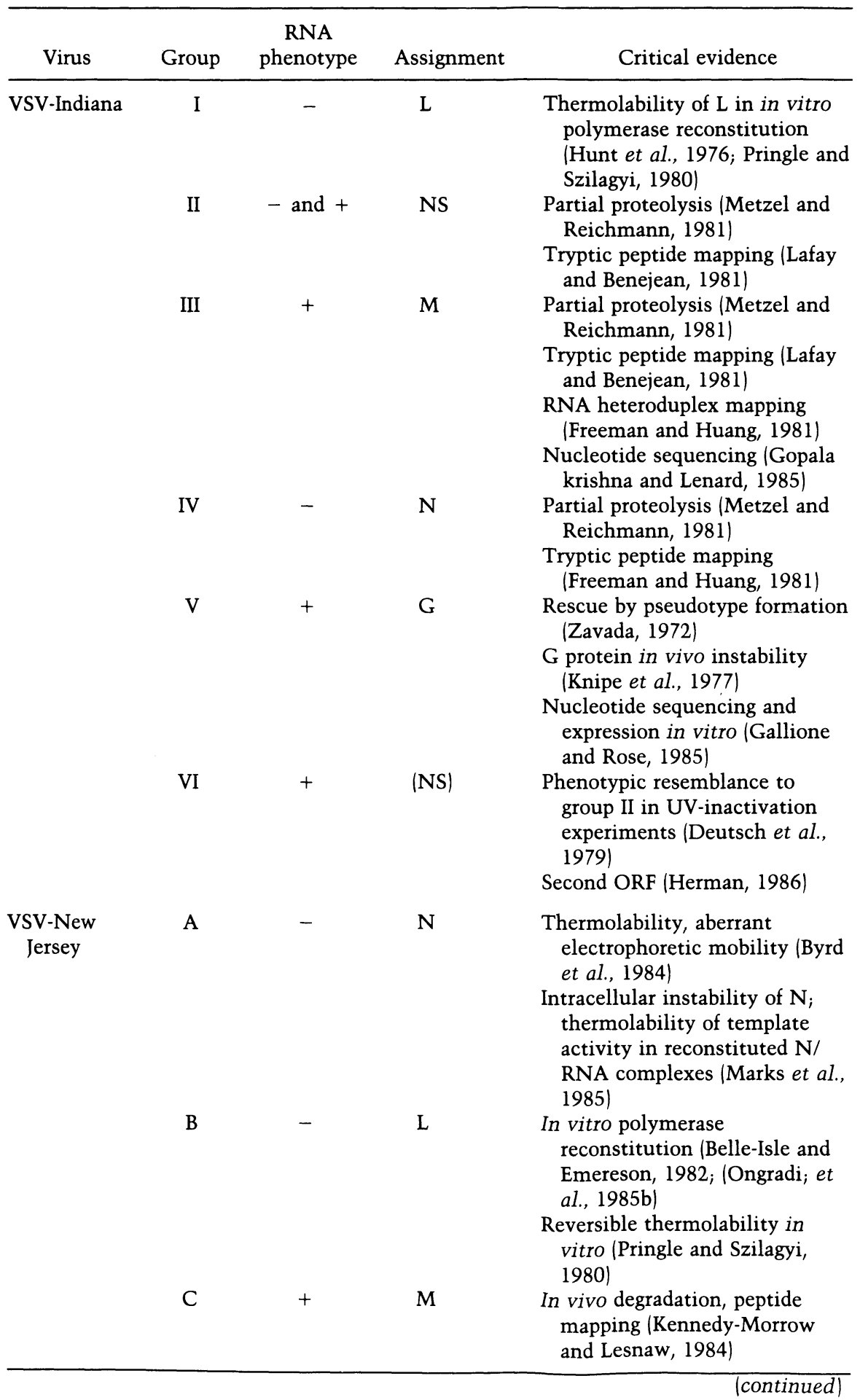


TABLE IV. (Continued)

\begin{tabular}{|c|c|c|c|c|}
\hline Virus & Group & $\begin{array}{c}\text { RNA } \\
\text { phenotype }\end{array}$ & Assignment & Critical evidence \\
\hline & D & + & (G) & $\begin{array}{l}\text { None. Assignment by exclusion } \\
\text { only }\end{array}$ \\
\hline & $\mathrm{E}$ & - and + & NS & $\begin{array}{l}\text { Aberrant electrophoretic } \\
\text { mobility (Evans et al., 1979; } \\
\text { Lesnaw et al., 1979) }\end{array}$ \\
\hline & & & & $\begin{array}{l}\text { In vitro polymerase } \\
\text { reconstitution (Ongradi et al., } \\
\text { 1985a) }\end{array}$ \\
\hline & & & & $\begin{array}{l}\text { Tryptic peptide maps (Maack } \\
\text { and Penhoet, 1980) }\end{array}$ \\
\hline & & & & $\begin{array}{l}\text { Nucleotide sequencing } \\
\text { [McGeoch } \text { et al., 1980 (Table } \\
\text { VII); Rae and Elliott, 1986b } \\
\text { (Fig. 7)] }\end{array}$ \\
\hline & $\mathrm{F}$ & - and + & L & $\begin{array}{l}\text { In vitro polymerase } \\
\text { reconstitution (Belle-Isle and } \\
\text { Emerson, 1982; Ongradi et al., } \\
\text { 1985) }\end{array}$ \\
\hline VsV-Cocal & $\gamma$ & + & G & $\begin{array}{l}\text { Glycosylation defect (Buller, } \\
\text { 1975; Kotwal et al., 1986) }\end{array}$ \\
\hline Chandipura & $\mathrm{ChV}$ & + & M & $\begin{array}{l}\text { In vivo degradation (Gadkari } \\
\text { and Pringle, 1980b) }\end{array}$ \\
\hline
\end{tabular}

change corresponding to an Asn $\rightarrow$ Asp substitution. The latter could not be responsible for the atypical phenotype, since it was present in both mutant and revertant.

The occurrence of two nucleotide changes within a stretch of approximately 400 extrapolates to 56 changes within a genome of 11,162 nucleotides, assuming random distribution. If this is compared with the estimate of Rowlands et al. (1980) of 200 changes accumulating in mutant tsG31(III) of VSV-Indiana maintained as a persistent infection over a period of 5 years, it is clear that rapid change in nucleotide sequence can occur during a few cycles of lytic infection.

Curiously, reversion of the G-protein aberrant mobility was never obtained without prior reversion of the $\mathrm{N}$ protein to a normal-mobility phenotype.

\section{B. Large-Protein Mutants}

\section{Temperature-Sensitive Mutants}

Temperature-sensitive mutants of complementation group I of VSVIndiana, and groups B and F of VSV-New Jersey, have been unequivocally identified as large (L)-protein mutants (Table IV). In most cases, the as- 
signment has been made in terms of reconstitution of in vitro preparations.

Hunt (1983) observed that the group I mutant tsG16(I) produced mRNA in vitro with longer poly(A) tracts than either wild-type virus or some other $t s$ mutants including $t s \mathrm{G} 13(\mathrm{I})$, another group I mutant. The overproduction of poly $(\mathrm{A})$ tracts occurred at all temperatures. Homologous and heterologous reconstitution experiments showed that the atypical polyadenylation phenotype correlated with the presence of tsG16(I) L protein and not its NS or N protein (Hunt et al., 1984). Poly(A) synthesis, measured as the ratio of AMP to UMP incorporation, was temperaturesensitive in reconstitution experiments whenever $t s \mathrm{G} 16(\mathrm{I}) \mathrm{L}$ protein was present. Although a non-ts revertant of $t s \mathrm{G} 16(\mathrm{I})$ was not included in this analysis, the evidence is consistent with the hypothesis that the $\mathrm{L}$ protein is associated with the atypical polyadenylation phenotype. Control experiments excluded any possibility that the phenotype might be due to contamination of the L-protein fraction by $\mathrm{M}$ protein, and the temperature sensitivity of the $L$ protein in reconstitution experiments eliminated extraneous host components. These experiments demonstrate that the $\mathrm{L}$ protein of VSV affects the polyadenylation of mRNA, but do not prove that the VSV L protein is in fact the poly(A) polymerase.

\section{Conditional Lethal Mutants}

Many of the conditionally temperature-sensitive mutants of VSV and Chandipura virus that are unable to multiply in chick-embryo cells at $39^{\circ} \mathrm{C}$, the $t d \mathrm{CE}$ phenotype, exhibit thermosensitive in vitro polymerase activity. Mutant $t d \mathrm{CE} 3$ of VSV-Indiana has been shown unequivocally by reconstitution experiments to be an L-protein mutant (Szilagyi et al., 1977). These mutants, and also mutant tsB1 of VSV-New Jersey, which is also restricted in chick-embryo cells at $39^{\circ} \mathrm{C}$, differ from the other conventional $t s$ mutants because the thermosensitive defectiveness of in vitro virion polymerase activity is reversible, suggesting a conformational change, and is not the result of inactivation (Szilagyi and Pringle, 1979; J. F. Szilagyi, personal communication).

Frey and Youngner (1982) have described group I ts mutants of the Orsay strain of VSV-Indiana with a distinctive phenotype. These mutants originated from two independent cultures of persistently infected mouse $\mathrm{L}$ cells initiated by ts023(III), a group III mutant. At permissive temperature, replicative RNA synthesis was enhanced and mRNA synthesis diminished in these mutants relative to wild-type or ts023(III), although both were severely restricted at $40^{\circ} \mathrm{C}$. Normal RNA synthesis was restored in non-ts revertants of these mutants. Paradoxically, protein synthesis was normal or even enhanced in mutant-infected cells despite the reduction in mRNA synthesis. It was suggested that these properties together with reduced inhibition of host macromolecular synthesis facilitate persistent infection. However, since mutants with this phenotype 
were subsequently isolated from stocks propagated by lytic infection, the evidence is not compelling.

\section{Host-Range Mutants}

The host-range ( $h r$ ) mutants isolated by Simpson and Obijeski (1974), which multiply in chick-embryo cells but are restricted in human cells, were tentatively identified as polymerase mutants on the basis of their phenotypic properties. Horikami and Moyer (1982) have shown that one of these mutants, $h r 1$, was defective for methylation of mRNA in vitro, although full-length polyadenylated mRNA with unmethylated guanylylated 5' termini were synthesized in normal amounts, and another mutant, $h r 8$, was partially defective for methylation. The unmethylated mRNA synthesized by $h r l$ was translated less efficiently in vitro.

Horikami et al. (1984) found that synthesis of mRNA in restrictive Hep-2 cells infected by these two mutants was diminished and the residual guanylylated but unmethylated mRNA present was not translated in vitro. These results suggest that the methyltransferase activities associated with VSV are virus-coded and that there is a strict requirement for methylation of the guanosine residue of the cap structure. Revertants of these mutants have not been isolated and characterized. Horikami and colleagues also observed that coinfection of restrictive cells with an $h r$ mutant and rabbitpox virus released the restriction and resulted in the synthesis of mRNA with fully methylated caps, presumably through the action of the poxvirus methyltransferase enzyme.

Two other $h r$ mutants, $h r 5$ and $h r 7$, however, appeared to synthesize methylated mRNA in restricted cells and appeared to be blocked at the level of replication. These mutants were only poorly rescued by poxvirus coinfection. It is unlikely, therefore, that defective methylation is directly responsible for the host-range phenotype. Furthermore, permissive cells must be able to overcome the methylation defect, perhaps by activation of the viral enzyme. There is no evidence of a methylation defect associated with the $t d \mathrm{CE}$ conditional host-range phenotype (Rasool and Pringle, 1986).

\section{Suppressible Amber Mutants}

White and McGeoch (1985) have described isolation of two putative amber mutants by screening mutagenized virus on cell lines possessing or lacking a functional amber suppressor to tRNA ${ }^{\text {tyr }}$. The mutants grow to high titer on $\mathrm{su}^{+}$cells but are restricted on $\mathrm{su}^{-}$cells. One mutant has been characterized and the mutational lesion localized to the $\mathrm{L}$ gene by complementation tests using $t s$ mutants of the five complementation groups. No viral proteins are synthesized in su- cells, but in $\mathrm{su}^{+}$cells the $200-\mathrm{kd} \mathrm{L}$ protein is present in reduced amounts together with a novel 37 - 
$\mathrm{kd}$ protein which is possibly a truncated $\mathrm{L}$ protein. The properties of this mutant suggest that it has arisen by an amber mutation in the $\mathrm{L}$ gene.

\section{Glycoprotein Mutants}

\section{Vesiculovirus Mutants \\ a. Glycosylation Defects}

The ts mutants classified in group V of VSV-Indiana and group $\gamma$ of VSV-Cocal are G-protein mutants on the basis of their phenotypic properties (Table IV). Other G-protein mutants include the $t 117$ mutant obtained by Zavada (1982), which shows extreme thermolability and was derived by cycles of mutagenesis and neutralization by specific antiserum. The $t 117$ mutant is a complex mutant, however, failing to complement ts mutants of both groups I and V. Robertson et al. (1982) found that the glycosylation sites and oligosaccharide structure of this mutant were unaltered, but the content of sialic acid and fucose was increased and small amounts of an additional branched side chain were present.

The $t s \gamma 1$ mutant of VSV-Cocal, on the other hand, has a temperaturesensitive defect in glycosylation (Buller, 1975; Kotwal et al., 1986). At permissive temperature only one of the two available sites is glycosylated. $\mathrm{G}$ protein containing only one oligosaccharide residue is still transported to the plasma membrane and is incorporated into infectious particles. At nonpermissive temperature neither of the two sites become glycosylated and the unglycosylated $G$ protein is not transported to the cell surface. These results indicate that at least for VSV-Cocal glycosylation of the G protein is essential for its transport to the plasma membrane, and the presence of a single carbohydrate chain in sufficient for this purpose. The requirement for addition of carbohydrate for transport of the $G$ protein from its site of synthesis on the endoplasmic reticulum to the cell membrane is strain-dependent. Transport was dependent on glycosylation at all temperatures in the San Juan strain of VSV-Indiana, but only at $39.8^{\circ} \mathrm{C}$ in the Orsay strain. Mutant $t s 011(\mathrm{~V})$, one of two group $\mathrm{V}$ ts mutants derived from the Orsay strain, was not dependent on glycosylation at $39.8^{\circ} \mathrm{C}$. The other, $t s 044(\mathrm{~V})$, was dependent but became independent on reversion of the ts phenotype (Chatis and Morrison, 1981). These results indicate that glycosylation can be affected by simple genetic mutations and that the conformation of the polypeptide chain presumably determines whether addition of carbohydrates is necessary for migration of the G protein to the plasma membrane. Zilberstein et al. (1980) and Bergmann et al. (1981) analyzed the site of action of several group $\mathrm{V} t s$ mutants and concluded that three $[t s 045(\mathrm{~V}), t s L 513(\mathrm{~V}), t s L 501(\mathrm{~V})]$ of four were not transported to the Golgi apparatus after synthesis on the endoplasmic reticulum. The fourth, tsL511(V), was unique among virus mutants in being blocked at a stage subsequent to migration to the Golgi apparatus. 
b. Site of the ts045(V) Mutation

Gallione and Rose (1985) have determined the site of the ts045(V) mutational lesion responsible for conditional transport of $G$ protein to the cell surface in a series of ingenious experiments with cloned cDNA copies of G-protein mRNA of $t s 045(\mathrm{~V})$, a spontaneous non-ts revertant of $t s 045(\mathrm{~V})$, and wild-type virus. The nucleotide sequence of each was determined with the results shown in Table Va. The mutant differed from wild-type at nine sites, producing five predicted amino acid substitutions. Surprisingly, in the revertant, three of the amino acid changes had reverted to wild-type. Since one or all of these changes could be responsible for the reversion of phenotype, Gallione and Rose constructed recombinant molecules in vitro and used an SV40-based vector to obtain expression

TABLE Va. Nucleotide Changes in mRNA and Predicted Amino Acid Substitutions in the G Protein for $t s 045(V)$ and a Non- $t s$ Revertant ${ }^{a}$

\begin{tabular}{llllll}
\hline & \multicolumn{5}{c}{ Residue no. } \\
\cline { 2 - 6 } \multicolumn{1}{c}{ Genotype } & 50 & 200 & 204 & 394 & 434 \\
\hline Wild-type (VSV-Indiana, & AAU & ACG & UUC & UUA & \\
Orsay strain) & Asn & Thr & Phe & Leu & - \\
$t s 045(\mathrm{~V})$ & AAG & AUG & UCC & UCA & UUU \\
& Lys & Met & Ser & Ser & + Phe \\
Non- $t s$ revertant & AAU & AUG & UUC & UCA & \\
& Asn & Met & Phe & Ser & - \\
\hline
\end{tabular}

${ }^{a}$ From Gallione and Rose (1985). $b \mid+$ Phe) Insertion.

TABLE Vb. Temperature Sensitivity of Surface Antigen Expression at $39.8^{\circ} \mathrm{C}$ of COS-1 Cells Carrying Recombinant Constructs with Permutation of the Three Mutational Changes Associated with the $t s 045$ Phenotype ${ }^{a}$

\begin{tabular}{|c|c|c|c|}
\hline \multicolumn{3}{|c|}{$\begin{array}{l}\text { Predicted amino acid phenotype of } \\
\text { recombinant }\end{array}$} & \multirow{3}{*}{$\begin{array}{l}\text { Temperature sensitivity of surface- } \\
\text { antigen expression at } 39.8^{\circ} \mathrm{C}\end{array}$} \\
\hline \multicolumn{3}{|c|}{ Residue no. } & \\
\hline 50 & 204 & 434 & \\
\hline Lys & Ser & - & Sensitive \\
\hline Asn & Phe & $+\mathrm{Ph}^{b}$ & Resistant \\
\hline Lys & Phe & - & Resistant \\
\hline Asn & Ser & + Phe & Sensitive \\
\hline Lys & Phe & + Phe & Resistant \\
\hline Asn & Ser & - & Sensitive \\
\hline \multicolumn{4}{|c|}{$\begin{array}{l}\text { Conclusion: the Phe } \rightarrow \text { Ser substitution at site } 204 \text { is responsible for the } t s \text { phenotype of } \\
\text { mutant } t s 045(\mathrm{~V}) \text {. }\end{array}$} \\
\hline
\end{tabular}


of these recombinants in COS-1 cells. Expression was monitored by indirect immunofluoresence. Surface expression of G protein in COS-1 cells carrying the $t s 045(\mathrm{~V})$ expression vector was temperature-sensitive, whereas it was not in the wild-type and revertant. Three sets of reciprocal recombinant molecules were constructed as indicated in $\mathrm{Table} \mathrm{Vb}$, and the temperature sensitivity of expression was assayed by immunofluorescence. The results show that a single substitution of phenylalanine by serine at site 204 is sufficient to prevent transport of $G$ protein to the cell surface at $39.8^{\circ} \mathrm{C}$. It is presumed that the co-reversion observed in the revertant reflects heterogeneity of the wild-type stock; however, other explanations are possible and the two apparently silent reverse mutations may affect some other important G-protein function. Previously, Rose and Bergmann (1983) had shown by in vitro mutagenesis that the 29amino-acid cytoplasmic domain of the $\mathrm{G}$ protein was critical for efficient transport. Location of the $t s 045(\mathrm{~V})$ mutation shows that other regions of the protein are also important.

Synthetic peptides corresponding to the amino-terminal region of the $\mathrm{G}$ protein have a $\mathrm{pH}$-dependent hemolytic activity. However, oligonucleotide-directed mutagenesis has shown that this hemolytic activity is not synonymous with the membrane fusion function of the $G$ protein. Woodgett and Rose (1986), by in vitro mutagenesis, produced a DNAencoding $G$ protein with a lysine-glutamic acid change at the amino terminus of the protein. The same amino acid substitution abolishes the hemolytic activity of the synthetic peptides, but the mutant protein expressed transiently in COS cells retained the $\mathrm{pH}$-dependent fusion activity of wild-type virus.

It has been shown that at $39^{\circ} \mathrm{C}$ the $\mathrm{G}$ protein synthesized by mutant $t s 045(\mathrm{~V})$ remains in an endoglycosidase $\mathrm{H}$-sensitive state and is gradually degraded. Noninfectious virions lacking spikes are released to the exterior. Further characterization of the $t s 045(\mathrm{~V})$ mutant has revealed that at $39^{\circ} \mathrm{C}$ the $\mathrm{G}$ protein is converted to the truncated soluble $\mathrm{G}_{\mathrm{s}}$ form which is fully glycosylated but lacks the cytoplasmic and transmembrane portion of the molecule and which accumulates in the extracellular medium in the course of normal infection (Chen and Huang, 1986). Since G protein in the mutant is not transported to the surface, the $G$ to $G_{s}$ cleavage must occur intracellularly rather than at the surface as previously thought. There is some evidence that the other product of the cleavage reaction, the cytoplasmic tail and transmembrane region, is transported to the membrane and is involved in the budding of virions.

\section{Lyssavirus Mutants}

\section{a. Monoclonal-Antibody-Resistant Mutants}

Since the rhabdovirus $G$ protein is the site of the antigen that induces neutralizing antibody, selection for resistance to neutralizing monoclonal antibodies has generated collections of G-protein mutants. Lafon et al. 
(1983), using a battery of 24 neutralizing monoclonal antibodies to the CVS strain of rabies virus, have derived an epitope map of the rabies virus $G$ protein, which has three functionally independent antigenic sites: $I$; IIA, IIB, IIC; and IIIA, IIIB.

Coulon et al. (1983) reported that nine of ten mutants of the CVS strain of rabies virus resistant to two monoclonal antibodies, 194-2 and 248-8, were either nonpathogenic or reduced in virulence for adult Swiss mice. These monoclonal antibodies were specific for the antigenic site III defined by Lafon et al. (1983). Dietzschold et al. (1983) confirmed and extended these observations and found that an amino acid substitution of arginine at position 333 in the G protein had occurred in all four neutralization-resistant nonpathogenic mutants examined by them. Arginine at position 333 was replaced by isoleucine in three mutants of the ERA strain and by glutamine in one mutant of the CVS strain.

\section{b. Pathogenicity}

Seif et al. (1985) have isolated a further 58 mutants of the CVS strain of rabies virus selected using four site-specific monoclonal antibodies to test the hypothesis that loss of pathogenicity is related to the amino acid substitution at position 333 of the G protein. These mutants were classified into five groups in terms of their pattern of resistance to the four monoclonal antibodies. Only mutants in one of the five groups (group II) were nonpathogenic or reduced in virulence. Eight of the nonpathogenic mutants were examined, and it was established by dideoxy sequencing on the RNA genome from a synthetic oligonucleotide primer that the arginine at position 333 was substituted by glutamine or glycine. In eight mutants that retained full pathogenicity, amino acid substitutions had occurred at positions 330 (lysine), 336 (asparagine), and 338 (isoleucine), but not at position 333. Thus, although amino acid substitutions in this region of the $G$ protein alter neutralization, only substitution at position 333 (arginine) affects pathogenicity. The mechanism responsible for the loss of pathogenicity is not known.

\section{Mutation and Secondary Structure}

Wunner et al. (1985) have located the mutational lesion in two neutralization-resistant mutants representing epitopes IIA and IIIA by mapping of tryptic peptides and sequence analysis. The wild-type $G$ protein exists in two forms, GI and GII, that differ only in glycosylation. Two of the four glycosylation sites from the nucleotide sequences predicted are used in GI and only one in GII. A single G-protein band corresponding to GI was present in one of the mutants, RV231-22. Sequence analysis of this mutant revealed a base mutation specifying an amino acid change six residues upstream from the predicted glycosylation site utilized in the GI form of G, but not in the GII form. Apparently, this amino acid substitution allows utilization of this glycosylation site in the GII form 

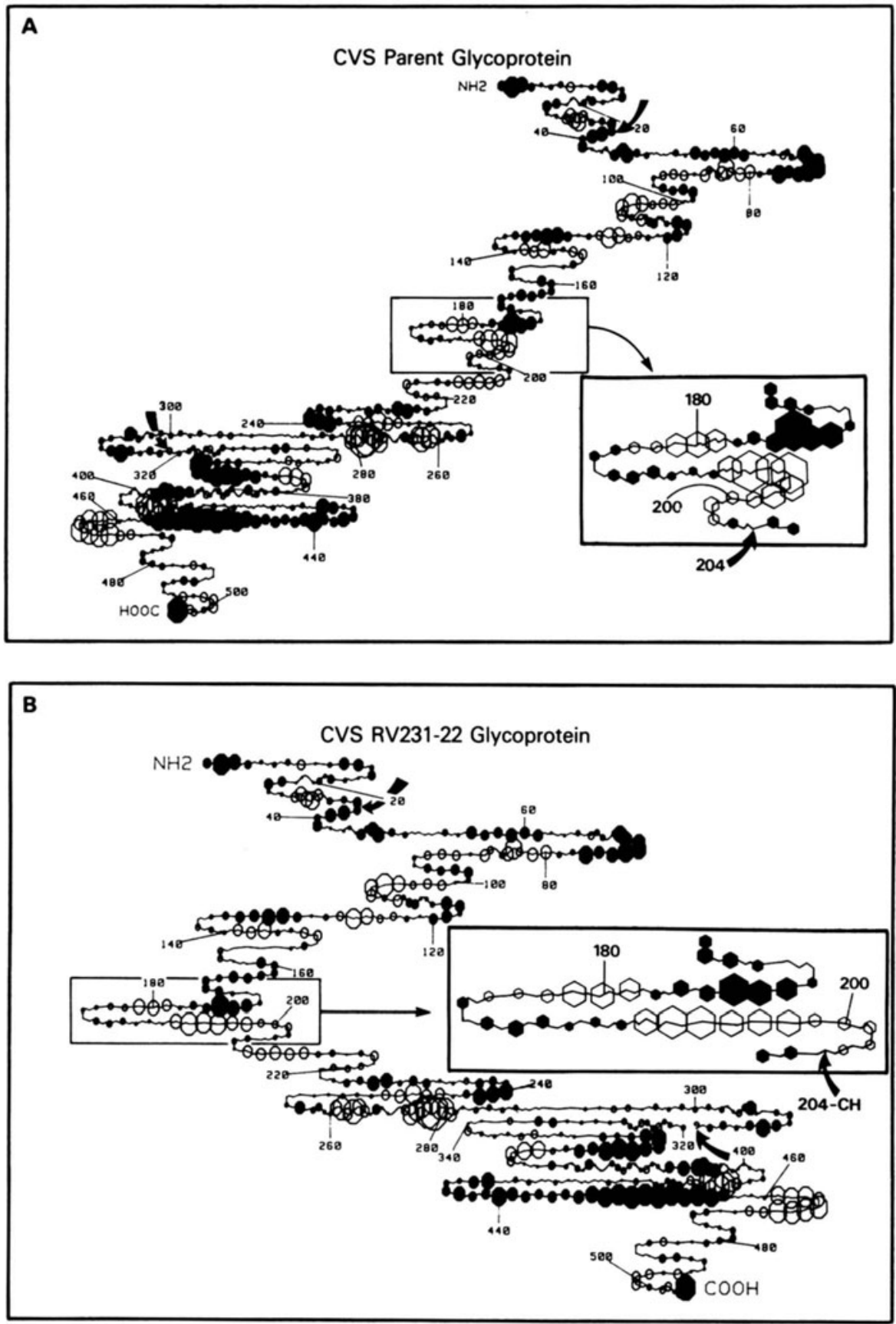

FIGURE 5. Predicted secondary structure and hydrophobicity of the G protein of the parental (CVS-11) strain of rabies virus (A) and the monoclonal-antibody-resistant mutant RV231-22 (B). (ㅇ) Hydrophilic regions; ( $)$ hydrophobic regions. The radius of the circle over a residue site is proportional to the average hydrophilicity or hydrophobicity as calculated for that residue and the next five residues. The numbers correspond to amino acid residues from the $\mathrm{NH}_{2}$-terminal lysine of the mature $\mathrm{G}$ protein. Heavy arrows indicate potential glycosylation sites at asparagine residues 37,204 , and 319 . The enlarged insert shows the region of the mutation. Reproduced from Wunner et al. (1985). 
of mutant RV231-22, resulting in comigration with GI and giving the observed single band in gel electrophoresis.

In the case of the other mutant, RV194-2, which represents antigenic site IIIA, both forms of G protein were present, although they differed slightly from wild-type in electrophoretic mobility. An extra glycosylation site was identified in both forms of $G$ protein in this mutant. A single amino acid substitution of lysine by asparagine creates a new glycosylation site at residue 158 that is in fact utilized in this variant. However, this mutation was not observed in another variant, RV194-2(F2), from the same group, and it is unlikely to be solely responsible for the neutralization-resistant phenotype.

These results show clearly that not all predicted glycosylation sites are utilized and that the extent of glycosylation is probably dependent on the secondary structure of the molecule. A computer prediction of the conformational change in the region of the amino acid substitution in mutant RV231-22 is illustrated in Fig. 5. One of the four $\beta$-turns assigned to the predicted sequence of the wild-type $G$ protein has been lost by the substitution of glutamic acid for lysine at residue 198, although local hydrophilicity and hydrophobicity are unchanged. The elimination of the $\beta$-turn in the vicinity of the glycosylation site apparently renders it more accessible for carbohydrate attachment. This analysis represented the first attempt to assess the precise effect of amino acid substitution on the conformational state of a rhabdovirus protein and a forerunner to the use of more advanced techniques in analysis of viral-gene function.

\section{Enrichment Selection}

The group V mutants initially were all derived from the Orsay strain of VSV-Indiana as spontaneous mutants, and none was found among 177 ts mutants of the Glasgow strain derived by mutagenesis (see Table IIIa). Later, other group $\mathrm{V}$ mutants were obtained by enrichment techniques. Lodish and Weiss (1979) have described a procedure for selective isolation of mutants defective in synthesis of $G$ protein, which depends on rescue of pseudotypes of a group $\mathrm{V}$ ts mutant in cells preinfected with Rousassociated virus 1 (RAV-1) and incubated at restrictve temperature. This procedure also somewhat unexpectedly resulted in recovery of a slightly higher proportion of group IV N-protein mutants, which suggested that reduced synthesis of nucleocapsid resulted in a deficit of $G$ protein at the surface.

\section{Matrix-Protein Mutants}

\section{Temperature-Sensitive Mutants}

The ts mutants of group III of VSV-Indiana, group C of VSV-New Jersey, and group $\mathrm{ChV}$ of Chandipura virus are M-protein mutants. Some of these mutants have been exploited experimentally in different situa- 
tions. The M protein appears to be associated with both the plasma membrane and the viral nucleocapsid, and Lenard et al. (1981) reported that there was an enhanced association between the VSV-Indiana group III mutants and the plasma membrane in contradistinction to wild-type and non-ts revertants of these mutants. These observations suggest that the M-protein molecule has two independent binding sites and that one of these sites was preferentially affected in the mutants studied.

The M-protein mutants of all three viruses overproduce mRNA, and direct experimentation suggests that $M$ protein is involved in control of transcription. The M protein of VSV plays a regulatory role in viral RNA synthesis in addition to its structural role. M protein from wild-type virus inhibits transcription in vitro, whereas $\mathrm{M}$ protein from group III mutants has no [ts023(III) and ts089(III)] or low [tsG31(III) and tsG33(III)] inhibitory activity. RNP-M protein interactions have been shown to be weaker for these four mutants (Carroll and Wagner, 1979; Wilson and Lenard, 1981). Pal et al. (1986) have reported that monoclonal antibody to epitope 1, but not antibody to epitopes 2 and 3, abolished the inhibitory activity of wildtype $M$ protein. Monoclonal antibody to epitope 1 failed to bind to $M$ protein from mutant $t s 023$ (III), whereas binding and inhibitory activity were restored by reversion of this mutant. These results indicate that exposure of epitope 1 on the surface of the M protein is necessary for inhibitory activity.

Experiments with $t s$ mutants indicate that $\mathrm{M}$ protein plays a determining role in the polykaryocyte formation observed in certain host cells in place of the normal cytolytic response. The M-protein-defective mutant ts G31(III), unlike ts mutants representing the other four complementation groups, induced cell fusion at nonpermissive temperature (Storey and Yong Kang, 1985). Polykaryocyte formation can also be induced by inhibition of protein synthesis shortly after infection and it has been shown that the intracellular M-protein pool is the first to be depleted. It is likely, therefore, that cell fusion occurs when functional $M$ protein falls below a critical level while $G$ protein continues to be present in the surface membrane.

The nucleotide sequences of group III mutants, two spontaneous mutants (ts023 and ts089) derived from the Orsay wild-type and two 5Fu-induced mutants (tsG31 and $t s \mathrm{G} 33)$ derived from the Glasgow wildtype, have been published by Gopalakrishna and Lenard (1985). Each of the mutants differed from wild-type in one or two point mutations, all of which caused a change from or to a charged amino acid. The mutations were distributed throughout the coding sequence in contradistinction to the VSV-New Jersey NS gene mutations.

Analysis of a series of 25 non-ts revertants of these mutants has revealed greater complexity (J. Lenard, personal communication). Additional nucleotide changes have been found in each mutant such that ts023(III) carries three nucleotide changes producing three amino acid exchanges, ts089(III) carries two coding changes, tsG31(III) carries two 
coding and one noncoding change, and tsG33(III) carries three coding and one noncoding change. Twenty-four of the 25 revertants differ from their parent mutant by a single change only. In four cases only does this involve one of the mutated codons in the parental mutant; in the remainder the nucleotide changes are located at different sites producing a further coding change. It is evident that the $M$ protein can tolerate mutation at many sites and that reversion occurs predominantly by intragenic suppression. It will be necessary to sequence low-passage material to determine unambiguously the primary site of mutation.

Small spherical defective interfering (DI) particles in which $90 \%$ of the genome is deleted are uniquely associated with the three 5-fluorouracil-induced group III mutants $t s \mathrm{G} 31$ (III), $t s \mathrm{G} 32$ (III), and $t s \mathrm{G} 33$ (III). One of these mutants [tsG31(III)], in the presence of its homologous DI virus at semipermissive temperature to suppress cytopathogenicity, was used by Holland and Villareal (1974) to initiate long-term persistent infection of BHK-21 cells. This mutant and its DI particles were more manageable experimentally than other combinations of virus and DI particles.

Several $t s$ mutants of VSV-Indiana induced unique forms of central nervous system (CNS) disease in mice (for a summary, see Pringle, 1982). Wild-type VSV inoculated intracerebrally induced fatal acute disease in 3 to 4-week-old mice. Mutant tsG31(III) and others induced a slow, progressive neurological disease characterised by hindlimb paralysis and a marked spongiform myelopathy in the spinal cord. Hughes and Johnson (1981) have shown by limited digestion with V8 protease that the $M$ protein of tsG31(III) can be distinguished from wild-type $M$ protein. A variant of $t s \mathrm{G} 31$ (III) designated $t s \mathrm{G} 31 \mathrm{BP}$ was isolated from the CNS and considered to be responsible for the CNS disease. This variant, which was a complex mutant unble to complement, had a wild-type-like $M$ protein. By peptide mapping, its $\mathrm{N}$ protein was clearly different from that of either tsG31(III) or wild-type virus, and it exhibited abnormal nucleocapsid structure, as revealed by an atypical hyperchromatic shift on heating and other properties. This $\mathrm{N}$-protein alteration and the reversion of the $M$ protein may be associated, separately or together, with the unique spongiform myelopathy and hindlimb paralysis that follows intracerebral inoculation of $t s \mathrm{G} 31(\mathrm{III})$.

\section{P-Function Mutants}

Stanners et al. (1977) have identified mutations in a viral function, $\mathrm{P}$, involved in the inhibition of host protein synthesis (see Section VIII.C). $\mathrm{P}$ - mutants are defective in ability to inhibit host protein synthesis. There is circumstantial evidence that the $\mathrm{P}$ function may be located in the $\mathrm{M}$ gene, since the $\mathrm{P}^{-}$ts $\mathrm{T} 1026$ and its non-ts $\mathrm{P}^{-}$revertants exhibit a small change in the electrophoretic mobility of the virion $M$ protein (Lodish and Porter, 1981); the mobility of the M polypeptide of these mutants is about $10 \%$ faster than that of the M protein of the HR wild-type from 
which they were derived. Stanners and colleagues (personal communication/ have now characterized a further series of $\mathrm{P}$ - mutants, one of which exhibits a similar M-protein electrophoretic-mobility shift.

\section{E. Nonstructural Protein Mutants}

Ths ts mutants of group II (and probably group VI) of VSV-Indiana, and group E of VSV-New Jersey, are NS-protein mutants. The group E mutants are remarkable in that the NS protein of each of the three mutants comprising this group has a distinctive electrophoretic mobility that reverts to wild-type mobility with reversion of the ts phenotype of $t s \mathrm{E} 1$ and $t s \mathrm{E} 3$; revertants of $t s \mathrm{E} 2$ have not been obtained. Therefore, these ts mutations appear to be directly responsible for the atypical mobility phenotype. Gross differences in phosphorylation were not responsible for the mobility differences (Evans et al., 1979). Analysis of the temperature sensitivity of the in vitro polymerase activity of these $t s$ mutants revealed that at $39^{\circ} \mathrm{C}, t s \mathrm{E} 1$ was almost completely defective, $t s \mathrm{E} 2$ was partially defective, and tsE3 was not significantly different from wild-type. A non$t s$ revertant of $t s \mathrm{E} 1$ was restored to wild-type activity, indicating that the ts phenotype, the polymerase defect, and the NS-protein mobility difference were all correlated. The heat stabilities of the infectivity and polymerase activity of mutant $t s E 1$ virions were equivalent to that of wildtype virions, the polymerase activity becoming heat-labile only after disruption of the virion and release of the core. Presumably, there is an interaction between the mutated polypeptide and an envelope protein in the virion that maintains the normal functional activity of the virion polymerase.

On the basis of these findings and the RNA phenotypes of the mutants, it has been proposed that the NS protein (like the other soluble component of the polymerase complex, the $\mathrm{L}$ protein) is a multifunctional protein that plays a role in mRNA transcription, genome replication, and virion maturation. The information on the properties of the RNA-negative $t s$ mutants of VSV-Indiana and VSV-New Jersey is summarized in Table VI. The nature of the gene products transcribed under restrictive conditions by the nondefective mutants in these groups remains to be characterized.

About half the nucleotide sequence from the end of the NS gene of wild-type virus, the mutants $t s \mathrm{E} 1, t s \mathrm{E} 2$, and $t s \mathrm{E} 3$, and a non-ts revertant of $t s \mathrm{E} 1$ and $t s \mathrm{E} 3$ was determined by primer extension synthesis using a synthetic primer corresponding to a terminal sequence of the $\mathrm{N}$ gene (McGeoch et al., unpublished data). A single base change producing an amino acid substitution in the predicted gene product was detected in all three group $\mathrm{E}$ mutants within a region of 18 nucleotides (positions 92-109 from the $5^{\prime}$-end of the mRNA). No other nucleotide changes were observed. The sequence of the two non-ts revertants was identical to wildtype, confirming the association of these nucleotide changes with the 


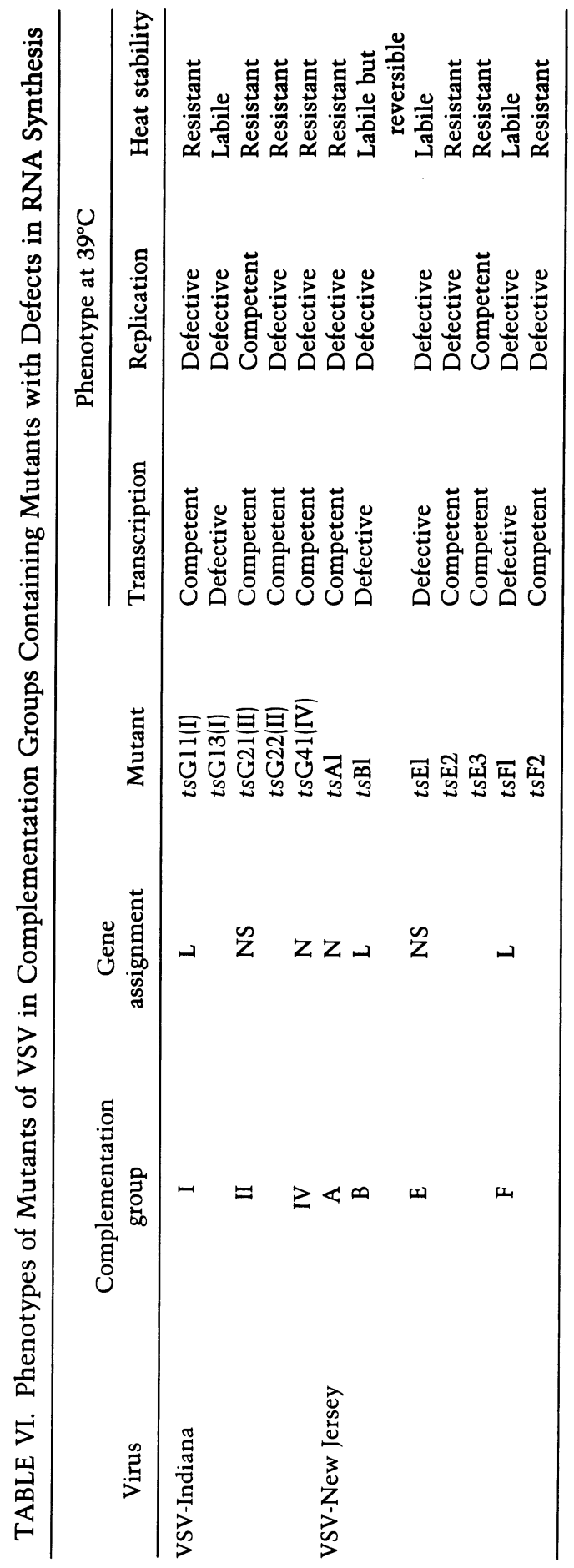



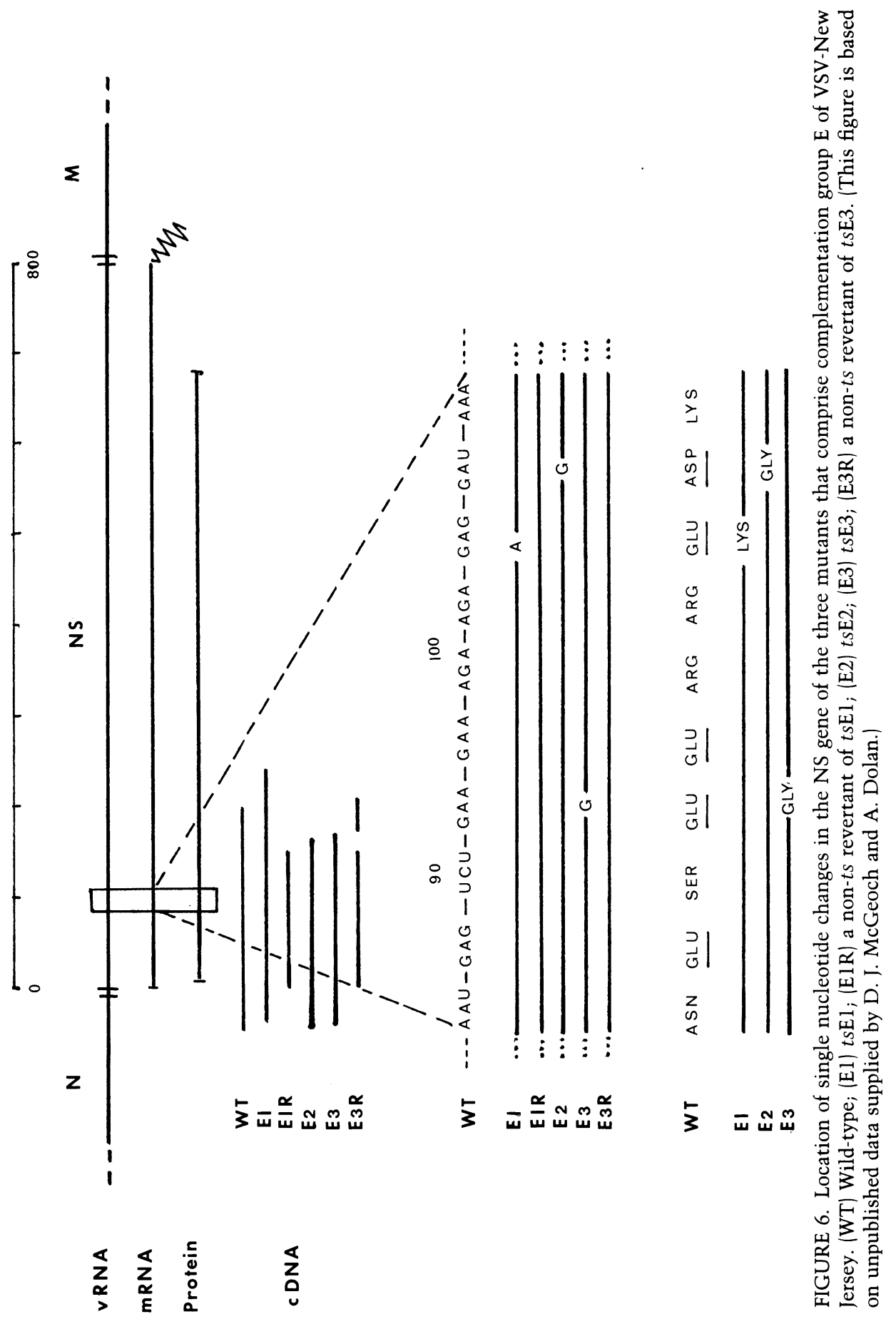
phenotypic changes (Fig. 6). Although the sequence of these NS genes had still to be completed, it was reasonable to assume that the sites of the mutational lesions had been located to a region of six adjacent amino acids. Single amino acid substitution in this critical region drastically alters the functional activity of the NS protein.

Subsequently, full-length cDNA copies of all three mutant NS mRNAs have been obtained and their nucleotide sequence determined (Rae and Elliott, 1986b). No other nucleotide changes were detected in mutants $t s \mathrm{E} 1$ and $t s \mathrm{E} 3$, but a second change was detected at position 413 in mutant $t s \mathrm{E} 2$. The presence of a second mutation in $t s \mathrm{E} 2$ explains past failure to isolate non-ts revertants of this mutant. Rae and Elliott also cloned and sequenced full-length cDNA copies of the mRNA of non-ts revertants of $t s \mathrm{E} 1$ and $t s \mathrm{E} 3$. The revertant NS genes were identical to wild-type at the site of mutation. These results confirm that the mutations responsible for the three distinct phenotypes are clustered in a region of 18 nucleotides. Curiously, both non-ts revertants contained the same additional point mutation at position 513 producing a Met to Arg substitution. Figure 7 illustrates a prediction of the secondary structure of the wild-type and NS proteins according to the algorithm of Chou and Fasman (1978). The mutations responsible for the $t s$ phenotype have marked effects on the

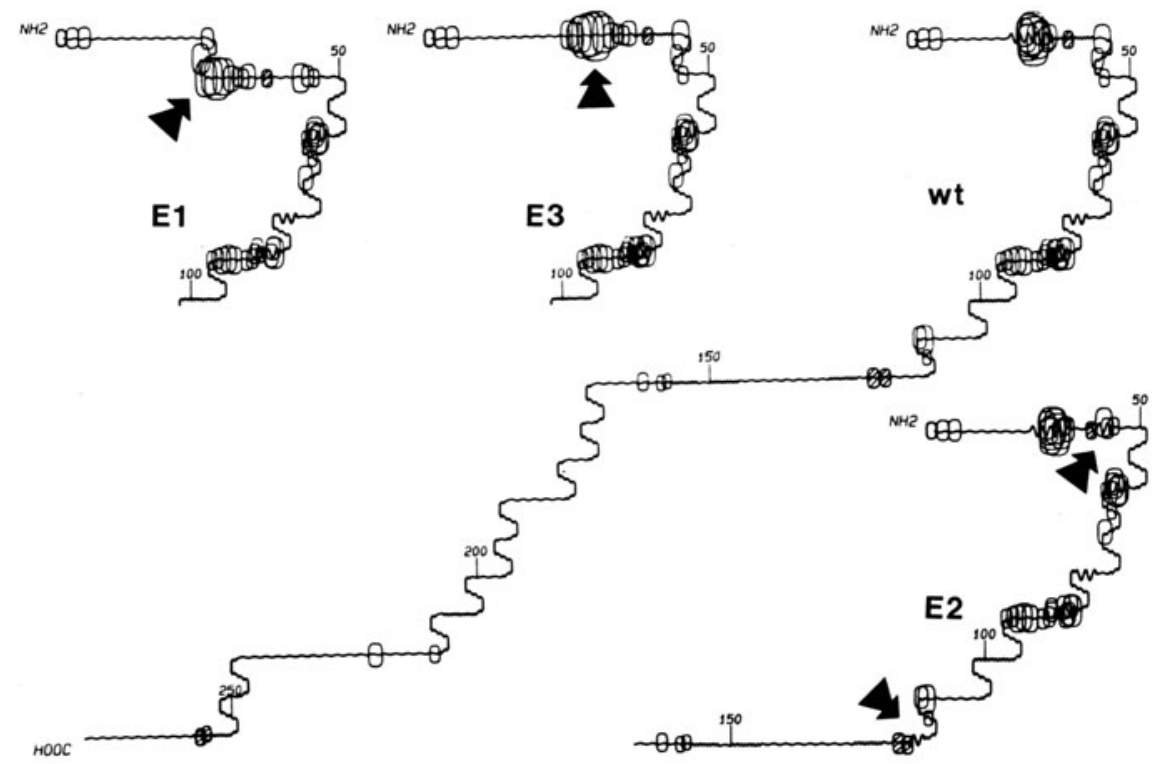

FIGURE 7. Secondary structures of the NS proteins of wild-type and complementation group E mutants of VSV-New Jersey predicted according to the method of Chou and Fasman (1978). The complete plot of wild-type (wt) NS protein is given, and the relevant portions of the plots of the group E mutants. The arrows indicate differences in the predicted secondary structures due to amino acid substitutions. w represents $\alpha$ helix, - represents $\beta$ strand, $\sim$ represents undefined, and a change of direction indicates $\beta$ turn. The open ovals represent hydrophilic regions, and shaded ovals hydrophobic regions. Reproduced from Rae and Elliott (1986). 
predicted secondary structure. The $t s \mathrm{E} 1$ mutation produces loss of a region of $\alpha$-helix and changes in the position of a $\beta$-turn. The tsE3 mutation produces loss of the same $\alpha$-helix without affecting the $\beta$-turn. The $t s E 2$ mutation produces an additional region of $\alpha$-helix and additional $\beta$-turns. (The second mutation in tsE2 at amino acid 114 and the two extraneous mutations in the revertants have little effect on the predicted secondary structure.) These effects on secondary structure may be responsible for the aberrant electrophoretic mobility of these mutants by affecting binding of sodium dodecyl sulfate.

Davis et al. (1986) have demonstrated that NS protein associated specifically with $\mathrm{N}$ protein in an in vitro replication system and that essentially all of the $\mathrm{N}$ protein was sequestered in $\mathrm{N}-\mathrm{NS}$ complexes. This implies that these complexes are important in maintaining $\mathrm{N}$ protein in a functional state and in regulating the availability of $\mathrm{N}$ protein.

It has been proposed that different phosphorylated forms of NS protein may regulate RNA synthesis by their association with $\mathrm{N}$ protein rendering it active or inactive in replication. It is possible that the critical site identified by the complementation group $\mathrm{E}$ mutants plays a role in complex formation.

\section{F. Nucleocapsid Protein Mutants}

\section{Temperature-Sensitive Mutants}

The temperature-sensitive mutants classified in group IV of VSVIndiana and group A of VSV-New Jersey are N-protein mutants. In addition to these mutants, some clones of mutant $t s \mathrm{Dl}$ of VSV-New Jersey have an $\mathrm{N}$ polypeptide that migrates in polyacrylamide gel faster than wildtype $N$, suggesting that the $N$ polypeptide is around 10 amino acids shorter than normal. This characteristic is independent of the ts phenotype. Determination of the nucleotide sequence to about 200 acids from each terminus of the $\mathrm{N}$ gene did not reveal any changes compatible with synthesis of a shorter polypeptide by premature termination or late initiation of translation (Pringle et al., 1981). Attacking this problem from a different direction, Brown and Prevec (1982), by specific chemical cleavages at tryptophan and methionine residues and enzymatic cleavage with carboxypeptidases $\mathrm{A}$ and $\mathrm{B}$, concluded that residues near the carboxy terminus are responsible for the aberrant electrophoretic behavior of this mutant. No tryptic peptide differences were detected in this region, but a tryptic peptide difference was located outside this region. From these observations, it was concluded, first, that in agreement with the sequencing results, the missense point mutation responsible for the aberrant phenotype was located at least 40 residues from the carboxy terminus, and, second, that the altered electrophoretic mobility was the result of interaction between this site and a carboxy-terminal proximal region. Intramolecular interactions of this sort may be responsible for the ma- 
jority of the electrophoretic variants generated by the $t s \mathrm{D} 1$ "mutator" polymerase.

\section{Pol R Mutants}

Perrault et al. (1981) have described mutants designated Pol $\mathrm{R}$ that generate unique DI particles. These DI particles read through the minusstrand leader termination signal in vitro, producing near full-length copies of the template RNA. These variants were obtained by a selection procedure involving several alternating cycles of heat inactivation and growth. The Pol R mutants were genetically stable following cloning by plaque isolation, but unexpectedly the virions were no more heat-resistant than wild-type. It was hypothesized that the Pol $R$ viruses were mutated in a function involved in the switch from transcription to replication; in accordance with this hypothesis, it was later observed that the plus-strand leader-N gene junction was also read through efficiently. Perrault et al. (1983) have now shown by dissociation and reconstitution experiments that the mutation responsible for the readthrough phenotype is located in the $\mathrm{N}$ protein. Two-dimensional gel electrophoresis corroborated this conclusion, the magnitude of the pI shift observed with the $\mathrm{N}$ proteins of Pol R1 and Pol R2 being consistent with a single charge change. It is probable that the phenotype of Pol R1 and Pol R2 is the result of a similar single amino acid substitution in the $\mathrm{N}$ protein.

\section{VIRUS-CELL INTERACTIONS}

\section{A. Cell-Killing Potential}

Infection of host cells with vesiculoviruses generally results in a rapid cessation of host macromolecular synthesis. Marcus and Sekellick (1980) have used temperature-sensitive $(t s)$ and deletion mutants to define the viral genes involved in the inhibition of cellular protein synthesis and the expression of cell killing. The cell-killing ability of $(t s)$ mutants at permissive and restrictive temperatures was measured from survival curves of Vero cells infected at a range of multiplicities. Vesicular stomatitis virus (VSV) stocks on average contained 5 cell-killing units per plaqueforming unit. From UV-inactivation experiments, it was concluded that VSV virions are not toxic per se and that cell killing requires expression of only some of the five viral genes. Of $14 \mathrm{ts}$ mutants examined, belonging to groups I, II, and IV, 6 did not induce cell killing at restrictive temperature, indicating that synthesis of functional core proteins is necessary for cell killing. Since the group II and group IV mutants tested were competent for primary transcription, it was concluded that primary transcription is necessary but not sufficient for cell killing. Loss of ability to inhibit cellular protein synthesis at restrictive temperatures correlated 
with loss of cell-killing ability and also with ability to induce interferon (Sekellick and Marcus, 1980), which suggested that the same gene function is involved in each case. Loss of ability of VSV to inhibit replication of pseudorabies virus, a nuclear DNA-containing virus, was also correlated with loss of ability to inhibit host protein synthesis.

From their mutant analysis, Marcus and Sekellick concluded that the proximate cell-killing factor was viral double-stranded RNA (dsRNA). Nilsen et al. (1981), although they could not detect viral dsRNA in wildtype infected HeLa cells using a cross-linking agent, were able to detect dsRNA by the same method in $t s G 114(\mathrm{I})$ - or $t s \mathrm{G} 11$ (I)-infected cells following shift-up to restrictive temperature. These mutants were presumed to provide optimal conditions for detection of dsRNA, since mRNA synthesis but not replicative RNA synthesis is inhibited on shift-up (Wertz, 1978). These observations suggest that under such conditions, template RNA may not be complexed with protein and able to anneal with nascent complementary RNA.

Similarly highly purified preparations of nontranscribing defective interfering (DI) particles (i.e., 3 '-end deletions) did not kill cells even at concentrations as high as $10^{5}$ particles per cell (Doyle and Holland, 1973). It was found, as was originally predicted by Cooper and Bellett (1959) long before the discovery of DI particles, that suppression of viral replication by a transmissible interfering component did not provide protection against cell-killing particles.

\section{B. Interferon Induction}

Interferon treatment did not protect murine embryonal teratocarcinoma cells from infection with wild-type VSV. Nevertheless, Nilsen $e t$ al. (1981) observed that embryonal teratocarcinoma cells did exhibit interferon-induced resistance to infection by the mutants $t s G 11(\mathrm{I})$ and ts G114(I). The production of dsRNA by these two mutants under restrictive conditions appeared to be the common factor linking them with two picornaviruses that were also susceptible to the action of interferon in these cells. Interferon treatment of teratocarcinoma cells induces synthesis of the 2-5A oligonucleotide polymerase, but not the protein kinase activity observed in other interferon-treated cells, and this polymerase activity appears to be sufficient to protect these cells from viruses that induces dsRNA synthesis during infection.

Sekellick and Marcus (1980) observed that the mutants tsG11(I), $t s \mathrm{G} 22(\mathrm{II})$, and $t s \mathrm{G} 41(\mathrm{IV})$, which were defective for cell killing and inhibition of host protein synthesis, were also good inducers of interferon. In the case of $t s \mathrm{Gl} 1(\mathrm{I})$ and the double-stranded DI particle (DI011), the maximal yield of interferon was obtained at a plaque-forming unit/cell ratio of $0.1-0.3$, indicating that induction of interferon was probably a quantal effect and that interferon-inducing particles were present in greater num- 
bers than infectious particles. Frey et al. (1981), on the other hand, comparing 12 DI particles with varying extents of double-strandedness, were unable to confirm this relationship. They did note, however, a correlation between interferon inducibility and the extent of virion contamination. It was concluded that ability to induce interferon is a determining factor in the initiation and maintenance of nonlytic persistent infection. The frequent association of $t s$ mutants, predominantly of group I, or smallplaque mutants with persistent infections is consistent with this hypothesis.

\section{Inhibition of Host Protein Synthesis}

By systematic analysis of a particular temperature-sensitive mutant, tsT1026(I), and its non-ts revertants, Stanners et al. (1977) have identified a function designated the $P$ function. This function is expressed by the normal VSV genome and is responsible for inhibition of protein synthesis in infected cells. Mutant $t s \mathrm{~T} 1026(\mathrm{I})$ is a group I ts mutant that is defective for inhibition of host protein synthesis. It is also a potent inducer of interferon and is able to initiate persistent infections in the absence of DI particles. Studies of non-ts revertants showed that $t s \mathrm{~T} 1026(\mathrm{I})$ is a complex mutant with a ts lesion in the L-protein gene and a non-ts lesion in the putative $\mathrm{P}$ function. These non-ts revertants, or $\mathrm{R}$ mutants, were defective for inhibition of host protein synthesis $\left(\mathrm{P}^{-}\right)$, were efficient inducers of interferon, and failed to initiate persistent infections, unlike ts T1026(I) itself. Therefore, it was concluded that for the establishment of persistent infection, the $\mathrm{P}^{-}$mutation is necessary to prevent inhibition of host-cell protein synthesis and the $t s$ group I (L-protein) mutation to reduce transcription and cell-killing ability. Francoeur et al. (1980) later developed a procedure [the plaque interferon (PIF) assay] for selectively isolating $\mathrm{P}-$ mutants that depends on the observation that the development of plaques initiated by the $\mathrm{P}^{-}$mutants is arrested due to autoinduction of interferon, whereas plaques initiated by $\mathrm{P}^{+}$virus increase in size linearly. One of these mutants has the same M-protein electrophoretic-mobility change observed in ts T1026(I) and its revertants. Lodish and Porter (1981), however, questioned the reality of the P function and argued that the rate of inhibition of host protein synthesis was dependent on the level of overall mRNA synthesis and not on a single gene product. Nevertheless, others have confirmed Stanners' findings (C. P. Stanners, personal communication), and the discrepancy may be due to the fact that the $\mathrm{P}$ function acts predominantly by inhibition of translational initiations and could have escaped detection in Lodish and Porter's experiments, which employed early exponential-phase L-cell cultures in which no free ribosomes were present and translational initiation was not rate-limiting. Recently, Stanners and colleagues (personal communication) have isolated $\mathrm{P}^{++}$mutants that enhance inhibition of host pro- 
tein synthesis in the early exponential phase, providing additional support for the $\mathrm{P}$ function.

\section{Inhibition of Host-Cell Transcription}

Infection of vertebrate cells by VSV results in inhibition of cellular DNA and RNA synthesis, probably by different mechanisms. The transcriptase-defective mutant $t s \mathrm{G} 114(\mathrm{I})$ has been employed to show that inhibition of both DNA and cellular RNA synthesis is dependent on at least limited transcription of the viral genome. Weck and Wagner (1979) showed that in MPC-11 cells, initiation of transcription may be due to diminished transcription of the cellular RNA polymerases, polII, more than of polI or polIII. On the basis of UV-inactivation studies, it was suggested that transcription of the leader sequence at the $3^{\prime}$ terminus of the genome is required to initiate inhibition of cellular transcription (Weck et al., 1979). In support of these findings, Kurilla et al. (1982) demonstrated the presence of VSV leader RNA in the cell nucleus at the time of inhibition, and McGowan et al. (1982) found that in vitro transcription in HeLa-cell extracts of SV40 DNA by polII, and of adenovirus DNA by polII and polIII, was inhibited by addition of VSV leader RNA. VSV-New Jersey leader RNA was more effective than VSV-Indiana leader RNA in this respect (Grinnell and Wagner, 1983).

Several other lines of evidence, however, suggest that synthesis of more than leader RNA is required for inhibition of cellular RNA synthesis by VSV. In mouse L cells, Wu and Lucas-Lenard (1980) found that tsG41(IV), $t s \mathrm{~W} 10(\mathrm{IV}), t s 045(\mathrm{~V})$, and $t s 011(\mathrm{~V})$ did inhibit host RNA synthesis. They suggested that the group II function (the NS protein) is necessary for inhibition of host RNA synthesis as well as for limited transcription of the genome. Furthermore, UV-inactivation studies estimated that transcription of $17 \%$ of the genome (the target size of the $\mathrm{N}$ gene) was necessary for inhibition. Poirot et al. (1985) observed that mutant tsG22(II), which supports viral genome transcription but not replication at $30^{\circ} \mathrm{C}$, also inhibited host RNA synthesis. This inhibition was abolished by protein-synthesis inhibitors, which do not affect transcription. These findings imply that viral protein synthesis is required for inhibition of host protein synthesis and that the inhibitory agent may be leader RNA complexed with either a viral protein (probably $\mathrm{N}$ ) or perhaps a cellular protein, such as the La protein, that is in limiting supply or subject to rapid turnover (Kurilla and Keene, 1983). However, rabies virus does not inhibit host RNA synthesis, although its leader RNA interacts with La protein in the same manner as VSV (Kurilla et al., 1984).

Earlier, Genty (1975) had presented evidence indicating that in addition to a protein synthesis-dependent mechanism, inhibition of host RNA synthesis in VSV-infected chick-embryo cells is partially due to a reduced capacity to transport uridine. Infection of chick-embryo cells 
with $t s$ mutants suggested that the $M$ protein might be involved in modification of uridine transport.

\section{HOST RANGE}

\section{A. Permissive and Restrictive Cells}

Vesicular stomatitis virus (VSV) infection produces cytopathic changes in a wide range of host cells. Mosquito cells, however, survive infection and continue to multiply, producing moderate amounts of VSV over long periods. Nevertheless, Sarvar and Stollar (1977) isolated a single clone of Aedes albopictus cells in which VSV produced a cytopathic response at 28 and $34^{\circ} \mathrm{C}$. Other clones were obtained that were lysed by VSV at $34^{\circ} \mathrm{C}$ only. The host-cell genome plays an important role in expression of cell killing. A few types of mammalian cells are resistant to the cytopathic effects of VSV. These include rabbit kidney (DRK3) cells (Chen and Crouch, 1978), rabbit corneal (RC-60) cells (Thacore and Youngner, 1975), and human lymphoblastoid cells (Nowakowski et al., 1973). Levinson et al. (1978) have also described a stock of VSV-Indiana that was restricted in duck-embryo cells, but not in chicken, quail, or pheasant cells.

Restriction of growth of VSV in DRK3 cells appeared to operate at the level of virus adsorption. Restriction of growth of VSV in rabbit corneal cells appeared to be due to inhibition of viral RNA replication, since transcription, translation, and posttranslational modification occurred normally. This restriction could be released by superinfection with wildtype rabbitpox virus or even certain host-range mutants defective in early functions. However, rabbitpox virus was unable to rescue VSV from persistently infected BHK-21 cells, which suggests that the mechanism of restriction of VSV multiplication in persistently infected cells is different from that in rabbit corneal cells (Hamilton et al., 1980).

Lymphoblastoid cells of the T-cell lineage are permissive for VSV replication, whereas those of B-cell origin are restrictive (Nowakowski et al., 1973). Most B-lymphoblastoid cells contain endogenous Epstein-Barr virus (EBV); e.g., Raji cells do not shed $E B V$, but the genome exists in an episomal form in multiple copies and some viral functions are expressed. Creager et al. $(1981,1982)$ showed that restriction of VSV in B cells is characterized by failure to inhibit host protein synthesis and by reduced VSV transcription and is dependent on the presence of endogenous EBV. Abolition of cell killing and the initiation of persistent infection were responses to the presence of the EBV genome in lymphoblastoid cells of B origin, since EBV-negative B cells were susceptible to VSV infection. Johnson and Herman (1984) observed that although VSV messages are abnormally modified in Raji cells, they were still functional and not ratelimiting. They concluded from analyses of the properties of the temperature-sensitive $t s \mathrm{Cl}$ matrix-protein mutant that mRNA synthesis in Raji 
cells is limited by the amount of available nucleocapsid and not by any defect in transcription. They concluded, as had Nowakowski et al. (1973) previously, that restriction of VSV multiplication in Raji cells might be at the level of replication. However, Piwnica-Worms and Keene (personal communication) have reported that the synthesis of minus- and plusstrand genome RNA is similar in permissive BHK-21 cells and restrictive Raji cells. At $16 \mathrm{hr}$ postinfection, $12 \%$ of the genomic RNA molecules synthesized in BHK-21 cells were packaged and exported, as against $0.8 \%$ in Raji cells. Virions released from Raji cells had reduced infectivity and a glycoprotein $(G)$ with a faster electrophoretic mobility than the $G$ protein of the more infectious virions released from BHK-21 cells. It is probable, therefore, that there are multiple biochemical lesions in Raji cells that together mediate restriction of VSV multiplication.

\section{B. Conditional Host-Range Mutants}

\section{Host Range and Methylation}

Host-range ( $h r)$ mutants of VSV-Indiana have been isolated that were restricted in HeLa or Hep-2 cells and were simultaneously temperaturesensitive in chick-embryo cells (Obijeski and Simpson, 1974; Simpson and Obijeski, 1974). Primary transcription was not affected, but amplification of RNA synthesis was defective in restrictive Hep-2 cells (Morrongiello and Simpson, 1979; Moyer et al., 1981). In vitro virion polymerase activity was diminished in some of these $h r-t s$ mutants at $31^{\circ} \mathrm{C}$, and in vivo weak (possibly intragenic) complementation was detected between some pairs of $h r-t s$ mutants. A gradient of permissiveness was observed in a comparison of 30 cell lines, cells of human origin being the most restrictive (Simpson et al., 1979). Furthermore, sublines of HeLa cells differed in restrictiveness, suggesting that host factors are concerned in viral replication. Simpson et al. (1979) considered these mutants to be large (L)-protein mutants.

Four of six of these $h r$ mutants and a non-ts revertant of one of them could be rescued by superinfection with rabbitpox virus, which indicates that the ts and hr phenotypes of these mutants are independently determined (Moyer et al., 1981). Horikami and Moyer (1982) reported that two of these $h r$ mutants of VSV were defective in mRNA methylation in vitro, although guanylylation and polyadenylation were unaffected. Mutant $h r 1$ was totally defective in methylation, although full-length messages were synthesized at the normal rate with $5^{\prime}$ termini in the form GpppA. It is not known whether this mutant is defective only in the first or in both the first and second steps in the normal pathway of $5^{\prime}$-terminal methylation (i.e., GpppA $\rightarrow 7 \mathrm{mGpppA} \rightarrow 7 \mathrm{mGpppA}^{\mathrm{m}}$ ), but the data suggest that at least one methyltransferase activity is encoded in the viral genome. The unmethylated mRNA produced by $h r 1$ was poorly translated in vitro. 
Mutant hr8 was partially defective for methylation, producing mRNA in vitro with predominantly GpppA and some $\mathrm{GpppA}^{\mathrm{m}} 5^{\prime}$ termini. Subsequently, Horikami et al. (1984) have shown that the mRNA synthesized in vivo in restrictive cells is also unmethylated and inactive in an in vitro reticulocyte translation system. The undermethylation of $h r 8$, however, could be partially reversed in vitro by addition of large amounts of $S$ adenosylmethionine. The association of an mRNA methylation defect with a host-range phenotype was unexpected and poses the question of how the permissive host cell compensates for this defect. In this respect, it is interesting that permissive BHK-21 cells have 10-fold higher levels of endogenous $S$-adenosylmethionine than restrictive Rep-2 cells, and mRNA from BHK-21 cells is predominantly in the monomethylated (7mGpppA) form. Both $h r$ mutants could be rescued from restriction by superinfection with a poxvirus, suggesting that the defective mRNA could be methylated by the poxvirus methyltransferases. However, two other $h r$ mutants ( $h r 5$ and $h r 7$ ) produced active capped and methylated mRNA in restrictive cells and appeared to be blocked at the level of replication. Consequently, host factors in general, rather than methylation deficiency in particular, appear to be implicated in the host-range phenotype. Methylation defects do not appear to be associated with the $t d C E$ mutants of VSV and Chandipura virus (Rasool and Pringle, 1986).

\section{Host-Range and Polymerase Defectivenẹss}

Conditional host-range mutants of VSV-New Jersey (designated $t d \mathrm{CE}$ mutants), which multiply at 31 and $39^{\circ} \mathrm{C}$ in $\mathrm{BHK}-21$ cells and at $31^{\circ} \mathrm{C}$ only in chick-embryo cells, have been characterized in some detail. These mutants were present in stocks of mutagenized virus at higher frequency than conventional ts mutants (Pringle, 1978). A reversible inhibition of in vitro polymerase activity at $39^{\circ} \mathrm{C}$, suggesting conformational change rather than inactivation, that was exhibited by some $t d \mathrm{CE}$ mutants was restored to normal activity on reversion of the $t d C E$ phenotype (Szilagyi and Pringle, 1975). The molecular site of the mutational lesion was shown to be the $\mathrm{L}$ polypeptide by dissociation and reconstitution experiments in the case of mutant $t d C E 3$ (Szilagyi et al., 1977). Similar mutants have been isolated from mutangenized stocks of VSV-Indiana and Chandipura virus (Gadkari and Pringle, 1980b; Rasool and Pringle, 1986). The initial analysis of four VSV $t d \mathrm{CE}$ mutants suggests that there might be discrete classes of polymerase defects, but comparison of the in vitro polymerase activity of 12 Chandipura virus $t d \mathrm{CE}$ mutants at $39^{\circ} \mathrm{C}$ showed that each mutant was unique, the 12 ranging in polymerase activity from complete thermosensitivity to almost no thermosensitivity. The $t d C E$ phenotype is expressed irrespective of the cell type in which the virus is propagated. Therefore, the host-range component of the phenotype implies that a factor in the cell environment (absent in chicken-embryo cells and in the in vitro polymerase reaction mixture) is involved in the correct func- 
tioning of the polymerase, maintaining it in an active configuration at $39^{\circ} \mathrm{C}$ (Szilagyi and Pringle, 1975). More than one host factor may be involved, since at least three types of $t d C E$ mutants of VSV-New Jersey could be defined according to their ability to multiply in other types of avian cells (Fig. 8). These $t d \mathrm{CE}$ mutants tended to be conditionally temperature-sensitive in the embryonic cells of some species. The temperature sensitivity of $t d \mathrm{CE}$ mutants in pluripotent murine embryonal carcinoma cells is no longer observed when the cultures undergo differentiation. Several host factors may interact with the VSV polymerase, and the absence of these factors at certain stages of development may have a protective effect.

Temperature-shift experiments indicated that the host restriction operated early in the growth cycle, and use of pseudotypes with the nucleocapsid of Chandipura virus and the envelope of VSV tdCE mutants confirmed that restriction occurs after adsorption (Pringle, 1978). The putative host factors have not been identified, although some possible mechanisms such as phosphorylation, methylation, interferon induction, and heat shock or stress proteins have been excluded (Rasool and Pringle, 1986, and unpublished data).

HeLa cell extracts enhance in vitro VSV RNA transcription. Fractionation of these extracts indicated that stimulatory activity was associated mainly with fractions containing microtubules and microtubuleassociated-protein (MAP). There was no stimulation of influenza A virus

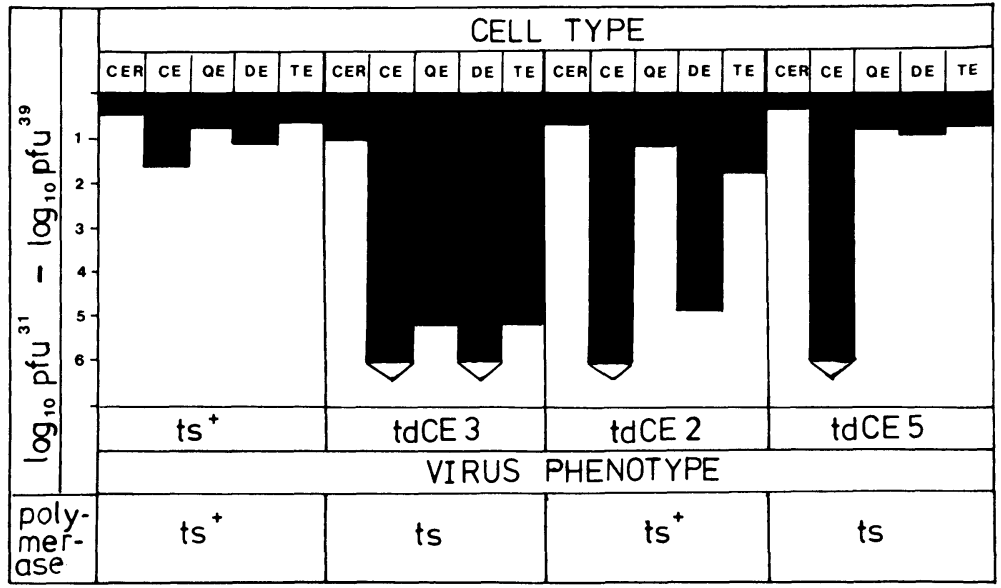

FIGURE 8. Efficiency of plating of three $t d C E$ mutants and wild-type virus in four avian embryo cell types at $39^{\circ} \mathrm{C}$. Mutants $t d \mathrm{CE} 2, t d \mathrm{CE} 3, t d \mathrm{CE} 5$, and wild-type virus were assayed on monolayers of hamster (CER), chick embryo (CE), Japanese quail embryo (QE), Pekin duck embryo (DE), and turkey embryo (TE) cells. The mean values from five experiments obtained from plaque counts after $48 \mathrm{hr}$ of incubation at 31 or $39^{\circ} \mathrm{C}$ are plotted as histograms; the longer the solid bar, the greater the temperature sensitivity. Data on the in vitro polymerase activity of these mutants are included. Reproduced from Pringle (1978). 
transcription. Separation of MAP and tubulin indicated that stimulatory activity was associated with the MAP rather than tubulin (Hill et al., 1986). It is conceivable that the MAP represents the specific host factors predicted by the genetic studies to be involved in VSV RNA replication. On the other hand, Moyer et al. (1986) found that tubulin stimulated in vitro VSV and Sendai virus transcription, and that addition of a monoclonal antibody to $\beta$-tubulin abolished all transcriptase activity. Direct association of tubulin and viral $\mathrm{L}$ protein was suggested because monoclonal and polyclonal antibodies to tubulin precipitated tubulin and $\mathrm{L}$ protein from the soluble fraction of infected cells. In view of the intimate association of $\mathrm{L}$ protein with the cytoskeleton throughout infection (Chatterjee et al., 1984), and the presence of small amounts of tubulin in virions, it is likely that cytoskeletal components are the elusive host factors involved in replication. The specificity of these components remains to be explored in detail. Nonconditional hr mutants of VSV-New Jersey have also been isolated that are completely restricted in both chick-embryo and Mardin-Darby bovine kidney (MDBK) cells (Pringle, 1978). These mutants were present at low frequency only and so far have not been found in VSV-Indiana or Chandipura virus.

\section{Piry Virus in Drosophila}

Brun (1981) has described host-range (agD) mutants of Piry virus that have reduced ability to multiply and induce $\mathrm{CO}_{2}$ sensitivity in adult Drosophila melanogaster (Paris strain). Many of these host-range mutants were also temperature-sensitive in chick-embryo cells. In the case of one of these mutants, it was shown that the restriction was under the control of a gene on chromosome III. The host gene that affects the multiplication of Piry virus was not one of the five genes known to be involved in the control of Sigma virus. Thus, either these two rhabdoviruses interact differently with the host organism or multiple host factors are concerned in the replication of rhabdoviruses in insects.

Most agD (affected growth in Drosophila) mutants are generally restricted in all strains of Drosophila. Other mutants, designated $\operatorname{rgD}$ /rapid growth in Drosophila), have been isolated from agD stocks or from wildtype by selection. These $\mathrm{rgD}$ mutants have lost general restriction in Drosophila strains but retain specific restriction in the Paris strain. Furthermore, they multiply in permissive strains with shorter incubation times and to higher yields than wild-type Piry virus (Brun, 1984). The agD and $\mathrm{rgD}$ mutants could be tentatively classified into complementation groups by a UV-inactivation-rescue procedure in which cells are infected with one mutant at low multiplicity in the presence of UVinactivated wild-type virus or another mutant. This technique was developed by Deutsch (Deutsch, 1975, 1976; Deutsch et al., 1977) for analysis of the function of $t s$ mutants of VSV. The conclusion from preliminary analysis was that the majority of the $\mathrm{agD}$ and $\mathrm{rgD}$ mutants were $\mathrm{L}$ - 
protein mutants. Intracistronic complementation among L-protein (group I) mutants was frequent, resembling the pattern described for Chandipura virus by Gadkari and Pringle (1980a).

These observations are all consistent with the concept that the hostrange properties of rhabdoviruses are determined primarily by specific interactions between host-cell factors and the viral polymerase.

\section{PATHOGENESIS}

\section{A. Patterns of Disease and Protection}

Altered patterns of disease have been associated with temperaturesensitive ( $t s$ ) mutants of vesicular stomatitis virus (VSV) and Chandipura virus. In particular, changes in neurovirulence following intracerebral injection into adult mice or hamsters have been described, as have also the protective potential of $t s$ mutants administered intranasally to adult mice. These observations have been summarized previously (Pringle, 1982) and have not been substantially extended.

Differences in the pathogenic properties of rabies virus ts mutants have been reported by Selimow and Nikotina (1970), Clark and Koprowski (1971), Aubert et al. (1980), and Bussereau et al. (1982). In the absence of characterization of these mutants by complementation analysis, direct comparison of these results is difficult.

\section{B. Host Resistance}

Fultz et al. $(1981,1982)$ used Syrian hamsters to study the protective effects of defective interfering particles, polyinosinic acid-polycytidylic acid, and interferon. VSV-Indiana wild-type produces a lethal disease in Syrian hamsters with $70 \%$ of the animals dying within $72 \mathrm{hr}$ of injection of 10-100 plaque-forming units. The UTI strain, however, is relatively resistant, with $90 \%$ of animals surviving intraperitoneal injection. Resistance appeared to be multifactorial, with three independent loci interacting, two on autosomes and one on the $\mathrm{X}$ chromosome. Preliminary data suggested that the mechanism of resistance to VSV involves cells of the lymphohematopoietic system.

Murine resistance to intraperitoneal infection with street rabies virus is genetically determined. Certain strains of mice are fully susceptible, other strains do not exhibit signs of disease, and in still other strains, individual animals survive after clinical illness. Lodmel and Chesebro (1984) have shown that resistance to infection is controlled by two segregating genes and that the resistance genes in the SJL/J and CBA/J strains are allelic. These strains provide an opportunity to investigate how ani- 
mals recover from infection and the role of the immune system in this process.

In a comparison of seven inbred strains of mice inoculated with i.p. street rabies virus, differences in susceptibility to CNS disease were correlated with restriction of virus multiplication within the CNS. Limitation of virus replication correlated with antibody response, resistant strains having high neutralizing antibody titers and susceptible strains low antibody levels (Lodmell and Ewalt, 1985). Resistant SJL/J mice were rendered susceptible by cyclophosphamide treatment, and resistance was restored by transfusion with immune spleen cells or serum. Other experiments indicated that antibody in the cerebrospinal fluid was not an important factor in resistance in mice which remained asymptomatic, but was important in survival of mice that developed clinical disease.

Templeton et al. (1986) have also studied the genetic control of serumneutralizing antibody in mice. They showed that serum-neutralizing antibody response to vaccination and resistance to rabies virus challenge was controlled by separate unlinked genes. Hyperresponsiveness and hyporesponsiveness to rabies vaccination were controlled by dominant and recessive alleles, respectively. Survival after rabies virus challenge infection was dominant to nonsurvival. This result implies that even the most potent rabies vaccines may not induce protection in some genetically susceptible individuals. Host resistance to rabies infection is undoubtedly complex and cytotoxic $T$ cells also play an essential role in protection.

\section{PHENOTYPIC MIXING AND PSEUDOTYPES}

\section{A. Prevalence of Phenotypic Mixing}

Phenotypic mixing occurs widely between related and even unrelated enveloped viruses multiplying in the same cells. This contrasts with the pattern of genetic complementation, which in general is confined to closely related viruses. Phenotypic mixing between heterologous viruses involves the envelope glycoproteins only, and particles invested completely in the envelope antigens of a heterologous virus are described as "pseudotypes." Phenotype mixing of the internal proteins of heterologous viruses has not been observed.

Within the genus Vesiculovirus, heterologous complementation has been observed between the two subtypes (Concan and Hazelhurst) of vesticular stomatitis virus (VSV)-New Jersey and betweenVSV-Indiana and VSV-Cocal. In the latter, significant complementation involved only the two groups of mutants representing the envelope proteins. Complementation has not been observed in any of the other heterologous combinations tested, i.e., Indiana and New Jersey, New Jersey and Cocal, Cocal and Chandipura, Indiana and Chandipura, New Jersey and Chan- 
dipura. The level of discrimination of nongenetic interactions in pseudotype analysis is probably at least an order of magnitude better than that of complementation analysis using temperature-sensitive $(t s)$ mutants.

The extent of phenotypic mixing between enveloped viruses is reviewed in Table VII. Phenotypic mixing in one direction at least has been recorded between rhabdoviruses and nine of the other ten families of enveloped viruses, the highest frequency $(50 \%)$ of pseudotypes being recorded in coinfections with herpesvirus (Huang et al., 1974).

Preparations of pure pseudotypes can be obtained using deletion or conditional lethal mutants completely defective for glycoprotein (G) transport or synthesis; examples are BH-RSV (VSV) (Weiss et al., 1977) and VSV ts045(V) (MMTV) (Chan et al., 1982). Mutant ts045(V) of VSVIndiana has been used extensively for production of pseudotype particles because the $t s$ lesion renders the $G$ protein thermolabile. This thermolability allows elimination of the non-phenotypically mixed VSV and facilitates resolution of the pseudotype particles enveloped in heterologous nonthermolabile protein. Zavada (1972) derived for the same purpose a more thermolabile $(t l)$ nonleaky genetically stable G-protein multiple mutant $t 117$ by alternating 5-fluorouracil mutagenization and cycles of neutralization with specific antiserum. Weiss and Bennett (1980) demonstrated that pseudotypes of the form VSV(RSV) were obtained from RSV-infected cells superinfected with mutant $t s 045(\mathrm{~V})$, whereas RSV(VSV) pseudotypes were produced in the same cells infected with the matrix (M)-protein mutant $t s \mathrm{G} 31$ (III). Synthesis of M protein is essential for maturation of VSV, but not for the insertion of G protein into the plasma

TABLE VII. Phenotypic Mixing between Rhabdoviruses and Other Enveloped Viruses ${ }^{a}$

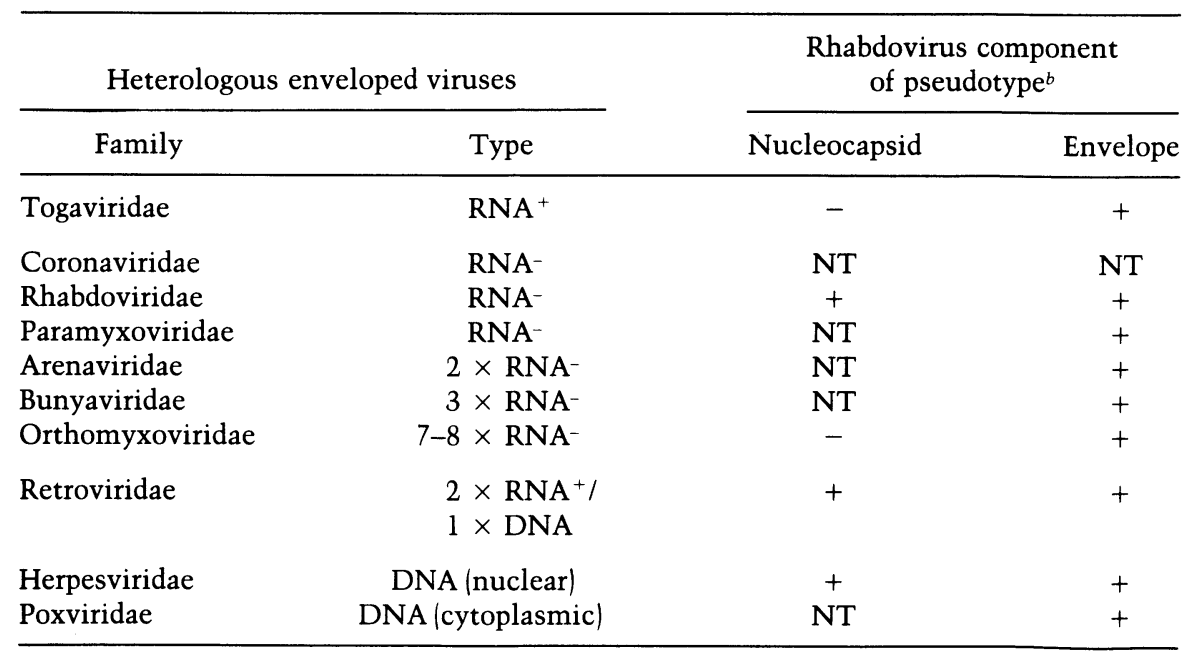

${ }^{a}$ Adapted from Zavada (1982). $\quad b|+| \operatorname{Identified} ;(-)$ not identified; (NT) not tested. 
membrane. Consequently, no VSV particles are released from tsG31(III)infected cells at restrictive temperature despite the presence of $G$ protein in the plasma membrane.

\section{B. Selective Incorporation of Host Antigens}

Although cell-specific membrane proteins are generally excluded from the envelope of budding viruses during maturation, this exclusion is not absolute. Calafat et al. (1983) have demonstrated selective incorporation of murine cell-surface $G$ proteins by immuno-electron microscopy with monoclonal antibodies; the Thy-1 G protein was present in the envelope of VSV and murine leukemia virus, but Pgp-1, T200, and the $H-2$ antigens were excluded. Zavada et al. (1983b) demonstrated selective assembly of human cell-surface proteins into VSV envelopes using surface ${ }^{125 I-l a b e l e d}$ human tumor-cell lines and mutant $t s 045(V)$. At least three human tumor-specific antigens were detected in the VSV envelope. Little et al. $(1983 a, b)$ also found that a non-VSV antigen was present in the envelope of VSV grown in HeLa cells, since VSV propagated in HeLa cells was precipitated, although not neutralized, by antisera to HeLa-cell determinants. This non-VSV antigen appeared to correspond to a tumor-specific surface antigen of HeLa cells with a molecular weight of 75,000 . Zavada (1982), in discussing the paradox of unrestricted phenotypic mixing between enveloped viruses and the almost complete exclusion of host proteins, suggested that there may be a common recognition mechanism for specific assembly of virus $G$ proteins. Hence, the cell-surface proteins selected by VSV from human tumor-cell lines may be retrovirus-related gene products. Zavada and Huang (1984) have applied the same approach to analysis of proteins shed in particulate structures in large amounts from several human melanoma-cell lines. They found that the same sets of proteins were present in these structures as assembled into VSV particles propagated in these cell lines, and some of these proteins were antigenically cross-reactive with proteins from HeLa and T47D (breast carcinoma) cells. It was suggested that these proteins might be products of an endogenous human retrovirus.

Polakova et al. (1984) have produced a monoclonal antibody specific for one of these HeLa-cell antigens, using mutant $t s 045(\mathrm{~V})$ propagated in $\mathrm{HeLa}$ cells at $39^{\circ} \mathrm{C}$ because particles devoid of the thermolabile $\mathrm{G}$ protein are produced under these conditions. This technique will facilitate characteristics of these HeLa-cell antigens that appear to be specifically associated with certain tumors or types of tissue. The data of Polakova and co-workers suggest that the tumor antigen recognized by their monoclonal antibody is present in low amounts and that VSV is highly selective and endowed with the ability to concentrate this antigen from the cell surface. 


\section{Pseudotypes as Biological Probes}

Screening for pseudotypes with the genome of VSV and the envelope of a heterologous virus can be an extremely sensitive method for detection of cryptic or latent enveloped viruses (e.g., chick helper factor in avian cells) or as a rapid quantitation assay for slow or non cytopathogenic viruses. The sensitivity of the method can be increased using immunoprecipitation with Staphylococcus aureus rather than neutralization as the detection system (Zavada et al., 1983a). Chandipura virus can be used in place of VSV in situations in which there are veterinary restrictions on use of VSV (Zavada et al., 1979; Zavadova and Zavada, 1980). Analysis of pseudotype production has been employed as a quantitative procedure for detection and assay of bovine leukemia virus (Zavada et al., 1979; Bruck et al., 1982), mouse mammary tumor virus (Chan et al., 1982), and human T-cell lymphoma virus types I and II (Clapham et al., 1984).

\section{SIGMA VIRUS OF DROSOPHILA}

\section{A. General Features}

Sigma virus of Drosophila has been identified as a rhabdovirus on the basis of size and bullet-shaped morphology. The complex biology, assay procedures, and germinal transmission of Sigma virus have been reviewed by Brun and Plus (1980) and Teninges et al. (1980) and will not be considered in detail here. The physical properties of Sigma virus remain uncharacterized, although Richard-Molard et al. (1984) have tentatively identified five virion proteins (p210, gp68, p57, p44, and p28) in partially purified virus from Drosophila tissue culture. The host range of Sigma virus is limited to Drosophila, whereas certain vertebrate rhabdoviruses (VSV, Piry virus, and Chandipura virus, but not rabies virus) can multiply in Drosophila. None of these viruses, Sigma virus included, produces pathogenic effects in insects or cytopathic effects in Drosophila cells in vitro. The vertebrate vesiculoviruses, however, produce the enhanced $\mathrm{CO}_{2}$ sensitivity in adult insects that was earlier considered to be a unique property of Sigma virus. Sigma virus is not contagious and is transmitted germinally.

\section{B. Temperature-Sensitive and Host-Range Mutants}

Temperature-sensitive (ts) mutants and host-range variants have been used by Contamine (1984) to investigate the growth cycle of Sigma virus. Three classes of $t s$ mutants have been defined: The first class (represented 
by ts4) has been designated early mutants (Contamine, 1973) and are mutants defective in hereditary transmission at restrictive temperature $\left(32^{\circ} \mathrm{C}\right)$. These mutants are defective throughout the whole growth cycle, but maturation is not affected. The second class (represented by $t s$ ) / have been designated late mutants (Contamine, 1973) and are mutants defective in maturation. Maternal hereditary transmission is normal at elevated temperature. The third class (represented by haP7) are a second type of early mutants (Contamine, 1980, 1981) that exhibit an early temperature-sensitive phase only; hereditary transmission and maturation are not heat-sensitive. These mutants identify four stages in the growth cycle. At $20^{\circ} \mathrm{C}$, there is a rapid adsorption-penetration phase (approximately 20 $\mathrm{min}$ ), followed by a stage defined by the period of time corresponding to the temperature sensitivity of mutant haP7. This lasts from 0 to $7 \mathrm{hr}$. The next stage corresponds to the period of temperature sensitivity of $t s 4$ and lasts from $4 \mathrm{hr}$ to $60 \mathrm{hr}$, which covers the entire period of genome replication and can be subdivided into an initial phase from 4 to $11 \mathrm{hr}$, an intermediate period from 11 to about $60 \mathrm{hr}$ during which the viral functions necessary to establish the stabilized state are expressed, and a final maturation phase defined by the temperature sensitivity of mutant ts9. The prolonged growth cycle is due to the presence of a particular restrictive allele $[$ ref (3)D] of one of the host controlling genes.

At least five independent loci in Drosophila influence Sigma virus growth. The haP mutants of Sigma virus referred to above (many of which are also temperature-sensitive) were selected for specific resistance to gene $r e f(2) P^{p}$. By this procedure, a range of haP mutants was obtained with a spectrum of host-restricted phenotypes. It was concluded that the haP phenotype represents mutation affecting a viral protein-genome complex, whereby virus interactions with any of the five independent host genes affecting Sigma virus replication may be modified (Coulon and Contamine, 1982; Contamine, 1984).

\section{FUTURE PROSPECTS}

Reverse mutagenesis and ability to express individual genes in vitro in different genetic environments will open up the study of the functional activity of rhabdovirus genes. The sequencing of variants selected for resistance to neutralization by monoclonal antibodies has initiated study of the effect of mutation at the level of secondary structure, a crucial stage in progress toward understanding of gene function.

The diversity of the family Rhabdoviridae awaits exploration.

ACKNOWLEDGMENTS. I am indebted to the many colleagues who supplied information prior to publication, and in particular to Duncan McGeoch, who made available unpublished results for inclusion in this chapter. 


\section{REFERENCES}

Agol, V. I., Grachev, V. P., Drozdov, S. G., Kolesnikova, M. S., Kozlov, V. G., Ralph, N. M., Romanova, L. I., Tolskaya, E. A., Tyafanov, A. V., and Viktorova, E. G., 1984, Construction and properties of intertypic poliovirus recombinants: First approximation mapping of the major determinants of virulence, Virology 136:41.

Akashi, H., Gay, M., Ihara, T., and Bishop, D. H. L., 1984, Localised conserved regions of the SRNA gene products of bunyaviruses are revealed by sequence analyses of the Simba serogroup Aino virus, Virus Res. 1:51.

Anilionis, A., Wunner, W. H., and Curtis, P. J., 1981, Structure of the glycoprotein gene in rabies virus, Nature (London) 294:275.

Aubert, M. F. A., Bussereau, F., and Blancon, J., 1980, Pathogenic, immunogenic and protective powers of ten temperature sensitive mutants of rabies virus in mice, Ann. Virol. (Inst. Pasteur) 131E:217.

Auperin, D. D., Romanowski, V., Galinski, M., and Bishop, D. H. L., 1984, Sequencing studies of Pichinde arenavirus S RNA indicate a movel coding strategy, an ambisense viral S RNA, J. Virol. 52:897.

Banerjee, A. K., Rhodes, D. P., and Gill, D. S., 1984, Complete sequence of the mRNA coding for the $\mathrm{N}$ protein of vesicular stomatitis virus (New Jersey serotype), Virology 137:432.

Bay, P. H. S., and Reichmann, M. E., 1979, UV inactivation of the biological activity of defective interfering particles generated by vesicular stomatitis virus, J. Virol.32:876.

Bell, J. C., and Prevec, L., 1985, Phosphorylation sites on phosphoprotein NS of vesicular stomatitis virus. J. Virol. 54:697.

Belle-Isle, H. D., and Emerson, S. U., 1982, Use of a hybrid infectivity assay to analyse primary transcription of temperature-sensitive mutants of the New Jersey serotype of vesicular stomatitis virus, $J$. Virol. 43:37.

Bergmann, J. E., Tokuyasu, K. T., and Singer, S. J., 1981, Passage of an integral membrane protein, the vesicular stomatitis virus glycoprotein, through the Golgi apparatus en route to the plasma membrane, Proc. Natl. Acad. Sci. U.S.A. 78:1746.

Blumberg, B. M., Giorgio, C., and Kolakofsky, D., 1983, N protein of vesicular stomatitis virus selectively encapsidates leader RNA in vitro, Cell 32:559.

Brand, C., and Palese, P., 1980, Sequential passage of influenza virus in embryonated egg or tissue culture: Emergence of mutants, Virology 107:424.

Brown, E., and Prevec, L., 1982, Characterization of the electrophoretic mobility mutation in the $\mathrm{N}$ protein of the $t s \mathrm{D} 1$ mutant of vesicular stomatitis virus New Jersey serotype, Can. J. Biochem. 60:1065.

Brown, F., Bishop, D. H. L., Crick, J., Francki, R. I. B., Holland, J. J., Hall, R., Johnson, K., Martelli, G., Murphy, F. A., Obijeski, J. F., Peters, D., Pringle, C. R., Reichmann, M. E., Schneider, L. G., Shope, R. E., Simpson, D. I. H., Summers, D. F., and Wagner, R. R., 1979, Rhabdoviridae, Intervirology 12:1.

Bruck, C., Portelle, D., Burny, A., and Zavada, J., 1982, Topographical analysis by monoclonal antibodies of BLV-gp 51 epitopes involved in viral functions, Virology 122:353.

Brun, G., 1963, Etude d'une association du virus et de son hôte la drosophile: 1'Etat stabilisée, Thèse Biol. Exp.

Brun, G., 1981, Are the Drosophila ref genes for Piry and Sigma rhabdoviruses identical?, in: The Replication of Negative Strand Viruses (D. H. L. Bishop and R. W. Compans, eds.), pp. 921-928, Elsevier/North-Holland, New York.

Brun, G., 1984, Host-range mutants of Piry virus: A new type of mutant in Drosophila, in: Negative Strand Viruses: Paramyxoviruses and Rhabdoviruses (D. H. L. Bishop and R. W. Compans, eds.), pp. 413-420, Academic Press, Orlando, Florida.

Brun, G., and Plus, N., 1980, The viruses of Drosophila, in: The Genetics and Biology of Drosophila (M. Ashburner and T. R. F. Wright, eds.), pp. 625-693, Academic Press, London. 
Buller, R. M. L., 1975, Biological and biochemical characterization of vesicular stomatitis virus and temperature-sensitive maturation mutants, Ph.D. thesis, University of Glasgow.

Bussereau, F., and Flamand, A., 1978, Isolation and preliminary characterization of $t s \mathrm{mu}$ tants of rabies virus, in: Negative Strand Viruses and the Host Cell (B. W. J. Mahy and R. D. Barry, eds.), pp. 701-708, Academic Press, New York.

Bussereau, F., Benejean, J., and Saghi, N., 1982, Isolation and study of temperature-sensitive mutants of rabies virus, J. Gen. Virol. 60:153.

Byrd, A. D., Kennedy-Morrow, J., Marks, M. D., and Lesnaw, J. A., 1984, Functional relationships within the New Jersey serotype of vesicular stomatitis virus: Genetic and physiological comparisons of the Hazelhurst and Concan subtypes, J. Gen. Virol. 65:1769.

Calafat, J., Janssen, H., Demant, P., Helgers, J., and Zavada, J., 1983, Specific selection of host cell glycoproteins during assembly of murine leukaemia virus and vesicular stomatitis virus: Presence of Thy-1 glycoprotein and absence of H-2, Pgp-1 and T-200 glycoproteins on the envelopes of these virus particles, J. Gen. Virol. 64:1241.

Carroll, A. R., and Wagner, R. R., 1979, Role of the membrane protein in endogenous inhibition of in vitro transcription by vesicular stomatitis virus, $J$. Virol. 29:134.

Chan, J. C., East, J. L., Bowen, J. M., Massey, R., and Schochetman, G., 1982, Monoclonal and polyclonal antibody studies of VSV (hr MMTV) pseudotypes, Virology 120:54.

Chatis, P. A., and Morrison, T. G., 1981, Mutational changes in the VSV glycoprotein affect the requirement of carbohydrate in morphogenesis, J. Virol. 37:307.

Chatteriee, P. K., Cervera, M. M., and Penman, S., 1984, Formation of vesicular stomatitis virus nucleocapsid from cytoskeletal framework-bound $\mathrm{N}$ protein: Possible model for structure assembly, Mol. Cell. Biol. 4:2231.

Chen, C.-Y., and Crouch, N. A., 1978, Shope fibroma virus-induced facilitation of vesicular stomatitis virus adsorption and replication in nonpermissive cells, Virology 85:43.

Chen, S. S.-L., and Huang, A. S., 1986, Further characterization of the vesicular stomatitis virus temperature-sensitive 045 mutant: Intracellular conversion of the glycoprotein to a soluble form, $J$. Virol. 59:210.

Chou, P. Y., and Fasman, G. D., 1978, Prediction of the secondary structure of proteins from their amino acid sequence, $A d v$. Enzymol. 47:45.

Clapham, P., Nagy, K., and Weiss, R. A., 1984, Pseudotypes of human T-cell leukemia virus types 1 and 2: Neutralization by patients' sera, Proc. Natl. Acad. Sci. U.S.A. 81:2886.

Clark, H. F., 1978, Rabies viruses increase in virulence when propagated in neuroblastoma cell culture, Science 199:1072.

Clark, H. F., and Koprowski, H., 1971, Isolation of $t s$ conditional lethal mutants of "fixed" rabies virus, $J$. Virol. 7:295.

Clark, H. F., and Wiktor, T. J., 1974, Plasticity of phenotypic characters of rabies related viruses: Spontaneous variation in plaque morphology, virulence and temperature-sensitivity characters of serially propagated Lagos bat and Mokola viruses, I. Infect. Dis. 130:608.

Clewley, J. P., Bishop, D. H. L., Kang, C. Y., Coffin, J., Schnitzlein, W. M., Reichmann, M. E., and Shope, R. E., 1977, Oligonucleotide fingerprints of RNA species obtained from rhabdoviruses belonging to the vesicular stomatitis virus subgroup, I Virol. 23:152.

Contamine, D., 1973, Etude de mutants thermosensibles du virus Sigma, Mol. Gen. Genet. 124:233.

Contamine, D., 1980, Two types of early mutants among temperature-sensitive mutants of Drosophila Sigma virus, Ann. Virol. (Inst. Pasteur) 131E:113.

Contamine, D., 1981, Role of the Drosophila genome in Sigma virus multiplication. I. Role of the ref (2) $P$ gene; selection of host-adapted mutants at the non-permissive allele $\mathrm{P}$, Virology 114:474.

Contamine, D., 1984, The late functions of Drosophila Sigma virus, Arch. Virol. 82:31.

Cormack, D. V., Holloway, A. F., and Pringle, C. R., 1973, Temperature-sensitive mutants of vesicular stomatitis virus: Homology and nomenclature, J. Gen. Virol. 19:295. 
Cooper, P. D., and Bellett, A. J. D., 1959, A transmissible interfering component of vesicular stomatitis virus preparations, J. Gen. Microbiol. 21:485.

Coulon, P., and Contamine, D., 1982, Role of the Drosophila genome in sigma virus multiplication. II. Host spectrum variants among haP mutants, Virology 123:381.

Coulon, P., Rollin, P. E., and Flamand, A., 1983, Molecular basis of rabies virus virulence. II. Identification of a site on the CVS glycoprotein associated with virulence, I. Gen. Virol., 64:693.

Creager, R. S., Cardamone, J. J., and Youngner, J. S., 1981, Human lymphoblastoid cell lines of B- and T cell origin: Different responses to infection with vesicular stomatitis virus, Virology 111:211.

Creager, R. S., Whitaker-Dowling, P., Frey, T. K., and Youngner, J. S., 1982, Varied response of human B-lymphoblastoid cell lines to infection with vesicular stomatitis virus, Virology 121:414.

Davis, N. L., Arnheiter, H., and Wertz, G. W., 1986, Vesicular stomatitis virus $\mathrm{N}$ and NS proteins form multiple complexes, I. Virol. 59:751.

Deutsch, V., 1975, Nongenetic complementation of group V temperature-sensitive mutants of vesicular stomatitis virus by UV-irradiated virus, $J$. Virol. 15:788.

Deutsch, V., 1976, Parental G protein reincorporation by a vesicular stomatitis virus temperature-sensitive mutants of complementation group $\mathrm{V}$ at nonpermissive temperature, Virology 69:607.

Deutsch, V., Muel, B., and Brun, G., 1977, Action spectra for the rescue of temperaturesensitive mutants of vesicular stomatitis virus by ultraviolet-irradiated virions at nonpermissive temperature, Virology 77:294.

Deutsch, V., Muel, B., and Brun, G., 1979, Temperature-sensitive mutant $t$ s 082 of vesicular stomatitis virus. 1 . Rescue at non-permissive temperature by UV-irradiated virus, Virology 93:286-290.

Dietzschold, B., Wunner, W. H., Wiktor, T. J., Lopes, A. D., Lafon, M., Smith, C. L., and Koprowski, H., 1983, Characterization of an antigenic determinant of the glycoprotein that correlates with pathogenesis of rabies virus, Proc. Natl. Acad. Sci. U.S.A. 80:70.

Doyle, M., and Holland, J. J., 1973, Prophylaxis and immunization in mice by use of virusfree defective $\mathrm{T}$ particles to protect against intracerebral infection by vesicular stomatitis virus, Proc. Natl. Acad. Sci. USA 70:2105.

Duhamel, C., 1954, Etude de la sensibilité hereditaire a l'anhydride carbonique chez la Drosophile: Description de quelques variants du virus, C. R. Acad. Sci. 239:1157.

Evans, D., Pringle, C. R., and Szilagyi, J. J., 1979, Temperature-sensitive mutants of complementation group E vesicular stomatitis virus New Jersey serotype possess altered NS polypeptides, I. Virol. 31:325.

Flamand, A., 1970, Etude génétique du virus de la stomatite vesiculaire: Classement de mutants thermosensibles spontanées en groupes de complementation, J. Gen. Virol. 8:187.

Flamand, A., 1980, Rhabdovirus genetics, in: Rhabdoviruses, Vol. II (D. H. L. Bishop, ed.), pp. 115-140, CRC Press, Boca Raton, Florida.

Flamand, A., and Delagneau, J. F., 1978, Transcriptional mapping of rabies virus in vivo, $J$. Virol. 28:518.

Flamand, A., and Pringle, C. R., 1971, The homologies of spontaneous and induced temperature-sensitive mutants of vesicular stomatitis virus isolated in chick embryo and BHK-21 cells, J. Gen. Virol. 11:81.

Francoeur, A. M., Lam, T., and Stanners, C. P., 1980, PIF, a highly sensitive plaque assay for induction of interferon, Virology 105:526.

Freeman, G. J., and Huang, A. S., 1981, Mapping temperature-sensitive mutants of vesicular stomatitis virus by RNA heteroduplex formation, J. Gen. Virol. 57:103.

Frey, T. K., and Youngner, J. S., 1982, Novel phenotype of RNA synthesis expressed by vesicular stomatitis virus isolated from persistent infections, I. Virol. 44:167.

Frey, T. K., Frielle, D. W., and Youngner, J. S., 1981, Standard vesicular stomatitis virus is required for interferon induction in $\mathrm{L}$ cells by defective interfering particles, in: The 
Replication of Negative Strand Viruses (D. H. L. Bishop and R. W. Compans, eds.), pp. 901-907, Elsevier/North-Holland, New York.

Fultz, P. N., Shadduck, J. A., Kang, C. Y., and Streilein, J. W., 1981, Genetic analysis of resistance to lethal infections of vesicular stomatitis virus in Syrian hamsters, Infect. Immun. 32:1007.

Fultz, P. N., Shadduck, J. A., Kang, C. Y., and Streilein, J. W., 1982, Mediators of protection against lethal systemic vesicular stomatitis virus infection in hamsters: Defective interfering particles, polyinosinate-polycytidylate, and interferon, Infect. Immun. 37:679.

Gadkari, D. A., and Pringle, C. R., 1980a, Temperature-sensitive mutants of Chandipura virus. I. Inter- and intra-group complementation, J. Virol. 33:100.

Gadkari, D. A., and Pringle, C. R., 1980b, Temperature-sensitive mutants of Chandipura virus. II. Phenotype characteristics of the six complementation groups. J. Virol. 32:107.

Gallione, C. J., and Rose, J. K., 1983, Nucleotide sequence of a cDNA clone encoding the entire glycoprotein from the New Jersey serotype of vesicular stomatitis virus, $J$. Virol. 46:162.

Gallione, C. J., and Rose, J. K., 1985, A single amino acid substitution in a hydrophobic domain causes temperature sensitive cell-surface transport of a mutant viral glycoprotein, J. Virol. 54:374.

Gallione, C. J., Greene, J. R., Iverson, L. E., and Rose, J. K., 1981, Nucleotide sequences of the mRNA's encoding the vesicular stomatitis virus $\mathbf{N}$ and NS proteins, J. Virol. 39:529.

Genty, N., 1975, Analysis of uridine incorporation in chicken embryo cells infected by vesicular stomatitis virus and its temperature sensitive mutants: Uridine transport, $J$. Virol. 15:8.

Gill, D. S., and Baneriee, A. K., 1985, Vesicular stomatitis virus NS proteins: Structural similarity without extensive sequence homology, $J$. Virol. 55:60.

Gillies, S., and Stollar, V., 1980, Generation of defective interfering particles of vesicular stomatitis virus in Aedes albopictus cells, Virology 107:497.

Goldstein, L., 1949, Contribution a l'étude de la sensibilité hereditaire au gaz carbonique chez la Drosophile: Mise en évidence d'une forme nouvelle du génoide, Bull. Biol. Fr. Belg. 83:177.

Gopalakrishna, Y., and Lenard, J., 1985, Sequence alterations in the temperature-sensitive M-protein mutants (complementation group III) of vesicular stomatitis virus, $J$. Virol. 56:655.

Grinell, B., and Wagner, R. R., 1983, Comparative inhibition of cellular transcription by vesicular stomatitis virus serotypes New Jersey and Indiana: Role of each viral leader RNA, J. Virol. 48:88.

Grinnell, B. W., and Wagner, R. R., 1984, Nucleotide sequence and secondary structure of VSV leader RNA and homologous DNA involved in inhibition of DNA-dependent transcription, Cell 36:533.

Guillemain, A., 1953, Découverte et localization d'une gene empêchant le multiplication du virus de la sensibilité hereditaire au $\mathrm{CO}_{2}$ chez D. M., C. R. Acad. Sci. 236:1085.

Hamilton, D. H., Moyer R. W., and Moyer, S. A., 1980, Characterization of the non-permissive infection of rabbit cornea cells by vesicular stomatitis virus, J. Gen. Virol. 49:273.

Herman, R. C., 1986, Internal initiation of translation on the vesicular stomatitis virus phosphoprotein mRNA yields a second protein, J. Virol. 58:797.

Hill, V. M., Harmon, S. A., and Summers, D. F., 1986, Stimulation of vesicular stomatitis virus in vitro RNA synthesis by microtubule-associated protein, Proc. Natl. Acad. Sci. U.S.A. 83:5410.

Holland, J. J., and Villareal, L. P., 1974, Persistent noncytocidal vesicular stomatitis virus infections mediated by defective $\mathrm{T}$ particles that suppress virion transcriptase, Proc. Natl. Acad. Sci. U.S.A. 71:2956.

Holland, J. J., Villareal, L. P., and Breindl, M., 1976, Factors involved in the generation and replication of rhabdovirus defective T particles, J. Virol. 17:805. 
Holland, J. J., Kennedy, S. I. T., Semler, B. L., Jones, C. L., Roux, L., and Grabau, E. A., 1980, Defective interfering RNA viruses and the host cell response, in: Comprehensive Virology, Vol. 16 (H. Fraenkel-Conrat and R. R. Wagner, eds.), pp. 137-192, Plenum Press, New York.

Holland, J. J., Spindler, K. R., Horodyski, F. M., Grubau, E. A., Nichol, S. T., and VandePol, S., 1982, Rapid evolution of RNA genomes, Science 215:1577.

Holloway, A. F., Wong, P. K. Y., and Cormack, D. V., 1970, Isolation and characterization of temperature-sensitive mutants of vesicular stomatitis virus, Virology 42:917.

Horikami, S. M., and Moyer, S. A., 1982, Host range mutants of vesicular stomatitis virus defective in in vitro RNA methylation, Proc. Natl. Acad. Sci. U.S.A. 79:7694.

Horikami, S. M., De Ferra, F., and Moyer, S. A., 1984, Characterization of the infections of permissive and non-permissive cells by host range mutants of vesicular stomatitis virus defective in RNA methylation, Virology 138:1.

Horodyski, F. M., and Holland, J. J., 1980, Virus isolated from cells persistently infected with vesicular stomatitis virus show altered interations with defective interfering particles, I. Virol. 36:627.

Horodyski, F. M., and Holland, J. J., 1981, Continuing evolution of virus-DI particle interaction during VSV persistent infection, in: The Replication of Negative Strand Viruses (D. H. L. Bishop and R. W. Compans, eds.), pp. 887-892, Elsevier/North-Holland, New York.

Horodyski, F. M., and Holland, J. J., 1984, Reconstruction experiments demonstrating selective effects of defective interfering particles on mixed populations of vesicular stomatitis virus, J. Gen. Virol. 65:819.

Horodyski, F. M., Nichol, S. T., Spindler, K. R., and Holland, J. J., 1983, Properties of DI particle-resistant mutants of vesicular stomatitis virus isolated from persistent infections and from undiluted passages, Cell 33:801.

Hsu, C-H., and Kingsbury, D. W., 1985, Constitutively phosphorylated residues in the NS protein of vesicular stomatitis virus, J. Biol. Chem. 260:8990.

Huang, A. S., Palma, E. L., Hewlett, M., and Roizman, B., 1974, Pseudotype formation between enveloped RNA and DNA viruses, Nature (London) 252:743.

Hudson, L. D., Condra, C., and Lazzarini, R. A., 1986, Cloning and expression of a viral phosphoprotein: Structure suggests vesicular stomatitis virus NS may function by mimicking an RNA template, J. Gen. Virol. 67:1571.

Hughes, J. V., and Johnson, T. C., 1981, Alteration in peptide structure of vesicular stomatitis virus mutant and its central nervous system isolate, J. Gen. Virol. 53:309.

Hunt, D. M., 1983, Vesicular stomatitis virus mutant with altered polyadenylic acid polymerase activity in vitro, $J$. Virol. 46:788.

Hunt, D. M., Emerson, S. U., and Wagner, R. R., 1976, RNA-negative temperature-sensitive mutants of vesicular stomatitis virus: $\mathrm{L}$ protein thermosensitivity accounts for transcriptase restriction of group I mutants, J. Virol. 18:596.

Hunt, D. M., Smith, E. F., and Buckley, D. W., 1984, Aberrant polyadenylation by a vesicular stomatitis virus mutant is due to an altered L protein, J. Virol. 52:515.

Huprikar, J., Rabinowitz, S. G., Dal Canto, M. C., and Rundell, M. K., 1986, Persistent infection of a temperature-sensitive G31 vesicular stomatitis virus mutant in neural and nonneural cells; biological and virological characteristics, I. Virol. 58:493.

Iverson, L. E., and Rose, J. K., 1981, Localized attenuation and discontinuous synthesis during vesicular stomatitis virus transcription, Cell 23:477.

Johnson, G. P., and Herman, R. C., 1984, Non-permissive infection of lymphoblastoid cells by vesicular stomatitis virus. I. Synthesis and function of the viral transcripts, Virus Res. 1:259.

Kang, C. Y., and Allen, R., 1978, Host function dependent induction of defective interfering particles of vesicular stomatitis virus, J. Virol. 25:202.

Kang, C. Y., Weide, L. G., and Tischfield, J. A., 1981, Suppression of vesicular stomatitis virus defective interfering particle generation by a function(s) associated with human chromosome 16, J. Virol. 40:946. 
Kawai, A., and Matsumoto, S., 1977, Interfering and noninterfering defective particles generated by a rabies small plaque variant virus, Virology 76:60.

Keene, J. D., Schubert, M., and Lazzarini, R. A., 1979, Terminal sequences of vesicular stomatitis virus RNA are both complementary and conserved, J. Virol. 32:167.

Keene, J. D., Schubert, M., and Lazzarini, R. A., 1980, Intervening sequence between the leader region and the nucleocapsid gene of vesicular stomatitis virus RNA, $J$. Virol. 33:789.

Keene, J. D., Chien, I. M., and Lazzarini, R. A., 1981a, Vesicular stomatitis virus defective particle contains a muted internal leader RNA gene, Proc. Natl. Acad. Sci. U.S.A. 78:2090.

Keene, J. D., Thornton, B. T., and Emerson, S. U., 1981b, Sequence-specific contacts between the RNA polymerase of vesicular stomatitis virus and the leader RNA gene, Proc. Natl. Acad. Sci. U.S.A. 78:6191.

Kennedy-Morrow, J., and Lesnaw, J. A., 1984, Structural and functional characterization of the RNA-positive complementation groups, C and D, of the New Jersey serotype of vesicular stomatitis virus: Assignment of the $M$ gene to the $C$ complementation group, Virology 132:38.

King, A. M. Q., McCahon, D., Slade, W. R., and Newman, J. W. I., 1982, Recombination in RNA, Cell 29:921.

Knipe, D., Lodish, H. F., and Baltimore, D., 1977, Analysis of the defects of temperaturesensitive mutants of vesicular stomatitis virus: Intracellular degradation of specific viral proteins, $J$. Virol. 21:1140.

Kotwal, G. J., Capone J., Irving, R., Rhee, S. H., Bilan, P., Toneguzzo, F., Hotmann, T., and Ghosh, H. P., 1983, Viral membrane glycoproteins: Comparison of the amino terminal amino acid sequences of the precursor and mature glycoproteins of three serotypes of vesicular stomatitis virus, Virology 129:1.

Kotwal, G. J., Buller, R. M. L., Wunner, W. H., Pringle, C. R., and Ghosh, H. P., 1986, Role of glycosylation in transport of vesicular stomatitis virus envelope glycoprotein. A new class of mutant defection in glycosylation and transport of G protein. J. Biol. Chem. $261 ; 8936$.

Kurath, G., and Leong, J. C., 1985, Characterization of infectious hematopoietic necrosis virus mRNA species reveals a nonvirion rhabdovirus protein, $J$. Virol. 53:462.

Kurath, G., Ahern, K. G., Pearson, G. D., and Leong, J. C., 1985, Molecular cloning of the six mRNA species of infectious hematopoietic necrosis virus, a fish rhabdovirus, and gene order determination by R loop mapping, J. Virol. 53:469.

Kurilla, M. G., and Keene, J. D., 1983, The leader RNA of vesicular stomatitis virus is bound by a cellular protein reactive with anti-La lupus antibodies, Cell 34:837.

Kurilla, M. G., Piwnica-Worms, H., and Keene, J. D., 1982, Rapid and transient localization of the leader RNA of VSV in the nuclei of infected cells, Proc. Natl. Acad. Sci. U.S.A. 79:5240.

Kurilla, M. G., Cabradilla, C. D., Holloway, B. P., and Keene, J. D., 1984, Nucleotide sequence and host La protein interactions of rabies virus leader RNA, J. Virol. 50:773.

Lafay, F., and Benejean, J., 1981, Temperature-sensitive mutants of vesicular stomatitis virus: Tryptic peptide maps of the proteins modified in complementation groups II and IV, Virology 111:93.

Lafon, M., Wiktor, T. J., and Macfarlan, R. I., 1983, Antigenic sites on the CVS rabies virus glycoprotein: Analysis with monoclonal antibodies, J. Gen. Virol. 64:843.

Lai, M. M. C., Baric, R. S., Makino, S., Keck, J. G., Egbert, J., Leibowitz, J. L., and Stohlman, S. A., 1985, Recombination between nonsegmented RNA genomes of murine coronaviruses, J. Virol. 56:449.

Lazzarini, R. A., Keene, J. D., and Schubert, M., 1981, The origin of defective interfering particles of the negative-strand RNA viruses, Cell 26:145.

Lenard, J., Wilson, T., Mancarella, D., Reidler, J., Keller, P., and Elson, E., 1981, Interaction of mutant and wild type $M$ protein of vesicular stomatitis virus with nucleocapsids and membranes, in: The Replication of Negative Strand Viruses (D. H. L. Bishop and R. W. Compans, eds.), pp. 855-863, Elsevier/North-Holland, New York. 
Lentz, T. L., Wilson, P. T., Hawrot, E., and Speicher, D. W., 1984, Amino acid sequence similarity between rabies virus glycoprotein and snake venom curaremimetic neurotoxins, Science 226:847.

Lesnaw, J. A., Dickson, L. R., and Curry, R. H., 1979, Proposed replicative role of the NS polypeptide of vesicular stomatitis virus: Structural analysis of an electrophoretic variant, J. Virol. 31:8.

Levinson, W., Oppermann, H., Rubinstein, P., and Jackson, L., 1978, Host range restrictions of vesicular stomatitis virus on duck embryo cells, Virology 85:612.

Little, L. M., Lanman, G., and Huang, A. S., 1983a, Immunoprecipitating human antigens associated with vesicular stomatitis virus grown in HeLa cells, Virology 129:127.

Little, L. M., Zavada, J., Der, C. J., and Huang, A. S., 1983b, Identity of HeLa cell determinants acquired by vesicular stomatitis virus with a tumor antigen, Science 220:1069.

Lodish, H. F., and Porter, M., 1981, Vesicular stomatitis virus mRNA and inhibition of translation of cellular mRNA-is there a P function in vesicular stomatitis virus?, J. Virol. 38:504.

Lodish, H. F., and Weiss, R. A., 1979, Selective isolation of mutants of vesicular stomatitis virus defective in production of the viral glycoprotein, J. Virol. 30:177.

Lodmell, D. L., and Chesebro, B., 1984, Murine resistance to street rabies virus: Genetic analysis by testing second-backcross progeny and verification of allelic resistance genes in SJL/J and CBA/J mice, I. Virol. 50:359.

Lodmell, D. L., and Ewalt, L. C., 1985, Pathogenesis of street rabies virus infections in resistant and susceptible strains of mice, J. Virol. 55:788.

Maack, C. A., and Penhoet, E. E., 1980, Biochemical characterization of the $t s \mathrm{El}$ mutant of vesicular stomatitis virus (New Jersey), J. Biol. Chem. 255:9249.

Marcus, P., and Sekellick, M. J., 1980, Cell-killing by vesicular stomatitis virus: The prototype rhabdovirus, in: Rhabdoviruses, Vol. III (D. H. L. Bishop, ed.), pp. 13-50, CRC Press, Boca Raton, Florida.

Marks, D. M., Kennedy-Morrow, J., and Lesnaw, J. A., 1985, Assignment of the temperaturesensitive lesion in the replication mutant $t s \mathrm{Al}$ of vesicular stomatitis virus to the $\mathrm{N}$ gene, J. Virol. 53:44.

Matsumoto, S., 1970, Rabies virus, $A d v$. Virus Res. 16:257.

Matthews, R. E. F., 1982, Classification and nomenclature of viruses: Fourth report of the International Committee on Taxonomy of Viruses, Intervirology 17:1.

McGeoch, D. J., 1979, Structure of the gene N : gene NS intercistronic junction in the genome of VSV, Cell 17:673.

McGeoch, D. J., 1981, Structural analysis of animal virus genomes, J. Gen. Virol. 55:1.

McGeoch, D. J., Dolan, A., and Pringle, C. R., 1980, Comparison of nucleotide sequences in the genomes of the New Jersey and Indiana serotypes of vesicular stomatitis virus, J. Virol. 33:69.

McGowan, J. J., Emerson, S. U., and Wagner, R. R., 1982, The plus strand leader RNA of vesicular stomatitis virus inhibits DNA-dependent transcription of adenovirus and SV40 genes in a soluble whole cell extract, Cell 28:325.

Meier, E., Harmison, G. G., Keene, J. D., and Schubert, M., 1984, Sites of copy choice replication involved in generation of vesicular stomatitis virus defective interfering particle RNAs, I. Virol. 51:515.

Metzel, P. S., and Reichmann, M. E., 1981, Characterization of vesicular stomatitis virus mutants by partial proteolysis, J. Virol. 37:248.

Moreau, M.-C., 1974, Inhibition of a vesicular stomatitis virus mutant by rifampin, $J$. Virol. 14:517.

Morrongiello, M. P., and Simpson, R. W., 1979, Conditional lethal mutants of vesicular stomatitis virus. 4. RNA species detected in non-permissive cells infected with host restricted mutants, Virology 93:506.

Moyer, S. A., Horikami, S. M., and Moyer, R. W., 1981, The effect of the host cell and heterologous viruses on VSV production, in: The Replication of Negative Strand Viruses (D. H. L. Bishop and R. W. Compans, eds.), pp. 965-970, Elsevier/North-Holland, New York. 
Moyer, S. A., Baker, S. C., and Lessard, J. L., 1986, Tubulin: A factor necessary for the synthesis of both Sendai virus and vesicular stomatitis virus RNAs, Proc. Natl. Acad. Sci. U.S.A. 83:5405.

Mudd, J. A., Leavitt, R. W., Kingsbury, D. T., and Holland, J. J., 1973, Natural selection of mutants of vesicular stomatitis virus by cultured cells of Drosophila melanogaster, $I$. Gen. Virol. 20:341.

Nichol, S. T., O'Hara, P. J., Holland, J. J., and Perrault, J., 1984, Structure and origin of a novel class of defective interfering particle of vesicular stomatitis virus, Nucleic Acids Res. 12:2775.

Nilsen, T. W., Wood, D. L., and Baglioni, C., 1981, Cross-linking of viral RNA by 4'aminomethyl-4,5',8-trimethylpsoralen in HeLa cells infected with encephalomyocarditis virus and the $t s$ G114 mutant of vesicular stomatitis virus, Virology 109:82.

Nowakowski, M., Bloom, B. R., Ehrenfeld, E., and Summers, D. F., 1973, Restricted replication of vesicular stomatitis virus in human lymphoblastoid cells, J. Virol. 12:1272.

Obijeski, J. F., and Simpson, R. W., 1974, Conditional lethal mutants of vesicular stomatitis virus. II. Synthesis of virus-specific polypeptides in non-permissive cells infected with "RNA - " host restricted mutants, Virology 57:369.

Ohanessian-Guillemain, A., 1959, Etude génétique du virus hereditaire de la Drosophile (o); Mutations et recombination génétique, Ann. Genet. 1:59.

O'Hara, P. J., Nichol, S. T., Horodyski, F. M., and Holland, J. J., 1984, Vesicular stomatitis virus defective interfering particles can contain extensive genomic sequence rearrangements and base substitutions, Cell 36:915.

Ongradi, J., Cunningham, C., and Szilagyi, J. F., 1985a, The role of polypeptides L and NS in the transcription process of vesicular stomatitis virus New Jersey using the temperature-sensitive mutant tsE1, J. Gen. Virol. 66:1011.

Ongradi, J., Cunningham, C., and Szilagyi, J. F., 1985b, Temperature sensitivity of the transcriptase of mutants $t s \mathrm{~B} 1$ and $t s \mathrm{~F} 1$ of vesicular stomatitis virus New Jersey is a consequence of mutation affecting polypeptide L, J. Gen. Virol. 66:1507.

Pal, R., Grinnell, B. W., Snyder, R. M., and Wagner, R. R., 1986, Regulation of viral transcription by the matrix protein of vesicular stomatitis virus probed by monoclonal antibodies and temperature-sensitive mutants, $J$. Virol. 56:386.

Perrault, J., 1981, Origin and replication of defective interfering particles, Curr. Top. Microbiol. Immunol. 93:151.

Perrault, J., and Leavitt, R. W., 1977, Inverted complementary terminal sequences in singlestranded RNAs and snap-back RNAs from vesicular stomatitis virus defective interfering particles, J. Gen. Virol. 38:35.

Perrault, J., Lane, J. L., and McClure, M. A., 1981, In vitro transcription alterations in a vesicular stomatitis virus variant, in: The Replication of Negative Strand Viruses (D. H. L. Bishop and R. W. Compans, eds.), pp. 829-836, Elsevier/North-Holland, New York.

Perrault, J., Clinton, G. M., and McClure, M. A., 1983, RNP template of vesicular stomatitis virus regulates transcription and replication functions, Cell 35:175.

Pittman, D., 1965, Temperature-sensitive mutants of a rod-shaped RNA animal virus, $G e$ netics 52:468.

Poirot, M. K., Schnitzlein, W. N., and Reichmann, M. E., 1985, The requirement of protein synthesis and VSV inhibition of host cell RNA synthesis, Virology 140:91.

Polakova, K., Zavadova, Z., Zavada, J., and Russ, G., 1984, Monoclonal antibody against an antigen selectively assembled into vesicular stomatitis virus virions from HeLa cells, Int. J. Cancer 34:91.

Portner, A., Webster, R. G., and Bean, W. H., 1980, Similar frequencies of antigenic variation in Sendai virus, vesicular stomatitis virus and influenza A virus, Virology 104:235.

Pringle, C. R., 1970, Genetic characteristics of conditional lethal mutants of vesicular stomatitis virus induced by 5-fluorouracil, 5-azacytidine and ethyl methane sulphinate, J. Virol. 5:559.

Pringle, C. R., 1975, Conditional lethal mutants of vesicular stomatitis virus, Curr. Top. Microbiol. Immunol. 69:85. 
Pringle, C. R., 1977, Genetics of rhabdoviruses, in: Comprehensive Virology, Vol. 9 (H. Fraenkel-Conrat and R. R. Wagner, eds.), pp. 239-290, Plenum Press, New York.

Pringle, C. R., 1978, The $t d \mathrm{CE}$ and $h r C E$ phenotypes: Host range mutants of vesicular stomatitis virus in which polymerase function is affected, Cell 15:597.

Pringle, C. R., 1982, The genetics of vesiculoviruses, Arch. Virol. 72:1.

Pringle, C. R., and Wunner, W. H., 1973, Genetic and physiological properties of temperature-sensitive mutants of Cocal virus, J. Virol. 12:677.

Pringle, C. R., and Wunner, W. H., 1975, A comparative study of the structure and function of the VSV genome, in: Negative Strand Viruses, Vol. 2 (B. W. J. Mahy and R. D. Barry, eds.), pp. 707-723, Academic Press, New York.

Pringle, C. R., and Szilagyi, J. F., 1980, Gene assignment and complementation group, in: Rhabdoviruses, Vol. II (D. H. L. Bishop, ed.), pp. 141-161, CRC Press, Boca Raton, Florida.

Pringle, C. R., Duncan, I. B., and Stevenson, M., 1971, Isolation and characterization of temperature-sensitive mutants of vesicular stomatitis virus, New Jersey serotype, $J$. Virol. 8:836.

Pringle, C. R., Devine, V., Wilkie, M., Preston, C. M., Dolan, A., and McGeoch, D. J., 1981, Enhanced mutability associated with a temperature-sensitive mutant of vesicular stomatitis virus, J. Virol. 39:377.

Printz, P., 1970, Adaptation du virus de la stomatite vesiculaire à Drosophila melanogaster, Ann. Inst. Pasteur Paris 119:520.

Rae, B. P., and Elliott, R. M., 1986a, Conservation of potential phosphorylation sites in the NS proteins of the New Jersey and Indiana serotypes of vesicular stomatitis virus, $J$. Gen. Virol. 67:1351.

Rae, B. P., and Elliott, R. M., 1986b, Characterization of the mutations reponsible for the electrophoretic mobility differences in the NS proteins of vesicular stomatitis virusNew Jersey complementation group E mutants, J. Gen. Virol. 67:2635.

Rasool, N., and Pringle, C. R., 1986, In vitro transcriptase deficiency of temperature-dependent host range mutants of Chandipura virus, J. Gen. Virol. 67:851.

Reanney, D. C., 1982, The evolution of RNA viruses, Annu. Rev. Microbiol. 36:47.

Reanney, D. C., 1984, The molecular evolution of viruses, in: The Microbe 1984: I. Viruses (B. W. J. Mahy and J. R. Pattison, eds.), pp. 175-196, Cambridge University Press.

Reichmann, M. E., and Schnitzlein, W. M., 1979, Defective interfering particles of rhabdoviruses, Curr. Top. Microbiol. Immunol. 86:123.

Reichmann, M. E., Pringle, C. R., and Follett, E. A. C., 1971, Defective particles in BHK cells infected with temperature-sensitive mutants of vesicular stomatitis virus, $J$. Virol. 8:154.

Reichmann, M. E., Schnitzlein, W. M., Bishop, D. H. L., Lazzarini, R. A., Beatrice, S. T., and Wagner, R. R., 1978, Classification of the New Jersey serotype of vesicular stomatitis virus into two subtypes, $J$. Virol. 25:446.

Rettenmier, C. W., Dumont, R., and Baltimore, D., 1975, Screening procedure for complementation-dependent mutants of vesicular stomatitis virus, $J$. Virol. 15:41.

Richard-Molard, C., Blondel, D., Wyers, F., and Dezelee, S., 1984, Sigma virus: Growth in Drosophila melanogaster cell culture; purification; protein composition and localization, J. Gen. Virol. 65:91.

Robertson, J. S., Etchison, J. R., and Summers, D. F., 1982, Comparison of the oligosaccharide structure of the glycoprotein of vesicular stomatitis virus and a thermolabile mutant t117, J. Gen. Virol. 58:13.

Rose, J. K., 1980, Complete intergenic and flanking gene sequences from the genome of vesicular stomatitis virus, Cell 19:415.

Rose, J. K., and Bergmann, J. E., 1983, Altered cytoplasmic domains affect intracellular transport of the vesicular stomatitis virus glycoprotein, Cell 34:513.

Rose, J. K., and Gallione, C. J., 1981, Nucleotide sequences of the mRNA's encoding the vesicular stomatitis virus $G$ and $M$ proteins determined from cDNA clones containing the complete coding regions, J. Virol. 39:519. 
Rowlands, D., Grabau, E., Spindler, K., Jones, C., Semler, B., and Holland, J., 1980, Virus protein changes and RNA termini alterations evolving during persistent infection, Cell 19:871.

Sarvar, N., and Stollar, V., 1977, Sindbis virus-induced cytopathic effect in clones of Aedes albopictus (Singh) cells, Virology 80:390.

Schechmeister, I. L., Streckfuss, J., and St. John, R., 1967, Comparative pathogenicity of vesicular stomatitis virus and its plaque type mutants, Arch. Gesamte Virusforsch. 39:203.

Schlegel, R., and Wade, M., 1985, Biologically active peptides of the vesicular stomatitis virus glycoprotein, $J$. Virol. 53:319.

Schlesinger, S., Malfer, C., and Schlesinger, M. J., 1984, The formation of vesicular stomatitis virus (San Juan strain) becomes temperature-sensitive when glucose residues are retained as the oligosaccharides of the glycoproteins, J. Biol. Chem. 259:7597.

Schnitzlein, W. M., and Reichmann, M. E., 1985, Characterization of New Jersey vesicular stomatitis virus isolates from horses and black flies during the 1982 outbreak in Colorado, Virology 142:426.

Schubert, M., Keene, J. D., Herman, R. C., and Lazzarini, R. A., 1980, Site of the vesicular stomatitis virus genome specifying polyadenylation and the end of the L gene mRNA, J. Virol. 34:550.

Schubert, M., Harmison, G. G., and Meier, E., 1984, Primary structure of the vesicular stomatitis virus polymerase (L) gene: Evidence for a high frequency of mutations, $J$. Virol. 51:505.

Seif, I., Coulon, P., Rollin, P. E., and Flamand, A., 1985, Rabies virulence: Effect on pathogenicity and sequence characterization of rabies virus mutations affecting antigenic site III of the glycoprotein, J. Virol. 53:926.

Sekellick, M. J., and Marcus, P., 1980, Persistent infection of rhabdoviruses, in: Rhabdoviruses, Vol. III (D. H. L. Bishop, ed.), pp. 67-98, CRC Press, Boca Raton, Florida.

Selimow, M. A., and Nikotina, L. F., 1970, The "rct 40" marker of fixed rabies virus, Vopr. Virusol. 15:161.

Simpson, R. W., and Obijeski, J. F., 1974, Conditional lethal mutants of vesicular stomatitis virus. I. Phenotypic characterization of single and double mutants exhibiting host restriction and temperature sensitivity, Virology 57:357.

Simpson, R. W., Obijeski, J. F., and Morrongiello, M. P., 1979, Conditional lethal mutants of vesicular stomatitis virus. 3 . Host range properties, interfering capacity and complementation patterns of specific hr mutants, Virology 93:493.

Spindler, K. R., Horodyski, F. M., and Holland, J. J., 1982, High multiplicities of infection favor rapid and random evolution of vesicular stomatitis virus, Virology 119:96.

Stanners, C. P., Francoeur, A. M., and Lam, T., 1977, Analysis of a VSV mutant with attenuated cytopathogenicity: Mutation in viral function, $\mathrm{P}$, for inhibition of protein synthesis, Cell 11:273.

Storey, D. G., and Yong Kang, C., 1985, Vesicular stomatitis virus-infected cells from which the intracellular pool of functional $M$ proteins is reduced in the presence of $G$ protein, J. Virol. 53:374.

Szilagyi, J. F., and Pringle, C. R., 1975, Virion transcriptase activity differences in host range mutants of vesicular stomatitis virus, $J$. Virol. 16:927.

Szilagyi, J. F., and Pringle, C. R., 1979, Effect of temperature-sensitive mutation on the RNA transcriptase activity of vesicular stomatitis virus New Jersey, J. Virol. 30:692.

Szilagyi, J. F., Pringle, C. R., and Macpherson, T. M., 1977, Temperature-dependent host range mutation in vesicular stomatitis virus affecting polypeptide $\mathrm{L}, I$. Virol. 22:381.

Templeton, J. W., Holmberg, C., Garber, T., and Sharp, R. M., 1986, Genetic control of serum-neutralizing-antibody response to rabies vaccination and survival after a rabies challenge infection in mice, $J$. Virol. 59:98.

Teninges, D., Contamine, D., and Brun, G., 1980, Drosophila Sigma virus, in: Rhabdoviruses, Vol. III (D. H. L. Bishop, ed.), pp. 113-134, CRC Press, Boca Raton, Florida. 
Thacore, H. R., and Youngner, J. S., 1975, Abortive infection of a rabbit cornea cell line by vesicular stomatitis virus: Conversion to productive infection by superinfection with vaccinia virus, I. Virol. 16:322.

Tordo, N., Poch, O., Ermine, A., Keith, G., and Rougeon, F., 1986, Walking along the rabies virus genome: Is the large G-L intergenic region a remnant gene? Proc. Natl. Acad. Sci. U.S.A. 83:3914.

Unger, J. T., and Reichmann, M. E., 1973, RNA synthesis in temperature sensitive mutants of vesicular stomatitis virus, I. Virol. 12:570.

Vigier, P., 1966, Contribution a l'étude de l'mutabilité génétique du virus de la Drosophile, Ann. Genet. 9:5.

Villareal, L. P., Breindl, M., and Holland, J. J., 1976, Determination of molar ratios of vesicular stomatitis virus induced RNA species in BHK-21 cells, Biochemistry 15:1663.

Weck, P. K., and Wagner, R. R., 1979, Inhibition of RNA synthesis in mouse myeloma cells infected with vesicular stomatitis virus, J. Virol. 25:770.

Weck, P. K., Carroll, A. R., Shattuck, D. M. and Wagner, R. R., 1979, Use of UV irradiation to identify the genetic information of vesicular stomatitis virus responsible for shutting off cellular RNA synthesis, I. Virol. 30:746.

Weiss, R. A., and Bennett, P. L. P., 1980, Assembly of membrane glycoproteins studied by phenotypic mixing between mutants of vesicular stomatitis virus and retroviruses, Virology 100:252.

Weiss, R. A., Boettiger, D., and Murphy, H. M., 1977, Pseudotypes of avian sarcoma viruses with the envelope properties of vesicular stomatitis virus, Virology 76:808.

Wertz, G. W., 1978, Isolation of possible replicative intermediate structures from vesicular stomatitis virus infected cells, Virology 85:271.

Wertz, G. W., and Levine, M., 1973, RNA synthesis of vesicular stomatitis virus and a small plaque mutant: Effects of cycloheximide, J. Virol. 12:253.

White, B. T., and McGeoch, D. J., 1985, Suppressible amber mutants of vesicular stomatitis virus Indiana serotype, Virus Res. (Suppl. 1):27.

Wilson, T., and Lenard, J., 1981, Interaction of wild type and mutant M protein of vesicular stomatitis virus with nucleocapside in vitro, Biochemistry 20:1349.

Wilusz, J., Youngner, J. S., and Keene, J. D., 1985, Base mutations in the terminal noncoding regions of the genome of vesicular stomatitis virus isolated from persistent infections of L cells, Virology 140:249.

Wong, P. K. Y., Holloway, A. F., and Cormack, D. V., 1972, Characterization of three complementation groups of vesicular stomatitis virus, Virology 50:829.

Woodgett, C., and Rose, J. K., 1986, Amino-terminal mutation of the vesicular stomatitis virus glycoprotein does not affect its fusion activity, $J$. Virol. 59:486.

Wu, F. S., and Lucas-Lenard, J. M., 1980, Inhibition of RNA accumulation in mouse L cells infected with vesicular stomatitis virus requires viral ribonucleic acid transcription, Biochemistry 19:804.

Wunner, W. H., Dietzschold, B., Smith, C. L., Lafon, M., and Golub, E., 1985, Antigenic variants of CVS rabies virus with altered glycosylation sites, Virology 140:1.

Yelverton, E., Norton, S., Obijeski, J. F., and Goeddel, D. V., 1983, Rabies virus glycoprotein analogs: Biosynthesis in Escherichia coli, Science 219:614.

Young, J. F., Taussig, R., Aaronson, R. P., and Palese, P., 1981, Advantages and limitations of the oligonucleotide mapping technique for the analysis of viral RNAs, in: Replication of Negative Strand Viruses (D. H. L. Bishop and R. W. Compans, eds.), pp. 209-219, Elsevier/North-Holland, New York.

Youngner, J. S., and Quagliana, D. O., 1976, Temperature-sensitive mutants of vesicular stomatitis virus are conditionally defective particles that interfere with and are rescued by wild-type virus, I. Virol. 19:102.

Youngner, J. S., Dubovi, E. J., Quagliana, D. O., Kelly, M., and Preble, O. T., 1976, Role of temperature-sensitive mutants in persistent infections initiated with vesicular stomatitis virus, $J$. Virol. 19:90.

Zavada, J., 1972, VSV pseudotype particles with the coat of avian myeloblastosis virus, Nature (London) New Biol. 240:122. 
Zavada, J., 1982, The pseudotype paradox, J. Gen. Virol. 63:15.

Zavada, J., and Huang, A. S., 1984, Further characterization of proteins assembled by vesicular stomatitis virus from human tumour cells, Virology 138:16.

Zavada, J., Cerny, L., Zavadova, Z., Bozonova, J., and Altstein, A. D., 1979, A rapid neutralization test for antibodies to bovine leukemia virus, with the use of rhabdovirus pseudotypes, J. Natl. Cancer Inst. 62:95.

Zavada, J., Russ, G., Zavadova, Z., and Sabo, A., 1983a, Vesicular stomatitis virus phenotypically mixed with retroviruses: An efficient detection method, Acta Virol. 27:110.

Zavada, J., Zavadova, Z., Russ, G., Polakova, K., Rajcani, J., Stend, J., and Loksa, J., 1983b, Human cell surface proteins selectively asembled into vesicular stomatitis virus virions, Virology 127:345.

Zavadova, Z., and Zavada, J., 1980, Pseudotypes of vesicular stomatitis virus with coat antigen of bovine leukaemia virus-VSV(BLV): Antigenic surface mosaic and the roles of precipitating antibodies and polycations, Acta Virol. 24:166.

Zilberstein, A., Snider, M. D., Porter, M., and Lodish, H. F., 1980, Mutants of vesicular stomatitis virus blocked at different stages in maturation of the viral glycoprotein, Cell 21:417. 